NBER WORKING PAPER SERIES

\title{
MEDICARE PAYMENT TO SKILLED NURSING FACILITIES: THE CONSEQUENCES OF THE THREE-DAY RULE
}

\author{
Ginger Zhe Jin \\ Ajin Lee \\ Susan Feng Lu \\ Working Paper 25017 \\ http://www.nber.org/papers/w25017 \\ NATIONAL BUREAU OF ECONOMIC RESEARCH \\ 1050 Massachusetts Avenue \\ Cambridge, MA 02138 \\ September 2018
}

We use the State Inpatient Databases from the Healthcare Cost and Utilization Project (HCUP), Agency for Healthcare Research and Quality, provided by the Arizona Department of Health Services, the Florida Agency for Health Care Administration, the New York State Department of Health, and the Washington State Department of Health. We also use the American Hospital Association (AHA) Annual Survey Databases. We thank Jean Roth at the National Bureau of Economic Research for assistance with the data. John Bowblis and the participants at the 2018 ASHEcon conference and the 2018 Bates White Life Science Symposium have provided valuable comments on an earlier draft. All errors are ours. The views expressed herein are those of the authors and do not necessarily reflect the views of the National Bureau of Economic Research.

NBER working papers are circulated for discussion and comment purposes. They have not been peer-reviewed or been subject to the review by the NBER Board of Directors that accompanies official NBER publications.

(C) 2018 by Ginger Zhe Jin, Ajin Lee, and Susan Feng Lu. All rights reserved. Short sections of text, not to exceed two paragraphs, may be quoted without explicit permission provided that full credit, including $\odot$ notice, is given to the source. 
Medicare Payment to Skilled Nursing Facilities: The Consequences of the Three-Day Rule Ginger Zhe Jin, Ajin Lee, and Susan Feng Lu

NBER Working Paper No. 25017

September 2018

JEL No. D8,H51,I13,I18

\section{ABSTRACT}

Medicare does not pay for a skilled nursing facility (SNF) unless a fee-for-service patient has stayed in the hospital for at least three days. Discharges after the three-day cutoff consistently result in more transfers to SNFs. Using the three-day rule as an instrument, we find that SNF discharges decrease hospital readmission for patients with comorbidities. However, for knee and hip replacement patients, we find significant increases in readmission. This perverse effect is more severe when local SNFs have lower quality. Back-of-the-envelope calculations suggest that the three-day rule may have generated extra Medicare payments to SNFs by $\$ 100-447$ million per year.

Ginger Zhe Jin

University of Maryland

Department of Economics

3115F Tydings Hall

College Park, MD 20742-7211

and NBER

jin@econ.umd.edu

Ajin Lee

Department of Economics

Michigan State University

486 W. Circle Drive

110 Marshall-Adams Hall

New York, NY 10027

East Lansing, MI 48824

leeajin@msu.edu

\section{Susan Feng Lu}

KRA 441

Krannert School of Management

Purdue University

Rochester, NY, 14620

lu428@purdue.edu 


\section{Introduction}

Medicare is the largest single purchaser of personal health care in the US. The total Medicare spending has nearly doubled in the last decade, with $22 \%$ devoted to fee-forservice (FFS) inpatient care and 9.5\% to FFS post-acute care (MEDPAC 2017). Facing an aging population, ${ }^{1}$ Medicare spending is projected (by CBO) to reach $\$ 1$ trillion in 2021, and the Medicare Hospital Insurance Trust Fund, which helps to pay for FFS inpatient and post-acute care, is projected to be insolvent by 2028. These alarming predictions call for a better understanding of potential wastes and savings in the Medicare system.

To answer this call, we focus on a specific reimbursement rule that Medicare imposes on the intersection between inpatient and post-acute care: Medicare does not pay for the fee-for-service (FFS) care provided in a skilled nursing facility (SNF) unless the patient has stayed in the hospital for at least three days. This rule applies by number of midnights that a patient stays in a hospital, not the number of hours. For example, a patient admitted at $10 \mathrm{pm}$ on day 1 and discharged 9 am on day 4 satisfies this condition, but a patient admitted at 9 am on day 1 but discharged $10 \mathrm{pm}$ on day 3 is not qualified.

We study the effect of the three-day rule in a framework of difference-indifferences (DID). In particular, we compare regular Medicare patients (65-79) with nonMedicare patients (60-79), and focus on the patients that are initially discharged from a hospital within 24 hours before or after the three-day cutoff. After a long list of controls, ${ }^{2}$ we examine how the three-day rule affects Medicare patients' discharge to SNFs and the subsequent hospital readmission rate within 30 or 60 days.

Using 2.9 million hospital inpatient discharge records from four states (20042013), we find that Medicare patients discharged 0-24 hours after the three-day-cutoff are 6.8 percentage points more likely to be discharged to a SNF than those discharged 0-24 hours before the cutoff. This effect is enormous, considering the fact that only $9.4 \%$ of Medicare patients (and 8\% of all patients) in our sample were discharged to SNFs. When we use the three-day Medicare rule as an instrumental variable (IV) for SNF discharge,

\footnotetext{
${ }^{1}$ Population Reference Bureau Report (2016). https://assets.prb.org/pdf16/prb-wpds2016-web-2016.pdf

${ }^{2}$ As detailed in Section 5, we control for age, demographics, insurance type, health conditions, hospital fixed effects and time fixed effects.
} 
SNF discharge is found to have a negative effect on 30- or 60-day hospital readmission rate in the whole sample, but this beneficial impact is entirely driven by sicker patients with an above-median Elixhauser Comorbidity Index. ${ }^{3}$ If we focus on patients with no or fewer comorbidities, the IV results find no significant readmission difference between those discharged to SNFs and those discharged anywhere else.

To better understand these results, we develop a conceptual framework that incorporates both the hospital's discharge decision and the potential differences across SNFs. In addition to the three-day payment rule, Medicare also calculates payment to a SNF based on the patient's need for labor-intensive and non-labor services inside a SNF (CMS 2017a). Though the Medicare payment strives to reflect wage and other costs across geographic areas, it does not differ by SNF quality within the same geographic area (conditional on the same patient). As a result, even if a hospital has decided to discharge the patient to a SNF, every patient prefers higher quality SNFs and the costplus structure of Medicare payment may motivate SNFs to prefer patients that need more high-margin services. These settings imply further sorting across SNFs, with less profitable patients - for example, the healthier ones that cannot justify a lot of care or those that require many low-margin services - to be more exposed to the capacity constraint of high quality SNFs. Together, the conceptual framework predicts that (1) the three-day rule is likely to affect the relatively healthy patients that are on the margin of going to SNF or going home, (2) relative to staying home, adverse health outcomes are more likely to occur in low-quality SNFs that have capacity to admit the marginal patients, and (3) the financial burden on Medicare can come from overtreatment, adverse health outcomes, or both.

Consistently, we find the effect of the three-day rule on SNF discharge is the largest (14 percentage points) for knee and hip replacement (KHR), a major health condition that on average has much lower hospital readmission rate and much lower Elixhauser Comorbidity Index than heart disease, stroke and other conditions. Furthermore, among these four categories, KHR is the only one for which we find a significant increase in hospital readmission rate as a result of the three-day rule. This

\footnotetext{
${ }^{3}$ We compute Elixhauser Comorbidity Index according to Elixhauser et al. (1998) and the corresponding software developed by AHRQ (https://www.hcup-us.ahrq.gov/toolssoftware/comorbidity/comorbidity.jsp).
} 
perverse effect is larger in the health service areas (HSAs) where the average SNFs have a lower-than-state-median occupancy rate or a higher-than-state-median total deficiency count. These findings suggest that many KHR patients go to SNF simply because Medicare will pay for it and there is a bed available in nearby low-quality SNFs.

Back-of-the-envelope calculations suggest that the three-day Medicare rule has the potential to generate significant overuse of SNF services. Pooling all conditions and projecting from our sample to the whole Medicare system, we estimate that the three-day rule may have generated an extra Medicare payment to SNFs of \$100-447 million per year, without a significant reduction in hospital readmissions. The range reflects whether we focus on patients with no comorbidity at all or patients with a below-median Elixhauser Comorbidity Index. They correspond to $0.32-1.43 \%$ of Medicare's annual payment to SNFs as of 2016. For KHR only, the three-day rule is estimated to cost Medicare \$83.7 million per year, including payment to SNFs and the subsequent increase in hospital readmission. This number corresponds to $1.2 \%$ of Medicare's annual payment for KHR as of 2014.

The rest of the paper is organized as follows. Section 2 describes the Medicare payment rules and reviews the related literature. Section 3 presents a simple analytical framework for the potential effects of the three-day rule on hospital readmission. Section 4 describes our data. Section 5 defines our main econometric specification and presents empirical results. Section 6 concludes with back-of-the-envelope calculations for the potential implication of our analysis for Medicare spending.

\section{Background and Literature}

The US healthcare expenditure continues to grow rapidly. By 2016, it has exceeded $\$ 3$ trillion per year, contributing to $16.9 \%$ of the GDP. By 2030, one in every five US residents will be 65 years or older due to the aging of the baby boomer generation. Moreover, the composition of the elderly population will change with increase in the population over 85 years, as people live longer. In the face of an aging population and rising costs, the US healthcare system is in transition from volume-based

reimbursement models (e.g., fee-for-service) to value-based reimbursement models (e.g., prospective payment system or bundled payment). How to contain costs and improve 
health outcomes via reimbursement reforms is an important and urgent issue for the US healthcare system.

\subsection{Medicare’s three-day rule for skilled nursing care}

Medicare's three-day rule requires a patient to spend at least three consecutive days in hospital inpatient care in order to qualify for the Medicare-covered discharge to a SNF for post-acute care. This rule dates back to 1965 when inpatient hospital stays dominated healthcare. The original intention of the rule was to give doctors enough time to evaluate the severity of a patient's health condition, screen out healthier patients, and cover patients who need skilled nursing care. Another intention of the rule is to discourage hospitals from quickly discharging patients without careful observation and admitting new patients just for the sake of providing another billable service.

Since 1998, SNF services are no longer paid on a volume-determined rate, but rather on the basis of a prospective payment system (PPS). The PPS payment rates are case-mix adjusted and cover all costs of furnishing covered SNF services, where the costs are calculated according to labor and non-labor costs by geographic areas. Beginning in the summer of 2009, several states implemented a pay-for-performance reimbursement policy, which intended to reward SNFs that provide good quality services. However, SNF

quality changed little after the policy and the results on cost savings are mixed (Werner et al. 2011, Arling et al., 2013 and Grabowski et al. 2017). Because it is hard to measure quality and establish a clear link between effort, performance and rewards, qualityadjusted reimbursement is not widely adopted. Furthermore, rewarding health care providers based on their quality performance may give them perverse incentives to cherry-pick healthier patients and shun sicker ones. This explains why the current Medicare payment to SNFs is adjusted by patient risk and local cost but not by SNF quality.

\subsection{SNF Operations}

SNFs mainly serve three types of patients based on their insurance type. According to the Nursing Home Compare, $60 \%$ of SNF care is paid by Medicaid, 20\% by Medicare, and the rest by private insurers or patients themselves. Medicare residents 
generate the highest revenue per resident per day ( $\sim 500)$, while Medicaid residents generate the lowest revenue per resident per day (under \$194). ${ }^{4}$ High revenue does not necessarily imply high profit margin, because the cost of delivering the services that bear a higher CMS reimbursement rate may also be high. However, CMS adjusts the reimbursement rate according to local labor and non-labor cost across regions, and thus we believe revenue and margin are positively correlated. Moreover, SNFs do not independently evaluate patient need for SNF care when they admit patients from hospitals. Rather, they rely on the patient's hospital discharge record, including diagnosis, treatment, inpatient stay, demographics, insurance type, etc. Once a patient is admitted, the SNF determines the category of services the patient needs and the therapy minutes in that category. Bowblis and Brunt (2014) show that SNFs upcode patients by providing additional therapy minutes to increase revenue, but do not upcode related to patient functionality scores. Above all, SNFs usually prefer Medicare and privately insured patients to Medicaid patients. As shown by Nyman (1993), non-Medicaid patients typically gain admission first when there are not enough beds. According to a New York Times article in 2015, the entire industry is chasing those lucrative consumers while quality of care is said to lag. ${ }^{5}$

To assure quality of care, the Centers for Medicare and Medicaid Services (CMS) launched the Nursing Home Quality Initiative in 2002 and initiated the Five Star Quality Rating System (FSQRS) in 2008. These quality disclosure policies motivated SNFs to improve quality at least along the reported dimensions (Lu, 2012, 2016; Huang and Hirth, 2016; Zhao, 2016; Brickley et al, 2018). It is noteworthy that the FSQRS is constructed mainly using deficiency citations. The CMS weights deficiency citations more than other quality measures in calculating star ratings since they are produced by government inspections, as opposed to self-reports (CMS 2017c). Moreover, the count of deficiency citations is also widely used as a proxy of SNF quality in the literature (e.g. Harrington et al, 2000; Lu and Wedig, 2013).

\footnotetext{
${ }^{4}$ The information is obtained from Lu, Rui and Seidmann (2018), footnote 2. "These daily rates are taken from the quarterly report filed by Genesis Healthcare on May 8, 2015. https://www.sec.gov/Archives/edgar/data/1351051/000110465915036326/0001104659-15-036326index.htm.”

${ }^{5}$ https://www.nytimes.com/2015/04/15/business/as-nursing-homes-chase-lucrative-patients-quality-ofcare-is-said-to-lag.html.
} 
On average, a SNF has 104 beds. ${ }^{6}$ Due to the Certificate of Need Law, SNFs are not allowed to change their bed size without approval from state authority. According to the Medicare Payment Advisory Commission’s 2015 report to the Congress, the average length of stay for a Medicare resident in a SNF is 37 days (MedPAC 2015, p. 200). There exist severe excess demand issues from Medicaid patients (Ching et al, 2015). Therefore, the utilization of SNF beds is very high with an overall occupancy rate of $88.8 \%$.

Because most patients do not pay for SNF care themselves, they all prefer high quality SNFs to low quality SNFs. In addition, due to the state certificate of need laws, it is difficult for nursing homes to expand capacity. Naturally, SNFs with high occupancy rates usually provide good quality. A recent study by Hackman and Pohl (2018) shows that SNFs tend to discharge Medicaid patients in order to admit lucrative patients when occupancy rates increase. These lucrative patients tend to demand high quality services, which give SNFs an incentive to promote quality. In the annual OSCAR data of SNF characteristics (to be described in Section 4), we find a negative correlation between occupancy rates and deficiency citations (-0.147).

\subsection{Literature Review}

Our study contributes to a broad literature on the impact of Medicare reimbursement rules on healthcare spending and outcomes. Finkelstein (2007) shows that the introduction of Medicare in 1965 increased healthcare spending six times more than what was predicted. However, the fee-for-service payment adopted by Medicare at that time had no discernable impact on elderly mortality (Finkelstein and McKnight 2008). Duggan and Morton (2010) find that the introduction of Medicare Part D significantly reduces out-of-pocket prices and results in a substantial increase in utilization of Medicare-intensive drugs. Brown et al. (2014) show that the risk adjustment in the Medicare Advantage (MA) program significantly lowers healthcare costs conditional on patients’ health risk. Duggan et al. (2016, 2017) and Curto et al. (2017) investigate the impact of MA and find that health spending is lower for enrollees in MA than in the traditional Medicare, but it has no association with any measurable reduction in hospital quality or patient mortality. In this study, we investigate Medicare’s three-day

\footnotetext{
${ }^{6}$ https://meps.ahrq.gov/data_files/publications/rf4/rf4.shtml
} 
reimbursement rule on SNF discharge and the subsequent hospital readmission. We find that the three-day rule increases the likelihood of discharging Medicare patients to SNFs, which increases healthcare spending but does not necessarily reduce readmission rates.

Most relevant to our study is a small but growing literature on the impact of reimbursement rules on coordination care. Grebla et al. (2015) study the three-day rule within Medicare Advantage (MA) patients. Unlike Medicare FFS patients, MA patients may or may not be subject to the three-day rule depending on their MA plan. By comparing hospital discharges in the MA plans with and without the three-day rule, Grebla et al. (2015) find that eliminating the three-day rule may reduce the hospital length of stay (before discharge to SNF) by 0.7 days. But this reduction is from an average of more than 6 inpatient days, which is way over the key margin of discharging a patient on day 2 or day 3. Our study focuses on this particular margin, and includes all discharge outcomes after an inpatient stay, not just the discharge to SNFs. Unfortunately, only two of the four states in our data distinguish MA from Medicare FFS, and none of them spell out the identity of the MA plan or whether the MA plan adopts the three-day rule or not. For these reasons, we keep all Medicare patients as one group in the empirical analysis. Later on, we show that our results are robust if we exclude MA patients from the sample in Session 5.4.1.

More broadly on coordination care, Gornick and Hall (1988) document the trend in Medicare use of post-hospital care. Grabowski (2007) points out that Medicare and Medicaid provide conflicting incentives for long-term care. Meyers et al. (2018) shows that MA patients are more likely to enter lower-quality nursing homes compared to FFS enrollees. Recent research by Einav et al. (2017) investigates the effect of a payment "jump” on the timing of discharge and mortality in long-term acute-care hospitals (LTCHs). They find that the share of LTCH stays increases significantly at the precise day of the jump. However, the timing of discharge does not have significant effects on patient mortality. By contrast, Eliason et al. (2017) find that the gaming of discharge timing leads to worse outcomes for patients in LTCHs. Doyle et al. (2017) explore a random assignment of patients by ambulance companies to hospitals. They find that lack of productivity in post-acute care could be a possible reason for the waste in healthcare. 
We directly test whether SNF care in fact produces substantial waste in healthcare using the three-day rule as an instrument for SNF discharges.

Navathe et al. (2017) examine the impact of Medicare's bundled payments in joint replacement. They find that the implementation of bundled payment significantly reduced Medicare payment and almost half of the savings come from less spending in post-acute care. Our study tackles the impact of the three-day rule on SNF discharge, including patients with knee or hip replacement (KHR). We find a significant increase in hospital readmission rate for KHR patients as a result of the three-day rule. This perverse effect is larger in the HSAs where the average SNFs have a lower-than-state-median occupancy rate or a higher-than-state-median total deficiency count. To the best of our knowledge, this is the first study that examines the impact of the Medicare three-day rule on SNF discharge and hospital readmission, and quantifies this impact in Medicare overspending.

\section{Conceptual Framework}

The key question is how the three-day cutoff could create deviations from efficient allocation of health care. We propose a simple conceptual framework to address this question.

Suppose Medicare is a social planner aiming to maximize patient utility of health care minus post-acute care cost. Denote the net value as $\mathrm{V}(\mathrm{x} \mid \mathrm{s})=\mathrm{U}(\mathrm{x} \mid \mathrm{s})-\mathrm{C}(\mathrm{x})$, where $\mathrm{x}$ is the type and amount of post-acute care (hospital, SNF, home) and s is patient sickness before treatment. Obviously, patients may differ in many dimensions beyond sickness. For model simplicity, we summarize all patient heterogeneity in the single parameter of $s$, and assume a monotonic relationship between s and the need for health care. In empirical analysis, we will control for an extensive list of patient characteristics. If we normalize $\mathrm{V}$ (home|s) $=0$ for every s, then $\mathrm{V}$ (hospital|s) represents the net utility of receiving inpatient care with initial condition s and $\mathrm{V}(\mathrm{SNF} \mid \mathrm{s})$ represents the net utility of receiving care from SNF with initial condition s, all relative to staying home.

As shown in Figure 1, we further assume both V(hospital|s) and V(SNF|s) are positively sloped, i.e. the value of receiving either care is higher when the patient is sicker. And V(hospital $\mid s)$ is more steeply sloped than V(SNF|s), so that the sicker the patient is, the more utility she will derive from inpatient care than from SNF care. The 
intercept of each line is determined by the difference between patient utility and cost of the corresponding care. Inpatient care is the most expensive while staying home is the least among the three types of post-acute care. When the patient is sick enough, inpatient and SNF care are both better than staying home. However, when the patient is healthy enough, $\mathrm{V}$ (hospital $\mid \mathrm{s}$ ) and $\mathrm{V}(\mathrm{SNF} \mid \mathrm{s})$ can be negative, implying that it is better (for the social planner) that the patient stays home rather than consume costly care from a hospital or SNF. When patient sickness is somewhere in the middle, it is possible that $\mathrm{V}(\mathrm{SNF} \mid \mathrm{s})>\mathrm{V}($ hospital $\mid \mathrm{s})>\mathrm{V}($ home $\mid \mathrm{s})$.

In short, Figure 1 shows a monotonic sorting where patients with $\mathrm{s}>\mathrm{s}_{1}$ should be hospitalized, $\mathrm{s}_{2}<\mathrm{s}<\mathrm{s}_{1}$ should go to $\mathrm{SNF}$, and $\mathrm{s}<\mathrm{s}_{2}$ should stay home. To the extent that patient sickness is observable (to Medicare and hospital) and the hospital is a perfect agent of Medicare, the hospital should keep $\mathrm{s}>\mathrm{s}_{1}$ inpatient, discharge $\mathrm{s}_{2}<\mathrm{s}<\mathrm{s}_{1}$ to a SNF, and send $\mathrm{s}<\mathrm{s}_{2}$ home. In reality, patient sickness is observable to the hospital but not observable to Medicare. Given the non-trivial agency problem between Medicare and the hospital, Medicare proxies the true patient sickness at hospital discharge by an observable variable such as length of inpatient stay.

To the extent that the three-day rule is an imperfect proxy for patient sickness, it can make two errors: first, those with $\mathrm{s}_{2}<\mathrm{s}<\mathrm{s}_{1}$ (who should go to a SNF in the ideal world) does not satisfy the three-day rule, and they end up going home instead of to SNF. This is suboptimal because patients suffer from inadequate care at home although Medicare saves money. This error is denoted by a green diamond in Figure 1. Second, those with $s<s_{2}$ (who should go home in the ideal world) satisfy the three-day rule, and the patient may prefer unnecessary SNF care because the care is free. This is a typical moral hazard problem, which wastes money for Medicare, as the cost that Medicare pays to the SNF is more than the utility that the patient receives from the SNF (relative to home). The second error is denoted by a blue circle in Figure 1. To ease future discussion, we refer to the two types of errors as Error 1 (resulting in insufficient care) and Error 2 (driven by moral hazard).

So far, we take the timing and sickness at discharge as given. In reality, both are under the control of the hospital, and the hospital's discharge decision could be distorted by the three-day rule. One may concern whether this will mitigate or exacerbate the 
above two errors. Let us consider Error 1 first: those with $\mathrm{s}_{2}<\mathrm{s}<\mathrm{s}_{1}$ cannot go to SNFs because they have not stayed long enough in the hospital. If the hospital is not capacity constrained, allowing the patient to stay longer in the hospital could generate revenue to the hospital ${ }^{7}$ and help the patient to receive the optimal care (SNF) at discharge. This inducement behavior moves the error from the green diamond to the red triangle, which wastes Medicare money in inpatient care. If the hospital is so capacity constrained that it cannot keep the patient in the hospital in order to satisfy the three-day rule, the error stays in the green diamond and the cost is the same as before - the patient is discharged home and suffers from inadequate care after discharge. This could generate worse patient outcomes (such as hospital readmission) in the future. As for Error 2, patients with $\mathrm{s}<\mathrm{s}_{2}$ prefer SNF care because it is free. If the hospital is more of an agent for the patient than for Medicare, the patient will be discharged to SNF, generating unnecessary expenditure for Medicare as illustrated in the blue circle. Since we assume SNF care is better than home (before accounting for the cost), this suboptimal discharge to SNFs should only affect patient outcomes positively, if it has an effect at all.

Now let us add a third layer of complication. Suppose some SNF services are of high quality, and some are of low quality. For illustration, assume all SNFs in Figure 1 are high quality. Figure 2 repeats Figure 1, but adds a line below and parallel to the line of V(SNF). Now the two parallel lines represent high and low quality SNFs (SNF high and $\mathrm{SNF}_{\text {low }}$ ) respectively. The cost of these two types of SNFs is the same in the eyes of Medicare, because Medicare pays the same rate regardless SNF quality. For simplicity, we assume the actual cost of care is also the same for all SNFs and all health conditions. ${ }^{8}$ By definition, $\mathrm{V}\left(\mathrm{SNF}_{\text {high }}\right)>\mathrm{V}\left(\mathrm{SNF}_{\text {low }}\right)$. If $\mathrm{SNF}_{\text {high }}$ has no capacity constraint, $\mathrm{SNF}_{\text {low }}$ does not matter at all because it is always dominated by $\mathrm{SNF}_{\text {high. }}$ In that case we go back to Figure 1.

But in a world where the capacity constraint of $\mathrm{SNF}_{\text {high }}$ becomes binding at $\mathrm{S}_{\mathrm{c}}$ $\left(\mathrm{s}_{2}<\mathrm{s}_{\mathrm{C}}<\mathrm{s}_{1}\right)$, Medicare would prefer a sorting such that $\mathrm{s}>\mathrm{s}_{1}$ stay inpatient, $\mathrm{s}_{\mathrm{C}}<\mathrm{s}<\mathrm{s}_{1}$ go to $\mathrm{SNF}_{\text {high }}, \mathrm{s}_{2}<\mathrm{s}<\mathrm{S}_{\mathrm{c}}$ go to $\mathrm{SNF}_{\text {low }}$, and $\mathrm{s}<\mathrm{s}{ }_{2}$ go home. Note that the new cutoff for going

\footnotetext{
${ }^{7}$ Whether this will generate more revenue for the hospital depends on whether Medicare pays the hospital by procedure (DRG) or by length of stay.

${ }^{8}$ Under this assumption, high revenue implies high profit margin. Because sicker patients need more units of care, sicker patients bring in more revenue and more profits.
} 
home, $\mathrm{s}_{2}$, is higher than $\mathrm{s}_{2}$, because it is determined by $\mathrm{V}\left(\mathrm{SNF}_{\text {low }}\right)$ rather than $\mathrm{V}\left(\mathrm{SNF}_{\text {high }}\right)$. In other words, because of low quality SNF services, Medicare would prefer to send more patients home, as a social planner.

The three-day rule of Medicare is independent of SNF quality. If the rule attempts to proxy s $s_{2}$ in Figure 1, it fails to adjust for the existence of low quality SNFs. This alone will generate a new error as more patients should go home rather than go to $\mathrm{SNF}_{\text {low. }}$. We denote this new error caused by low quality SNF care as Error 3, in a yellow pentagon in Figure 2. The presence of low quality SNFs also exacerbates the value loss from the overuse of SNF (as denoted in the blue circle), because the overuse occurs in low quality SNFs rather than high quality SNFs. If the quality of $\mathrm{SNF}_{\text {low }}$ is so low that the patient may suffer more from $\mathrm{SNF}_{\text {low }}$ than staying home (say higher infection rate), it could increase the risk of adverse patient outcomes. The three types of errors, and their distortion on the health care system, are summarized in Table 1.

In addition to the information and incentive challenges facing Medicare, the presence of $\mathrm{SNF}_{\text {high }}$ and $\mathrm{SNF}_{\text {low }}$ also creates an incentive wedge between patients and SNFs. Because we assume $\mathrm{SNF}_{\text {high }}$ provides better quality care (at the same cost) than $\mathrm{SNF}_{\text {low }}$, every patient prefers $\mathrm{SNF}_{\text {high }}$ to $\mathrm{SNF}_{\text {low. }}$. However, Medicare commits to a higher SNF reimbursement rate for a sicker patient (to the extent that the sickness is observable). Under the (oversimplified) assumption that the cost of SNF care is the same for all SNFs and all conditions, $\mathrm{SNF}_{\text {high }}$ is incentivized to accept sicker patients first before it hits the capacity constraint. Bowblis and Brunt (2014) shows that nursing homes prefer patients with more therapy minutes. Since sicker patients tend to require more therapy minutes conditional on the diagnosis, it is reasonable to assume that profit-seeking nursing homes may have incentives to admit sicker patients. The same financial incentive exists for $\mathrm{SNF}_{\text {low }}$, but there may be enough SNFs in some market so that $\mathrm{SNF}_{\text {low }}$ never hits its capacity constraint. In that world, $\mathrm{SNF}_{\text {high }}$ will admit sick patients until it is full, whereas $\mathrm{SNF}_{\text {low }}$ accepts all the remaining patients for whom Medicare is willing to pay for SNF care. Such sorting across SNFs with different quality levels is also aligned with patient selection behavior that severe patients are more likely to seek for high quality SNFs for treatment.

The SNF admission priority by patient sickness is in the same order as the sorting 
by net value in Figure 2. However, it implies that, when the capacity constraint of $\mathrm{SNF}_{\text {high }}$ is binding at $\mathrm{s}_{\mathrm{c}}$ and the three-day rule is a local proxy for $\mathrm{s}_{2}{ }^{\prime}<\mathrm{S}_{\mathrm{S}}<\mathrm{s}_{\mathrm{c}}$, those that suffer most from the low quality of $\mathrm{SNF}_{\text {low }}$ will be the relatively healthy patients that should have gone home but end up discharged to $\mathrm{SNF}_{\text {low }}$ (the yellow pentagon and blue circle).

Overall, we have three predictions:

Prediction 1: The three-day rule may generate extra Medicare expenditure because of overtreatment at SNFs, late discharge at hospitals and adverse health outcomes. All of them tend to focus on relatively healthy patients who are on the margin of a wrongful discharge decision.

Prediction 2: Adverse health outcomes such as hospital readmission will disproportionally affect the relatively healthy patients, because of either over-treatment in low quality SNFs or under-treatment at home. Which one dominates depends on the quality difference between SNFs and home care.

Prediction 3: If we have a good measure of SNF quality, adverse outcomes (conditional on being discharged to SNFs) should be disproportionally concentrated in low quality SNFs. If we do not have a good measure of SNF quality, SNF occupancy rate might be an indirect measure. In that case, adverse outcomes (conditional on being discharged to SNFs) should be disproportionally concentrated in SNFs with a low occupancy rate.

\section{Data Summary}

We use three databases. The main one is the inpatient discharge data from Arizona (2004-2007), Florida (2005-2013), New York (2005-2013), and Washington (2004-2013) State Inpatient Databases (SID) of the Healthcare Cost and Utilization Project (HCUP). ${ }^{9}$ These datasets contain all inpatient records and thus capture all Medicare patients who have qualifying hospital stays for SNF coverage in our sample states and years. The data also contains important information such as the primary expected payer, length of stay, and discharge destination. In addition, the data provides

\footnotetext{
${ }^{9}$ The National Bureau of Economic Research (NBER) provided access to the HCUP data.
} 
encrypted person identifiers, which allow us to track readmissions of the same individual over time.

We merge the SID with the American Hospital Association's (AHA) Annual Survey of Hospitals, ${ }^{10}$ which provides additional information about the hospitals in our sample, such as hospital location and facilities.

The third database is the 2003-2013 Online Survey Certificate and Reporting Database (OSCAR), which includes all Medicare and Medicaid certified nursing homes operating in the US. This database provides nursing home characteristics such as facility locations, deficiency citations and occupancy rate. Since OSCAR is collected at the SNFyear level, we cannot link it to the SID data at the individual patient level. To address this shortcoming, we use the discharge hospital's health service area (HSA) to match with the average deficiency count and occupancy rate of SNFs in that HSA. ${ }^{11}$

Total deficiency count is a well-known measure of SNF service quality (Castle and Ferguson 2010). If the SNFs in a HSA have on average a higher number of deficiency citations ${ }^{12}$ than the median of the corresponding state in the preceding year, we classify the HSA as above-median deficiency. Similarly, if the SNFs in a HSA have on average a lower occupancy rate than the median of the corresponding state in the year preceding the admission year, we classify the HSA as below-median occupancy. We use predetermined values of deficiency and occupancy to address potential endogeneity between these quality measures and patients’ actual discharge destination.

We restrict our main analysis sample to patients with age between 60 and 79 who are discharged within 24 hours before and after the three-day cutoff. ${ }^{13}$ We also focus on new episodes of hospitalization, where an episode is new if the patient has not been hospitalized in the past 180 days. This way, readmissions following a new episode are not included in the sample, but they are used to construct the 30-day and 60-day readmission outcomes for that episode. We drop observations missing the key variables such as

\footnotetext{
${ }^{10}$ The National Bureau of Economic Research (NBER) also provided access to the AHA data.

${ }^{11}$ We drop SNFs with $100 \%$ Medicaid patients in computing the average deficiency and occupancy rate since these SNFs focus on long-term care instead of post-acute care.

12 We right-censor deficiency citations at top 1 percentile to exclude outliers.

13 We extend the age range from 65-79 to 60-79 by including some young non-Medicare patients mainly because there are few non-Medicare patients above 65. In the robustness checks (section 5.4), we shorten the age range and the results remain robust.
} 
discharge destination, primary expected payer, encrypted person identifiers, and average SNF quality at the HSA level. We also exclude patients whose initial visit ended with death and thus cannot be tracked over time.

Table 2 presents the share of patients discharged to various destinations, by whether their hospital discharge is above or below the three-day cutoff and whether their insurer is Medicare or non-Medicare. Home discharges are more common for patients discharged on the second day than those discharged on the third day. Non-Medicare patients are more likely to be discharged home than Medicare patients. In contrast, discharges to SNF are more common for discharges on the third day, especially for Medicare patients. Home health care (HHC) is also more common for those who are discharged on the third day, and the share is higher for Medicare patients.

Table 3 compares patient demographics, health conditions, and readmission rates by discharge destination (home or HHC vs. SNF), above/below threshold, and Medicare/non-Medicare. For patients who are discharged to SNF, Panel B also compares SNF characteristics by above/below threshold and Medicare/non-Medicare.

Unsurprisingly, Medicare patients are older, more likely to have heart disease, stroke, and various comorbidities. Readmission rates are also higher for Medicare patients than nonMedicare patients. Knee or hip replacement is more common for non-Medicare patients, and patients with knee or hip replacement are much more likely to be discharged on the third day.

Patients discharged to SNFs are generally older than those discharged home or HHC. More than $50 \%$ of the patients discharged to SNFs on the third day had knee or hip replacement. Patients discharged on the second day to SNFs are more likely to have comorbidities and are more likely to be readmitted than patients discharged home. However, patients discharged on the third day to SNFs are relatively similar to those discharged home in terms of the probability of having comorbidities and readmission rates. Among patients discharged to SNFs on the third day, Medicare patients tend to stay in HSAs with slightly higher deficiency citations and slightly lower occupancy rates.

Table 4 shows SNF discharge rates and readmission rates by health condition, above/below the cutoff, and Medicare/non-Medicare. The SNF discharge rates are the highest for Medicare patients discharged on the third day for all health conditions. This 
pattern is most pronounced for knee or hip replacement (KHR) patients. The 30-day readmission rates are the highest for patients with heart disease (9.1-13.7\%), followed by other conditions (7.4-10.3\%), stroke (6.5-9\%), and knee or hip replacement (2.4-4\%). The same order holds for the 60-day readmission rate. Consistently, KHR patients have the lowest Elixhauser Comorbidity Index, no matter whether we compute the Index in readmission score or mortality score. These patterns suggest that KHR patients are healthier than patients with heart disease, stroke and other conditions. Therefore, according to our conceptual framework, they should be more on the margin of discharging to SNFs versus home and more exposed to the capacity constraint of high quality SNFs.

\section{Empirical Analysis}

We examine the effects of the three-day rule in a difference-in-differences (DID) framework. Specifically, we first examine discharge destinations of Medicare patients (65-79) and non-Medicare patients (60-79), comparing patients who are discharged from a hospital within 24 hours before vs. after the three-day cutoff:

$$
Y_{i}=\delta \text { Day }_{i} * \text { Medicare }_{i}+\alpha_{1} \text { Day }_{i}+\alpha_{2} \text { Medicare }_{i}+X_{i}+e_{i}
$$

where $i$ denotes a patient. Day $3_{\mathrm{i}}$ is an indicator for discharges within 24 hours after the three-day cutoff. Medicare $_{i}$ is an indicator for patients with Medicare as the primary expected payer. Day $3_{i} *$ Medicare ${ }_{i}$ is the interaction between the two variables. $X_{i}$ is a vector of discharge characteristics including patients' demographics such as age, age squared, an indicator for sex, a series of indicators for race, health conditions (Diagnosis Related Group (DRG) fixed effects and indicators for all comorbidities ${ }^{14}$ ), as well as hospital fixed effects. We also control for discharge year and discharge month fixed effects. Moreover, to account for different discharge probabilities throughout the day, we

\footnotetext{
14 The list of comorbidities is: Agency for Healthcare Research and Quality (AHRQ) comorbidity measure for acquired immune deficiency syndrome, alcohol abuse, deficiency anemias, rheumatoid arthritis/collagen vascular diseases, chronic blood loss anemia, congestive heart failure, chronic pulmonary disease, coagulopathy, depression, diabetes (uncomplicated), diabetes with chronic complications, drug abuse, hypertension, hypothyroidism, liver disease, lymphoma, fluid and electrolyte disorders, metastatic cancer, other neurological disorders, obesity, paralysis, peripheral vascular disorders, psychoses, pulmonary circulation disorders, renal failure, solid tumor without metastasis, peptic ulcer disease excluding bleeding, valvular disease, weight loss.
} 
include a dummy for each discharge hour as well as a dummy for missing discharge hour. We report robust standard errors clustered at the HSA level.

The key coefficient of interest is $\delta$, which captures the difference between day 3 and day 2 discharges among Medicare patients relative to the difference among nonMedicare patients conditional on patient demographics, health conditions, seasonality, and discharge hour. We consider the probability of discharges to four different destinations as an outcome $Y_{i}$ : home or home health care (HHC), SNFs, other facilities (including another short-term hospital and a long-term care hospital), and discharge against medical advice (AMA).

We are ultimately interested in examining the effects of SNF discharges on readmission rates.

$$
R_{i}=\beta S N F_{i}+\alpha_{1} \text { Day }_{i}+\alpha_{2} \text { Medicare }_{i}+X_{i}+e_{i}
$$

where $R_{i}$ denotes whether the patient is readmitted to a hospital. We consider readmission within 30 days as well as 60 days. The estimate $\beta$ will be biased upwards if a discharge SNF is correlated with (unobserved) sickness. We instrument $S N F_{i}$ with Day $3_{i}{ }^{*}$ Medicare ${ }_{i}$ to estimate the causal effect of SNF discharge on readmission rates using a two stage least squared (2SLS) method. The 2SLS estimate $\beta$ describes the local average treatment effect for compliers, i.e. patients who are induced to be discharged to a SNF due to the three-day rule.

The key identification assumption is that all control variables - including hospital fixed effects, patient attributes, major diagnosis, comorbidities, day 3 alone and insurance type alone - are sufficient to capture observable and unobservable health conditions that may affect a hospital's discharge decision. As the result, the interaction of day3*Medicare mainly captures the financial incentive of discharging Medicare patients to different destinations. This assumption will be tested by robustness checks in Section 5.4 .

We prefer DID to the alternative approach of regression discontinuity (RD), mostly because only a small percent of hospitalization is around the midnight cutoff. Around $90 \%$ of patients are discharged from the hospital between 10 am and $6 \mathrm{pm}$, with the most at 2 pm (13.2\%). In Section 5.4, we show that the impact of the three-day rule on discharge to SNF is robust when we zoom in 5 hours before and 5 hours after the 
midnight cutoff. However, this window only accounts for $3 \%$ of our main sample, and patients discharged in this window are systematically different from other patients in health conditions and local SNF characteristics. Also, because discharge to SNF requires paperwork between hospital and SNF, such paperwork is unlikely to occur around the midnight, which explains why the probability of discharge to SNF in this time window (3\%) is much lower than the overall probability of SNF discharge (8\%). We worry that severe sample selection could potentially bias the estimation of the overall impact of SNF discharge on hospital readmission.

Including all new hospitalization episodes that are discharged 24 hours before and after the midnight cutoff alleviates the selection problem, but it also make our identification rely more on the comparability between Medicare and non-Medicare patients in this relatively large time window. In Section 5.4, we show that our results are robust if we narrow the age range from 60-79 to 62-67, and the differential effects we observe between Medicare and non-Medicare patients only occur around the three-day cutoff, not around the cutoff on day 4, day 5, day 6 and day 7.

\subsection{Results in the pooled sample}

We first estimate the effect of the three-day rule on discharge destinations. Table 5 reports $\delta$ from equation (1) for each of the four different discharge destinations. Medicare patients who are discharged after the three-day cutoff are 6.8 percentage points more likely to be discharged to a SNF than those who are discharged before the three-day cutoff. This effect is enormous, considering the fact that only 9.4\% of Medicare patients (and 8\% of all patients) in our sample were discharged to SNFs. The increase in discharge rate to SNFs is offset by a decrease in home and home health care discharges.

Subsequently, we estimate the effect of a SNF discharge on readmission rates using both OLS and 2SLS approaches. Table 6 summarizes the results. Columns 1 and 2 of Panel A show that patients who are discharged to SNF have higher readmission rates, if we use simple OLS. If patients with more severe conditions tend to be discharged to SNF, the unobserved differences in sickness may bias the OLS estimates upwards. Panel B shows that once we instrument the SNF discharge with Day3*Medicare, the estimates on 60-day readmission rates become negative and statistically significant. This suggests 
that holding health conditions constant, SNF care may be more beneficial than home care in terms of reducing hospital readmissions.

We unveil the negative readmission effects further by patient comorbidity. Columns 3 and 4 show that for patients without any comorbidity (12\% of the sample), SNF discharge has no effect on readmission rates. Patients with at least one comorbidity drive the negative readmission effects (Columns 5 and 6 in Table 6). If we split the full sample by whether a patient has above- or below-median Elixhauser Comorbidity Index, the significant, negative readmission effects only persist in the above-median subsample for 60-day readmission. In the below-median subsample, discharge to SNF has no significant effect on readmission (Columns 7 and 8 in Table 6). This suggests that SNF service is only effective in reducing hospital readmission for sicker patients.

\subsection{Results by health conditions}

We further examine the effects of the three-day rule and SNF discharges by health conditions. We separately consider heart disease, stroke, and knee or hip replacement since they are common conditions that may benefit from post-acute care at a SNF (MEDPAC 2010). Other conditions are grouped as the fourth category.

As shown in Table 7, the discharge effect of the three-day rule is the largest for knee or hip replacement. Medicare patients with knee or hip replacement discharged after the three-day cutoff are 14 percentage points more likely to be discharged to a SNF than those who are discharged before the three-day cutoff. This increase in SNF discharges is entirely offset by a decrease in home or HHC discharges. The discharge effect is the smallest for heart disease patients with a 1.8 percentage point increase. The increase in SNF discharges is also offset by a reduction in home discharges for heart disease, stroke, and other conditions. In short, finding the largest SNF discharge effect in KHR patients is consistent with Prediction 1, because KHR patients are healthier than other patients and therefore more on the margin of being discharged to SNFs or going home.

Table 8 presents OLS estimates on readmission rates by health conditions. Given the large discharge effect for KHR patients, we separately examine knee and hip replacement and pool the other conditions. The OLS estimates show that the positive coefficient of SNF discharge on readmission rates is lower for KHR patients than for all 
other conditions. This is not surprising because KHR patients have the lowest readmission rates in the raw data.

Table 9 shows the corresponding 2SLS estimates. When we instrument SNF discharge with the three-day rule, we find a significant increase in readmission rates for KHR patients. We generally do not find a significant effect on readmission for other conditions. Within knee and hip replacement, the perverse effect of SNF discharge on readmission is larger for KHR patients without comorbidity. This pattern is consistent with Prediction 2, where we argue that healthier patients are more exposed to low quality SNF services because they are closer to the margin of a wrongful discharge decision.

\subsection{Results by local SNF characteristics}

We further break down the sample by local SNF characteristics, using deficiency citation and occupancy rate. Panel A of Table 10 shows that the increase in readmission rates for Medicare KHR patients is driven by low occupancy HSAs. Panel B shows that the increase in readmission rates is higher and only significant in high deficiency areas, consistent with the fact that areas with high deficiency are often areas with low occupancy. Consistent with Prediction 3, these results suggest that KHR patients are relatively healthy and on the margin of going to SNF simply because Medicare will pay for it and there is a bed available in nearby low-quality SNFs. Not only does the overconsumption of SNF care increase post-acute care expenditure for Medicare, but it also generates a higher readmission rate, which requires even more spending from Medicare. We will quantify these costs for Medicare when we conduct our back-of-the-envelope calculation in Section 6.

\subsection{Robustness checks}

\subsubsection{Alternative sampling}

One key identification question is whether Medicare and non-Medicare patients are truly comparable. They obviously differ in age as Medicare patients are 65 and above but most non-Medicare patients are 60-65, with only a small fraction spreading above 65 . We have controlled for a polynomial function of age in all regressions, but one still wonders whether our results could be driven by Medicare patients being systematically 
sicker than non-Medicare patients, rather than the three-day rule of Medicare.

To consider this possibility, we employ an event study approach to examine pretrends, by the exact discharge hour. That is, instead of Day3*Medicare in equation (1), we include a series of interactions between Medicare and each discharge hour within the 24 hour window before and after the three-day cutoff. Panel (a) of Appendix Figure A.1 shows that there is little evidence of pre-trends between Medicare and non-Medicare patients, while the SNF discharge rate increases significantly 10-24 hours after the threeday cutoff. Similar results hold for the subsample of KHR patients only (panel (b) of Appendix Figure A.1), though the parallel shift of SNF discharge rate after the cutoff is less powerful for this subsample.

We then plot the same graph for the hypothetical cutoff at midnight of day 4, day 5, day 6 and day 7. If Medicare patients are systematically sicker than non-Medicare patients, we should observe the effects at these hypothetical cutoffs similar to the threeday cutoff. As shown in Appendix Figure A.2, the difference between Medicare and nonMedicare patients is mostly muted for day 4, day 5, day 6 and day 7.

Appendix Table B.1 runs the same regressions as our main results for these alternative cutoffs. Thanks to our enormous sample, the probability of discharge to SNFs is significantly different between Medicare and non-Medicare patients for day 4, day 5, day 6 and day 7, but the magnitude of this difference is much smaller than for the day 3 cutoff (-0.7 to 1.1 percentage points as compared to 6.8 percentage points). These results suggest that the Medicare-versus-non-Medicare difference is much more salient for the day 3 cutoff, likely because of the three-day rule of Medicare.

Another way to ensure comparability between Medicare and non-Medicare patients is adopting a narrower age range. Tables B.2-B.5 repeat the same regressions as our main results but use the age range 60-69 instead of 60-79. Tables B.6-B.9 further narrow the age range to 62-67. In both scenarios, the estimated impact of the three-day rule on SNF discharge is smaller (5 and 4.4 instead of 6.8 percentage points) but remains significant at 99\% confidence. In the second stage, we still observe a contrast between KHR and other conditions, where KHR patients suffer from a higher readmission rate because of the three-day rule but other patients have either similar or significantly lower readmission rate after staying at a SNF. The perverse readmission outcome for KHR 
patients continues to concentrate in the HSAs with a higher-than-state-median total deficiency count or a lower-than-state-median occupancy rate.

Similar robustness is achieved when we expand the sample to include all hospitalization episodes instead of new episodes only (Appendix Tables B.10-B.13); drop MA patients (Appendix Tables B.14-B.17); or reduce the sample to 12 hours (instead of 24 hours) before and after the three-day cutoff (Appendix Tables B.18-B.21). Moreover, when we use a regression discontinuity (RD) design focusing on Medicare patients discharged between 5 hours before and after the three-day cutoff, we still find a robust increase in SNF discharge rates above the threshold (Appendix Table B.22).

\subsubsection{Selection on patient condition}

We also investigate whether selection of patient condition can explain our results. In our main estimations, we already control for all observable differences in patient condition using the DRG fixed effects and indicators for comorbidities. Alternatively, we examine each comorbidity as an outcome using equation (1) (without the comorbidity controls) and find that 15 out of 29 comorbidities have significant difference between Medicare patients who are discharged after vs. before the three-day cutoff relative to nonMedicare patients. We drop patients with these 15 comorbidities so that the remaining sample does not have any comorbidity difference across the threshold on average. For this subsample, we find similar lift in the probability of discharge to SNFs (Appendix Table B.23), and either zero or negative impact of SNF stay on readmission rates for the full sample (Appendix Table B.24). However, we still find significant, positive readmission effects for KHR patients, which are larger for KHR patients without comorbidities and stronger in low occupancy HSAs (Appendix Tables B.25-B.26).

In Appendix B.27-B.30, we examine whether our estimates are robust to an additional set of controls. Patients who intend to take advantage of the three-day rule may differ in their method of admission, admission time, or the total hours in the hospital. We find that our estimates barely change when we include admission time, total hours in the hospital, and whether the initial hospital admission was through the emergency room (ER). Similar results arise when we further restrict the sample to ER admissions only (Appendix B.31-B.32). Such robustness suggests that patients are unlikely to manipulate 
their stay in the hospital due to the three-day rule.

To further test the validity of our instrument, we include Day3*Medicare in the OLS equation (2). In theory, this addition should not have a significant impact on readmission outcomes because the OLS regression already includes the endogenous variable, the SNF discharge. Appendix Table B.33 shows that the coefficients on SNF are almost identical to our main OLS estimations in Panel A of Table 6, although the coefficients on Day3*Medicare are statistically significant in the full sample as well as the subsample with any comorbidity. For the subsample without any comorbidity - where we find no readmission effects of SNF discharge due to the three-day rule - we find that adding Day3*Medicare to the OLS has no significant effect on readmission rates. This highlights our findings that SNF care may not improve health outcomes for patients with less severe conditions.

\subsubsection{Hospital Bed Availability}

We also concern that hospitals could manipulate the length of stay of Medicare patients for SNF coverage. Though Medicare is unlikely to pay for extra length of stay (because Medicare pays by DRG), the doctor may "help” a Medicare patient to stay longer in order to qualify for the SNF coverage. Such "help” is more feasible when the hospital beds are underutilized. Accordingly, we define hospital bed availability as months in which total inpatient days are below the median in a given hospital-year. Appendix Table B.34 shows that the likelihood of discharging Medicare patients to SNFs after the three-day cutoff is 5.2 percentage point more than before the cutoff for hospitals with different levels of bed utilization. Since the discharge effect varies little by hospital bed availability, we believe that hospitals are very unlikely to manipulate the length of stay for SNF coverage.

\section{Conclusion and Policy Implications}

Overall, we find alarming signs that suggest unnecessary Medicare spending and adverse health outcomes, all related to the three-day rule that Medicare imposes on its FFS reimbursement to SNFs. 
More specifically, in the pooled sample, the three-day rule leads to a 6.8 percentage point increase in the probability of discharging a Medicare patient to SNFs within 24 hours after the three-day-cutoff. This effect is enormous, considering the fact that only 9.4\% of Medicare patients (and 8\% of all patients) in our sample were discharged to SNFs. However, among those that have no comorbidity or below-median Elixhauser Comorbidity Index, there is no significant readmission difference between those discharged to SNF and those discharged somewhere else.

More than $50 \%$ of the patients discharged to SNFs on the third day had knee or hip replacement (KHR). For KHR patients alone, the three-day rule increases the probability of SNF discharge by 14 percentage points. Though KHR patients are on average healthier than patients with heart disease, stroke and other conditions, KHR is the only category for which we find a significant increase in hospital readmission rate as a result of the three-day rule. This perverse effect is larger and only significant in the HSAs, where the average SNFs have a lower-than-state-median occupancy rate or a higher-than-state-median total deficiency count. This suggests that many KHR patients are discharged to SNFs simply because Medicare will pay for it and there is bed available in nearby SNFs. Unfortunately, discharging KHR patients to SNF is associated with a greater likelihood of hospital readmission within 30 and 60 days.

What do these findings imply for Medicare expenditure? Table 11 presents two sets of back-of-the-envelope calculations, one for the pooled sample, and one for knee and hip replacement only. On the pooled sample, we focus on the patients with no or below-median comorbidities because, within these patients, SNF discharge makes no difference in hospital readmission. Thus, Medicare expenditure on their SNF discharge could be unnecessary. Assuming Medicare pays $\$ 500$ a day for FFS care in SNFs and an average Medicare patient stays in a SNF for 37 days per episode (Lu, Rui and Seidmann 2018), a 6.6 percentage point ${ }^{15}$ increase in the probability of SNF discharge implies an extra payment of \$139.6 million in our sample. Translating it into the annual spending of the whole Medicare, it amounts to $\$ 99.74$ million per year if we only count patients with

\footnotetext{
${ }^{15}$ We use 6.6 percentage points instead of 6.8 , because the former is the estimated effect of the three-day rule on the probability of SNF discharge for patients with no comorbidities, while the latter is the effect for all patients (Table 5).
} 
no comorbidities, or $\$ 446.86$ million per year if we include patients with below-median comorbidities. These numbers correspond to 0.32 to $1.43 \%$ of total Medicare payment to SNFs. ${ }^{16}$

Turning to knee and hip replacement only, we focus on two sources of unnecessary Medicare expenditure. The first one is Medicare payment for SNF discharge, and the second one is Medicare payment for the increased hospital readmission after the SNF discharge. For both of them, we focus on KHR patients with no complications, which accounts for $97.4 \%$ of the KHR patients in our sample. ${ }^{17}$

Assuming an average KHR patient discharged to a SNF will stay there for 15 days (DeJong et al. 2009) and Medicare pays \$500 per day, a 14 percentage point increase in SNF discharge implies an extra Medicare payment of \$223.2 million in our sample. Projecting it to the whole Medicare population, it implies unnecessary Medicare payment to SNFs by $\$ 112.5$ million per year. To calculate Medicare payment for the extra readmission after the SNF discharge, we assume each readmission entails $\$ 10,000$ per visit. ${ }^{18}$ That implies $\$ 6$ million in Medicare spending for our analysis sample, or \$4.24 million per year for the whole Medicare population. In combination, the two sources of unnecessary spending add up to $\$ 83.73$ million per year for Medicare, which accounts for $1.2 \%$ of the total Medicare expenditure on knee and hip replacement. ${ }^{19}$

These back-of-the-envelope calculations may be conservative, because we do not include the potential longer stay in hospital in order to qualify for the SNF discharge

\footnotetext{
${ }^{16}$ According to CMS (2017b) Table III.6, total Medicare payment to SNFs was $\$ 31.332$ billion in fiscal year 2016.

${ }^{17}$ We use procedure codes in the inpatient record to determine whether a KHR patient receives the joint replacement procedure with or without complications. Literature has shown that institutionalized post-acute care can be helpful for KHR patients with complications (McLawhorn and Buller 2017). Because KHR patients with complications often stay in the hospital longer than three days, our analysis sample has very few of them.

${ }^{18}$ Based on CMS data (https://www.cms.gov/Research-Statistics-Data-and-Systems/Statistics-Trends-andReports/Medicare-Provider-Charge-Data/Inpatient2015.html), the least expensive DRG at readmission for KHR is DRG 946 (Rehabilitation without CC/MCC) with an average payment of \$10,951 in 2014. We assume $\$ 10,000$ per readmission to be conservative.

19 According to CMS (https://innovation.cms.gov/initiatives/cjr, accessed May 16, 2018), there were more than 400,000 knee and hip replacement procedures in 2014, costing more than $\$ 7$ billion for the hospitalizations alone. We use $\$ 7$ billion to proxy for the total Medicare expenditure on knee and hip replacement.
} 
under the three-day rule. It is difficult to quantify this element, as we do not find strong evidence supporting hospital manipulation in length of stay (Appendix Table B.34).

Our findings are consistent with the perceived inefficiency in the Medicare system, which has motivated a number of alternative payment methods. In 2012, CMS experimented with the Bundled Payments for Care Improvement (BPCI) on a voluntary basis. Subsequently in 2016, CMS mandated the Comprehensive Care for Joint Replacement (CJR) reimbursement model in 67 MSAs. In both programs, Medicare commits to a bundled payment to a participating hospital, where the bundle covers inpatient, outpatient and post-acute care related to a particular procedure. In its extreme form, the participating hospital may receive a fixed amount for the whole knee and hip replacement episode, regardless how much care the patient actually receives from inpatient stay, SNF usage, rehabilitation center, or home care up to 90 days since the beginning of the procedure.

As summarized by McLawhorn and Buller (2017), early evidence suggests that bundled payments are able to reduce Medicare cost for the whole KHR episode, without reducing quality of care for most KHR patients. For example, Navathe et al. (2017) study 3,942 KHR patients in the Baptist Health System (BHS), a network of 5 hospitals in San Antonio, Texas. BHS adopted BPCI in October 2013, where the bundled payment covers acute hospitalization and 30 days of post-acute care. Between July 2008 and June 2015, average Medicare expenditure per KHR episode declined 20.8\%. In the meantime, readmissions, emergency department visits, and length of inpatient stay all declined. While some of the overall hospital savings came from internal cost reduction, average post-acute care spending declined 27\% per case. Most of the post-acute savings were driven by reductions in inpatient rehabilitation and SNF spending, and these savings only occurred when the bundle payment included financial responsibility for post-acute care.

While these results may be specific to BHS, they confirm the conclusion that traditional fee-for-service payment includes unnecessary waste. As shown in our study, the three-day payment rule has encouraged relatively healthy patients to overuse SNFs but stay in SNF does not improve hospital readmission rates. In some cases - such as knee and hip replacement - the overuse of SNFs is also related to higher readmission, leading to even more Medicare spending. Our findings suggest that discharge to SNFs 
should be based on a more complete assessment of patient conditions including the existence and severity of comorbidities rather than a single measure of length of stay in hospitals.

Finally, we caution readers that our back-of-the-envelope calculations focus on Medicare spending, not the total welfare. We lack individual records and cost data from SNFs, and do not consider the possibility that admission of Medicare patients may crowd out Medicaid and private-insured patients from capacity-constrained SNFs. Nor do we observe the cost of care provided by family members when a patient is discharged home instead of to SNFs. These costs could be substantial, but they are not included in Medicare spending.

\section{References}

Arling, G., V. Cooke, T. Lewis, A. Perkins, D. C. Grabowski and K. Abrahamson. 2013. "Minnesota's Provider-Initiated Approach Yields Care Quality Gains at Participating Nursing Homes." Health Affairs, 32(9), 1631-38.

Bowblis, J. R. and C. S. Brunt. 2014. "Medicare Skilled Nursing Facility Reimbursement and Upcoding." Health Economics, 23(7), 821-40.

Brickley, J, S.F. Lu and G. Wedig. 2018. "Quality Ratings and Corporate Governance: Evidence from the Nursing Home Industry," University of Rochester Working Paper.

Brown, J., M. Duggan, I. Kuziemko and W. Woolston. 2014. "How Does Risk Selection Respond to Risk Adjustment? New Evidence from the Medicare Advantage Program." American Economic Review, 104(10), 3335-64.

Castle, N. G. and Ferguson, J. C. (2010). "What Is Nursing Home Quality and How Is It Measured?" The Gerontologist, 50(4): 426-442. http://doi.org/10.1093/geront/gnq052

Centers for Medicare and Medicaid Services. (CMS 2017a). "Medicare Program; Prospective Payment System and Consolidated Billing for Skilled Nursing Facilities for FY 2018, SNF Value-Based Purchasing Program, SNF Quality Reporting Program, Survey Team Composition, and Correction of the Performance Period for the NHSN HCP Influenza Vaccination Immunization Reporting Measure in the ESRD QIP for PY 2020.” Federal Register, 82(149), Friday, August 4, 2017.

Centers for Medicare and Medicaid Services. (CMS 2017b). "2016 CMS Statistics,” accessed at https://www.cms.gov/Research-Statistics-Data-and-Systems/Statistics-Trends-and-Reports/CMS-StatisticsReference-Booklet/index.html, on May 16, 2018.

Centers for Medicare and Medicaid Services. (CMS 2017c). "Design for Nursing Home Compare Five-Star Quality Rating: Technical Users Guide,” 2017.

https://www.medicare.gov/nursinghomecompare/data/about.html.

Ching, A., Hayashi F. and H. Wang. (2015). "Quantifying the Impacts of Limited Supply: The Case of Nursing Homes.” International Economic Review, 56(4): 1291-1322. 
Curto V., Finkelstein A., Levin J. and Bhattacharya, J. (2017). "Healthcare Spending and Utilization in Public and Private Medicare,” NBER Working Paper \#23090.

DeJong, G., Hsieh, C.H., Gassaway, J., Horn, S.D., Smout, R.J., Putman, K., James, R., Brown, M., Newman, E.M. and Foley, M.P. (2009). "Characterizing Rehabilitation Services for Patients with Knee and Hip Replacement in Skilled Nursing Facilities and Inpatient Rehabilitation Facilities." Archives of Physical Medicine and Rehabilitation, 90(8): 1269-1283.

Doyle J. and Graves, J.. (2017). “Uncovering Waste in U.S. Healthcare.” Journal of Health Economics.

Duggan M. and F. Morton. (2010). "The Effect of Medicare Part D on Pharmaceutical Prices and Utilization." American Economic Review, 100(1): 590-607

Duggan M., Starc A., and Vabson, B. "Who Benefits When the Government Pays More? Evidence from the Medicare Advantage Program." Forthcoming in Journal of Public Economics.

Duggan M., Gruber, J. and Vabson, B. "The Consequences of Health Care Privatization: Evidence from Medicare Advantage Exits." Forthcoming in AEJ: Economic Policy.

Einav L., Finkelstein A. and Mahoney, N. (2017). "Provider Incentives and Healthcare Costs: Evidence from Long-Term Care Hospitals.” NBER Working Paper \#23100.

Eliason P., Grieco P., McDevitte R., and Roberts, J. (2017). "Strategic Patient Discharge: Evidence from Long-term Care Hospitals.” working paper.

Elixhauser A., Steiner C., Harris D.R., Coffey R.M. (1998). “Comorbidity Measures for Use with Administrative Data." Medical Care, 36:8-27.

Finkelstein A. (2007). "The Aggregate Effects of Health Insurance: Evidence from the Introduction of Medicare.” Quarterly Journal of Economics, 122(1): 1-37.

Finkelstein A. and McKnight, R.. (2008). "What Did Medicare Do? The Initial Impact of Medicare on Mortality and Out of Pocket Medical Spending.” Journal of Public Economics 92: 1644-1669.

Grebla, Regina C., Laura Keohane, Yoojin Lee, Lewis A. Lipsitz, Momotazur Rahman, and Amal N. Trivedi. (2015). "Waiving The Three-Day Rule: Admissions And Length-Of-Stay At Hospitals And Skilled Nursing Facilities Did not Increase.” Health Affairs, 34(8), August 2015.

Gornick, M. and M.J. Hall. (1988). “Trends in Medicare Use of Post-hospital Care.” Health Care Financing Review, Suppl: 27-38.

Grabowski, D.C. (2007). “Medicare and Medicaid: Conflicting Incentives for Long- Term Care.” The Milbank Quarterly, 2007 Dec, 85(4): 579-610.

Grabowski, D.C., Stevenson, D.G., Caudry, D.J., O'Malley, A.J., Green, L.H., Doherty, J.A.. and Frank, R.G. (2017). "The Impact of Nursing Home Pay-for-Performance on Quality and Medicare Spending: Results from the Nursing Home Value-Based Purchasing Demonstration.” Health Services Research, 2017 Aug, 52(4): 1387-1408.

Hackman, M. and V. Pohl. 2018. "Patient vs. Provider Incentives in Long Term Care," UCLA Working Paper.

Harrington, C., Woolhandler, S., Mullan, J., Carrillo, H., and Himmelstein, D. (2001). "Does Investor Ownership of Nursing Homes Compromise the Quality of Care?” American Journal of Public Health, 91: 1452-1455. 
Huang, S. S. and R. A. Hirth. 2016. "Quality Rating and Private-Prices: Evidence from the Nursing Home Industry." Journal of Health Economics, 50, 59-70.

Lu, S.F. (2012). "Multitasking, Information Disclosure and Product Quality: Evidence from Nursing Homes.” Journal of Economics \& Management Strategy, 21(3): 673-705.

Lu, S.F. (2016), "The Role of Donations in Quality Disclosure Evidence from Nonprofit Nursing Homes.” American Journal of Health Economics, 2(4): 431-462.

Lu, S.F. and G. Wedig. (2013). "Clustering, Agency Costs and Operating Efficiency: Evidence from Nursing Home Chains.” Management Science, 59(3): 677-694.

Lu, S.F., H. Rui and A. Seidmann. (2018). "Does Technology Substitute for Nurses? Staffing Decisions in Nursing Homes.” Management Science, 64(4), 1842-59.

Meyers, D. J., V. Mor and M. Rahman. 2018. "Medicare Advantage Enrollees More Likely to Enter LowerQuality Nursing Homes Compared to Fee-for-Service Enrollees." Health Affairs, 37(1), 78-85.

McLawhorn, A.S. and L.T. Buller. (2017). "Bundled Payments in Total Joint Replacement: Keeping Our Care Affordable and High in Quality.” Current Reviews in Musculoskeletal Medicine, 10: 370-377.

Medicare Payment Advisory Commission (MEDPAC 2010). "Most Common Diagnoses in Skilled Nursing Facilities.” available at http://67.59.137.244/chapters/Mar10_Ch03A_APPENDIX.pdf, accessed on May 18, 2018.

Medicare Payment Advisory Commission (MEDPAC 2015). "Report to the Congress: Medicare Payment Policy.” Washington, DC.

Medicare Payment Advisory Commission (MEDPAC 2017). “A DATA BOOK Health Care Spending and the Medicare Program.” available at http://www.medpac.gov/docs/default-source/databook/jun17_databookentirereport_sec.pdf?sfvrsn=0, accessed on May 16, 2018.

Navathe, A.S., Troxel, A.B., Liao, J.M., Nan, N., Zhu, J., Zhong, W. and Emanuel, E.J. (2017). “Cost of Joint Replacement Using Bundled Payment Models.” JAMA Internal Medicine, 177(2): 214-22.

Nyman, J.A. (1993). “Testing for Excess Demand in Nursing Home Care Markets.” Medical Care, 31(8): 680-693.

Werner, R., Kolstad, J., Stuart, E. and Polsky, D. (2011). "The Effect of Pay-for-Performance in Hospitals: Lessons for Quality Improvement.” Health Affairs, 30(4), 690-98.

Zhao, X. (2016). “Competition, Information, and Quality: Evidence from Nursing Homes.” Journal of Health Economics, 49: 136-152. 
Figure 1: Sorting of destination with homogenous SNFs

Assume all SNFs are high-quality

Net value of staying at home is normalized to zero conditional on sickness $\mathrm{s}$

$\mathrm{s}_{1}=$ social optimal threshold to discharge to SNF

$\mathrm{s}_{2}=$ social optimal threshold to discharge home

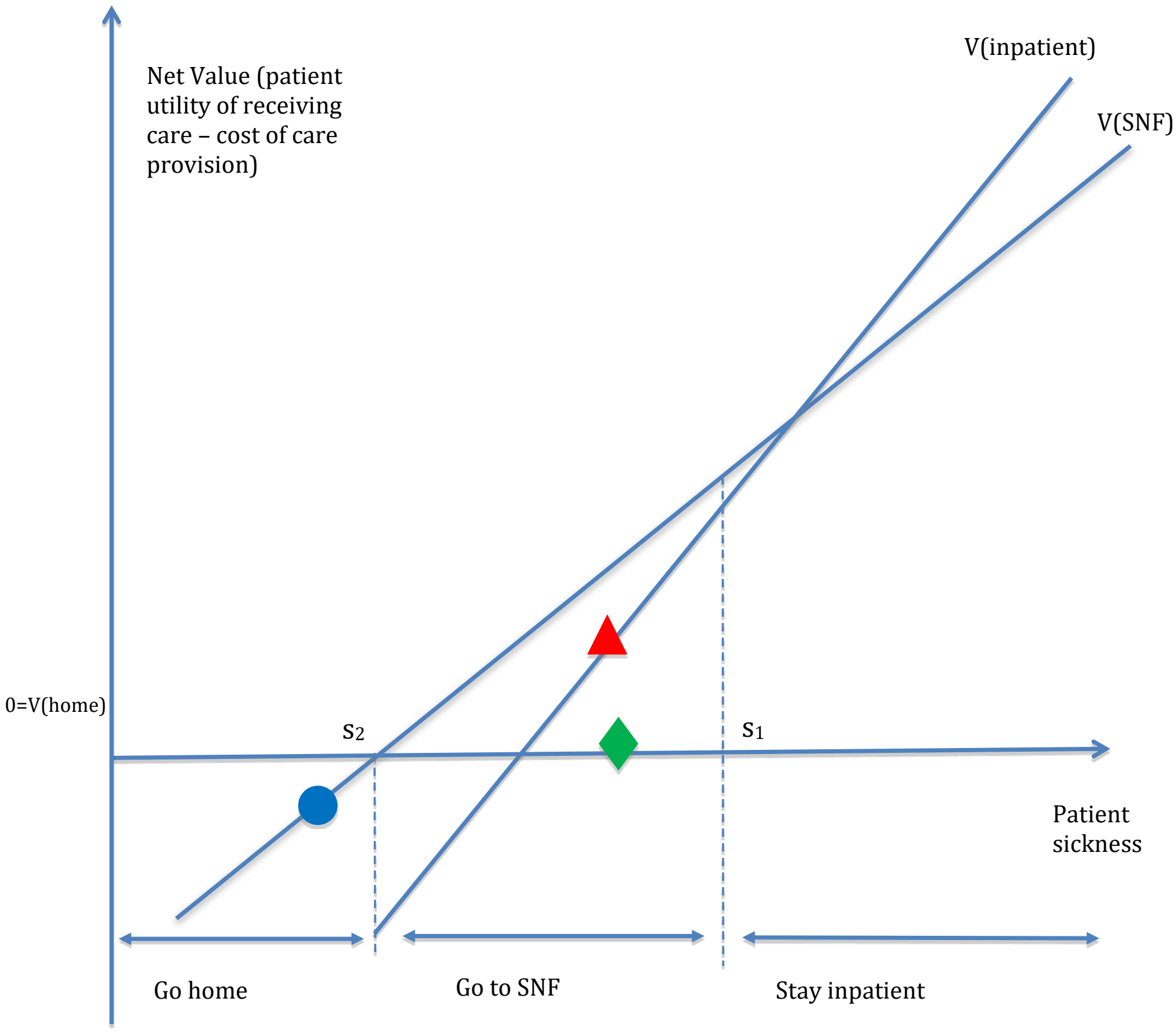


Figure 2: Sorting of destination with $\mathrm{SNF}_{\text {high }}$ and $\mathrm{SNF}_{\text {low }}$

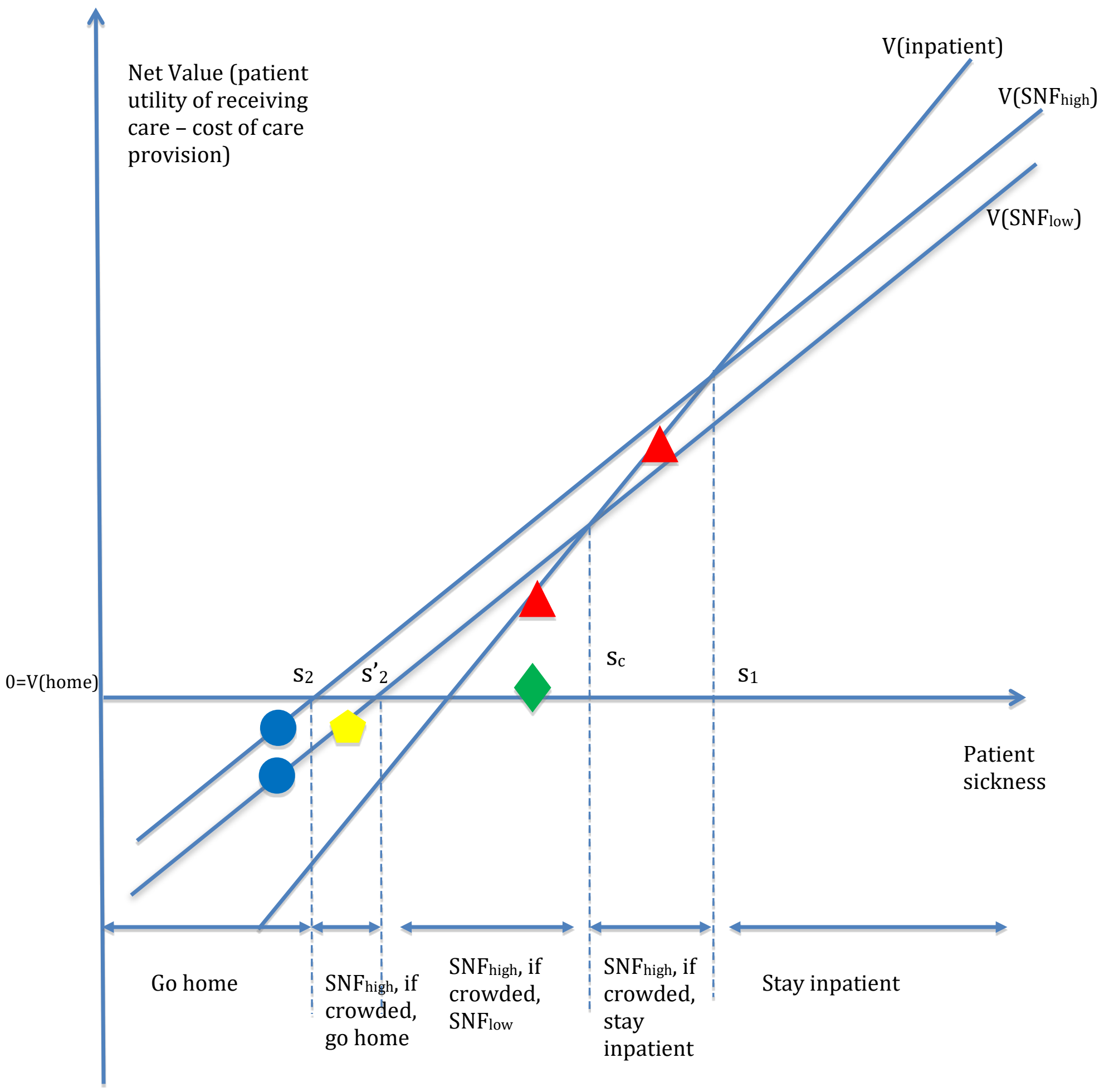


Table 1: Potential distortion from Medicare reimbursement rules for SNFs

\begin{tabular}{|c|c|c|c|c|c|}
\hline & Description & $\begin{array}{l}\text { Potential distortion in } \\
\text { hospital's discharge } \\
\text { decision }\end{array}$ & $\begin{array}{l}\text { Extra cost for CMS (as } \\
\text { a social planner) }\end{array}$ & $\begin{array}{l}\text { Any adverse effect on } \\
\text { patient readmission }\end{array}$ & $\begin{array}{l}\text { Graphic } \\
\text { illustration }\end{array}$ \\
\hline \multirow[t]{2}{*}{ Error 1} & \multirow[t]{2}{*}{$\begin{array}{l}\mathrm{s}_{2}<\mathrm{s}<\mathrm{s} 1 \text { (so the patient } \\
\text { should go to } \mathrm{SNF}_{\text {high, }} \text { or } \\
\mathrm{SNF}_{\text {low }} \text { if } \mathrm{SNF}_{\text {high is full) }} \\
\text { but the patient is ready for } \\
\text { discharge before reaching } \\
\text { the three-day cutoff }\end{array}$} & $\begin{array}{l}\text { Hospital keeps the } \\
\text { patient beyond the } \\
\text { cutoff and then } \\
\text { discharges her to SNF }\end{array}$ & $\begin{array}{l}\text { Medicare pays for } \\
\text { extra inpatient stay } \\
\text { while patient receives } \\
\text { better but unnecessary } \\
\text { care in hospital }\end{array}$ & No & $\begin{array}{l}\text { Red triangle } \\
\text { in Figure } 1 \\
\text { and Figure } 2\end{array}$ \\
\hline & & $\begin{array}{l}\text { Hospital discharges } \\
\text { the patient home } \\
\text { before the cutoff }\end{array}$ & $\begin{array}{l}\text { Patient suffers from } \\
\text { inadequate care after } \\
\text { discharge, Medicare } \\
\text { saves SNF cost }\end{array}$ & Yes & $\begin{array}{l}\text { Green } \\
\text { diamond in } \\
\text { Figure } 1 \text { and } \\
\text { Figure } 2\end{array}$ \\
\hline \multirow[t]{2}{*}{ Error 2} & \multirow{2}{*}{$\begin{array}{l}\mathrm{s}<\mathrm{s}_{2} \text { (so the patient should } \\
\text { go home regardless of SNF } \\
\text { quality) but the patient is } \\
\text { ready for discharge after } \\
\text { three-night inpatient stay }\end{array}$} & $\begin{array}{l}\text { Hospital discharges } \\
\text { the patient to } \mathrm{SNF}_{\text {high }} \\
\text { or } \mathrm{SNF}_{\text {low }}\end{array}$ & $\begin{array}{l}\text { Medicare pays for } \\
\text { unnecessary SNF care }\end{array}$ & $\begin{array}{l}\text { Potentially yes if } \\
\text { SNF }_{\text {low }} \text { has a risk of } \\
\text { providing worse care } \\
\text { than home }\end{array}$ & $\begin{array}{l}\text { Blue circle in } \\
\text { Figure } 1 \text { and } \\
\text { Figure } 2\end{array}$ \\
\hline & & $\begin{array}{l}\text { Hospital discharges } \\
\text { the patient home }\end{array}$ & $\begin{array}{l}\text { Same as efficient } \\
\text { outcome }\end{array}$ & No & \\
\hline \multirow[t]{2}{*}{ Error 3} & \multirow{2}{*}{$\begin{array}{l}\mathrm{S}_{2}<\mathrm{S}<\mathrm{S}_{2} \text { ( so the patient } \\
\text { should go home when } \\
\mathrm{SNF}_{\text {high is full) but the }} \\
\text { patient is ready for } \\
\text { discharge after three-night } \\
\text { inpatient stay }\end{array}$} & $\begin{array}{l}\text { Hospital discharges } \\
\text { the patient to } \mathrm{SNF}_{\text {low }}\end{array}$ & $\begin{array}{l}\text { Medicare pays for } \\
\text { unnecessary SNF care }\end{array}$ & $\begin{array}{l}\text { Potentially yes if } \\
\text { SNF }{ }_{\text {low }} \text { has a risk of } \\
\text { providing worst care } \\
\text { than home }\end{array}$ & $\begin{array}{l}\text { Yellow } \\
\text { pentagon in } \\
\text { Figure } 2\end{array}$ \\
\hline & & $\begin{array}{l}\text { Hospital discharges } \\
\text { the patient home }\end{array}$ & $\begin{array}{l}\text { Same as efficient } \\
\text { outcome }\end{array}$ & No & \\
\hline
\end{tabular}


Table 2: Discharge destination by above/below threshold and Medicare/non-Medicare

\begin{tabular}{lcccc}
\hline & Day 2 \& Medicare & Day 2 \& Non-Medicare & Day 3 \& Medicare & Day 3 \& Non-Medicare \\
\hline Home & 0.801 & 0.859 & 0.582 & 0.702 \\
SNF & 0.022 & 0.013 & 0.163 & 0.077 \\
Short-term & 0.022 & 0.023 & 0.018 & 0.018 \\
Other facilities & 0.022 & 0.014 & 0.050 & 0.032 \\
HHC & 0.123 & 0.080 & 0.182 & 0.163 \\
AMA & 0.010 & 0.011 & 0.005 & 0.007 \\
\hline Observations & 964,887 & 488,518 & $1,012,604$ & 449,129
\end{tabular}

Notes: SNF denotes skilled nursing facilities; HHC home health care; AMA against medical advice. 
Table 3: Summary statistics by discharge destination, above/below threshold, and Medicare/nonMedicare

Panel A. Discharged home or HHC

\begin{tabular}{|c|c|c|c|c|}
\hline & \multicolumn{4}{|c|}{ Panel A. Discharged home or $H H C$} \\
\hline & Day 2 \& Medicare & Day 2 \& Non-Medicare & Day $3 \&$ Medicare & Day3 \& Non-Medicare \\
\hline Age & 72.017 & 64.599 & 72.019 & 64.623 \\
\hline Female & 0.525 & 0.493 & 0.539 & 0.507 \\
\hline \multicolumn{5}{|l|}{ Main diagnosis } \\
\hline 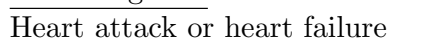 & 0.056 & 0.055 & 0.063 & 0.058 \\
\hline Stroke & 0.059 & 0.048 & 0.040 & 0.034 \\
\hline Knee or hip replacement & 0.042 & 0.056 & 0.137 & 0.170 \\
\hline Other & 0.843 & 0.842 & 0.759 & 0.738 \\
\hline \multicolumn{5}{|l|}{ Comorbidity } \\
\hline$\overline{\text { Deficiency anemia }}$ & 0.090 & 0.067 & 0.121 & 0.094 \\
\hline Chronic pulmonary disease & 0.170 & 0.136 & 0.187 & 0.150 \\
\hline Diabetes, uncomplicated & 0.246 & 0.222 & 0.248 & 0.223 \\
\hline Hypertension & 0.674 & 0.601 & 0.677 & 0.607 \\
\hline Hypothyroidism & 0.131 & 0.098 & 0.138 & 0.104 \\
\hline Fluid and electrolyte disorders & 0.140 & 0.120 & 0.171 & 0.145 \\
\hline Renal failure & 0.076 & 0.044 & 0.084 & 0.048 \\
\hline \multicolumn{5}{|l|}{ Readmission rates } \\
\hline$\overline{30 \text {-day readmission rates }}$ & 0.089 & 0.072 & 0.096 & 0.079 \\
\hline 60-day readmission rates & 0.132 & 0.105 & 0.142 & 0.116 \\
\hline \multirow[t]{3}{*}{ Observations } & 891,955 & 458,452 & 773,478 & 388,576 \\
\hline & \multicolumn{4}{|c|}{ Panel B. Transferred to SNF } \\
\hline & Day $2 \&$ Medicare & Day $2 \&$ Non-Medicare & Day $3 \&$ Medicare & Day3 \& Non-Medicare \\
\hline Age & 73.416 & 67.050 & 73.004 & 66.380 \\
\hline Female & 0.611 & 0.585 & 0.686 & 0.657 \\
\hline \multicolumn{5}{|l|}{ Main diagnosis } \\
\hline$\overline{\text { Heart attack or heart failure }}$ & 0.029 & 0.020 & 0.012 & 0.006 \\
\hline Stroke & 0.063 & 0.051 & 0.034 & 0.020 \\
\hline Knee or hip replacement & 0.115 & 0.256 & 0.545 & 0.719 \\
\hline Other & 0.793 & 0.674 & 0.409 & 0.255 \\
\hline \multicolumn{5}{|l|}{ Comorbidity } \\
\hline$\overline{\text { Deficiency anemia }}$ & 0.156 & 0.133 & 0.153 & 0.136 \\
\hline Chronic pulmonary disease & 0.208 & 0.179 & 0.177 & 0.159 \\
\hline Diabetes, uncomplicated & 0.304 & 0.265 & 0.240 & 0.227 \\
\hline Hypertension & 0.673 & 0.624 & 0.700 & 0.667 \\
\hline Hypothyroidism & 0.150 & 0.125 & 0.176 & 0.152 \\
\hline Fluid and electrolyte disorders & 0.191 & 0.150 & 0.150 & 0.112 \\
\hline Renal failure & 0.112 & 0.082 & 0.063 & 0.041 \\
\hline \multicolumn{5}{|l|}{$\underline{\text { Readmission rates }}$} \\
\hline$\overline{30 \text {-day readmission rates }}$ & 0.126 & 0.097 & 0.085 & 0.063 \\
\hline 60 -day readmission rates & 0.189 & 0.147 & 0.126 & 0.093 \\
\hline \multicolumn{5}{|l|}{ SNF characteristics } \\
\hline$\overline{\text { Deficiency citations, HSA level }}$ & 0.574 & 0.580 & 0.585 & 0.580 \\
\hline SNF occupancy, HSA level & 88.470 & 88.601 & 88.638 & 89.492 \\
\hline Observations & 21,141 & 6,431 & 165,103 & 34,696 \\
\hline
\end{tabular}

Notes: HSA denotes health service area. 
Table 4: SNF discharge rate and readmission rates by health condition, above/below threshold, and Medicare/non-Medicare

\begin{tabular}{|c|c|c|c|c|}
\hline & \multicolumn{4}{|c|}{ Panel A. Knee or hip replacement } \\
\hline & Day 2 \& Medicare & Day 2 \& Non-Medicare & Day 3 \& Medicare & Day3 \& Non-Medicare \\
\hline SNF & 0.052 & 0.056 & 0.400 & 0.251 \\
\hline 30-day readmission rates & 0.029 & 0.024 & 0.040 & 0.031 \\
\hline 60 -day readmission rates & 0.045 & 0.039 & 0.058 & 0.047 \\
\hline \multicolumn{5}{|c|}{ Elixhauser Comorbidity Index } \\
\hline Readmission score & 3.633 & 2.925 & 5.044 & 4.002 \\
\hline Mortality score & -0.272 & -0.835 & -0.099 & -0.742 \\
\hline \multirow[t]{3}{*}{ Observations } & 46,285 & 29,311 & 225,132 & 99,329 \\
\hline & \multicolumn{4}{|c|}{ Panel B. Heart disease } \\
\hline & Day 2 \& Medicare & Day $2 \&$ Non-Medicare & Day 3 \& Medicare & Day3 \& Non-Medicare \\
\hline SNF & 0.011 & 0.004 & 0.035 & 0.008 \\
\hline 30-day readmission rates & 0.119 & 0.091 & 0.137 & 0.113 \\
\hline 60 -day readmission rates & 0.175 & 0.135 & 0.204 & 0.164 \\
\hline \multicolumn{5}{|c|}{ Elixhauser Comorbidity Index } \\
\hline Readmission score & 9.751 & 7.021 & 11.613 & 8.239 \\
\hline Mortality score & 1.929 & 0.768 & 2.596 & 1.242 \\
\hline \multirow[t]{3}{*}{ Observations } & 57,182 & 28,639 & 56,095 & 24,866 \\
\hline & \multicolumn{4}{|c|}{ Panel C. Stroke } \\
\hline & Day $2 \&$ Medicare & Day 2 \& Non-Medicare & Day $3 \&$ Medicare & Day3 \& Non-Medicare \\
\hline SNF & 0.023 & 0.014 & 0.130 & 0.044 \\
\hline 30 -day readmission rates & 0.076 & 0.065 & 0.090 & 0.077 \\
\hline 60 -day readmission rates & 0.115 & 0.098 & 0.134 & 0.111 \\
\hline \multicolumn{5}{|c|}{ Elixhauser Comorbidity Index } \\
\hline Readmission score & 6.575 & 5.554 & 8.030 & 6.518 \\
\hline Mortality score & 1.041 & 0.456 & 1.596 & 0.866 \\
\hline \multirow[t]{3}{*}{ Observations } & 58,029 & 23,528 & 42,904 & 15,779 \\
\hline & \multicolumn{4}{|c|}{ Panel D. Other } \\
\hline & Day $2 \&$ Medicare & Day 2 \& Non-Medicare & Day $3 \&$ Medicare & Day3 \& Non-Medicare \\
\hline $\mathrm{SNF}$ & 0.021 & 0.011 & 0.098 & 0.029 \\
\hline 30-day readmission rates & 0.090 & 0.074 & 0.103 & 0.088 \\
\hline 60 -day readmission rates & 0.134 & 0.108 & 0.152 & 0.128 \\
\hline \multicolumn{5}{|c|}{ Elixhauser Comorbidity Index } \\
\hline Readmission score & 8.888 & 7.183 & 10.878 & 8.790 \\
\hline Mortality score & 2.578 & 1.652 & 3.506 & 2.389 \\
\hline Observations & 803,391 & 407,040 & 688,473 & 309,155 \\
\hline
\end{tabular}

Notes: We compute Elixhauser Comorbidity Index according to Elixhauser et al. (1998) and the corresponding software developed by AHRQ (https://www.hcup-us.ahrq.gov/toolssoftware/comorbidity/comorbidity.jsp). 
Table 5: First stage: discharge outcomes

\begin{tabular}{|c|c|c|c|c|}
\hline & Home/HHC & $\mathrm{SNF}$ & Other facilities & AMA \\
\hline \multicolumn{5}{|c|}{ Panel A. Full sample } \\
\hline Day $3^{*}$ Medicare & $\begin{array}{c}-0.076^{* * *} \\
(0.003)\end{array}$ & $\begin{array}{c}0.068^{* * *} \\
(0.004)\end{array}$ & $\begin{array}{c}0.008^{* * *} \\
(0.003)\end{array}$ & $\begin{array}{l}-0.000 \\
(0.000)\end{array}$ \\
\hline Observations & $2,915,127$ & $2,915,127$ & $2,915,127$ & $2,915,127$ \\
\hline Adjusted $R^{2}$ & 0.237 & 0.215 & 0.124 & 0.053 \\
\hline Mean Y & 0.862 & 0.078 & 0.052 & 0.008 \\
\hline \multicolumn{5}{|c|}{ Panel B. No comorbidity } \\
\hline Day $3^{*}$ Medicare & $\begin{array}{c}-0.079^{* * *} \\
(0.004)\end{array}$ & $\begin{array}{c}0.066^{* * *} \\
(0.005)\end{array}$ & $\begin{array}{c}0.013^{* * *} \\
(0.004)\end{array}$ & $\begin{array}{l}-0.000 \\
(0.001)\end{array}$ \\
\hline Observations & 352,749 & 352,749 & 352,749 & 352,749 \\
\hline Adjusted $R^{2}$ & 0.215 & 0.184 & 0.128 & 0.101 \\
\hline Mean Y & 0.904 & 0.052 & 0.038 & 0.006 \\
\hline \multicolumn{5}{|c|}{ Panel C. Any comorbidity } \\
\hline Day $3^{*}$ Medicare & $\begin{array}{c}-0.075^{* * *} \\
(0.003)\end{array}$ & $\begin{array}{c}0.068^{* * *} \\
(0.004)\end{array}$ & $\begin{array}{c}0.008^{* * *} \\
(0.003)\end{array}$ & $\begin{array}{l}-0.000 \\
(0.000)\end{array}$ \\
\hline Observations & $2,562,350$ & $2,562,350$ & $2,562,350$ & $2,562,350$ \\
\hline Adjusted $R^{2}$ & 0.241 & 0.219 & 0.124 & 0.049 \\
\hline Mean Y & 0.856 & 0.082 & 0.054 & 0.008 \\
\hline \multicolumn{5}{|c|}{ Panel D. Below-median Elixhauser Comorbidity Index readmission score } \\
\hline Day $3^{*}$ Medicare & $\begin{array}{c}-0.080^{* * *} \\
(0.004)\end{array}$ & $\begin{array}{c}0.069^{* * *} \\
(0.005)\end{array}$ & $\begin{array}{c}0.012^{* * *} \\
(0.004)\end{array}$ & $\begin{array}{l}-0.000 \\
(0.000)\end{array}$ \\
\hline Observations & $1,437,652$ & $1,437,652$ & $1,437,652$ & $1,437,652$ \\
\hline Adjusted $R^{2}$ & 0.255 & 0.229 & 0.139 & 0.060 \\
\hline Mean Y & 0.877 & 0.070 & 0.048 & 0.006 \\
\hline \multicolumn{5}{|c|}{ Panel E. Above-median Elixhauser Comorbidity Index readmission score } \\
\hline Day $3^{*}$ Medicare & $\begin{array}{c}-0.073^{* * *} \\
(0.003) \\
\end{array}$ & $\begin{array}{c}0.067^{* * *} \\
(0.004)\end{array}$ & $\begin{array}{c}0.006^{* * *} \\
(0.002)\end{array}$ & $\begin{array}{c}0.000 \\
(0.000) \\
\end{array}$ \\
\hline Observations & $1,477,450$ & $1,477,450$ & $1,477,450$ & $1,477,450$ \\
\hline Adjusted $R^{2}$ & 0.228 & 0.209 & 0.116 & 0.050 \\
\hline Mean Y & 0.848 & 0.086 & 0.057 & 0.010 \\
\hline
\end{tabular}

Notes: Each cell shows an estimate from a different regression. In addition to Day $3^{*}$ Medicare, each regression includes an indicator for Day 3, an indicator for Medicare as well as a vector of discharge characteristics such as patients' age, age squared, an indicator for sex, a series of indicators for race, health conditions (Diagnosis Related Group (DRG) fixed effects and indicators for all comorbidities), hospital fixed effects, discharge year and discharge month fixed effects, discharge hour fixed effects, and a dummy for missing discharge hour. Standard errors are clustered at the HSA level. ${ }^{*}$ Significant at $10 \%,{ }^{* *}$ significant at $5 \%,{ }^{* * *}$ significant at $1 \%$. 
Table 6: Readmission rates

\begin{tabular}{|c|c|c|c|c|c|c|c|c|c|c|}
\hline & (1) & $(2)$ & $(3)$ & $(4)$ & $(5)$ & $(6)$ & $(7)$ & (8) & $(9)$ & $(10)$ \\
\hline & \multicolumn{2}{|c|}{ Full sample } & \multicolumn{2}{|c|}{ No comorbidity } & \multicolumn{2}{|c|}{ Any comorbidity } & \multicolumn{2}{|c|}{$\begin{array}{l}\text { Below-median } \\
\text { readmission score }\end{array}$} & \multicolumn{2}{|c|}{$\begin{array}{l}\text { Above-median } \\
\text { readmission score }\end{array}$} \\
\hline & 30-day & 60 -day & 30-day & 60-day & 30-day & 60-day & 30-day & 60-day & 30-day & 60-day \\
\hline \multicolumn{11}{|l|}{ Panel A. OLS } \\
\hline Discharge to SNF & $\begin{array}{c}0.021^{* * *} \\
(0.002)\end{array}$ & $\begin{array}{c}0.031^{* * *} \\
(0.002)\end{array}$ & $\begin{array}{c}0.013^{* * *} \\
(0.003)\end{array}$ & $\begin{array}{c}0.018^{* * *} \\
(0.003)\end{array}$ & $\begin{array}{c}0.022^{* * *} \\
(0.002)\end{array}$ & $\begin{array}{c}0.032^{* * *} \\
(0.002)\end{array}$ & $\begin{array}{c}0.017^{* * *} \\
(0.002)\end{array}$ & $\begin{array}{c}0.024^{* * *} \\
(0.002)\end{array}$ & $\begin{array}{c}0.025^{* * *} \\
(0.002)\end{array}$ & $\begin{array}{c}0.037^{* * *} \\
(0.002)\end{array}$ \\
\hline Observations & $2,915,127$ & $2,915,127$ & 352,749 & 352,749 & $2,562,350$ & $2,562,350$ & $1,437,652$ & $1,437,652$ & $1,477,450$ & $1,477,450$ \\
\hline Adjusted $R^{2}$ & 0.031 & 0.045 & 0.044 & 0.053 & 0.030 & 0.043 & 0.028 & 0.036 & 0.027 & 0.039 \\
\hline Mean Y & 0.084 & 0.124 & 0.061 & 0.088 & 0.088 & 0.129 & 0.065 & 0.094 & 0.104 & 0.154 \\
\hline \multicolumn{11}{|l|}{ Panel B. 2SLS } \\
\hline Discharge to SNF & $\begin{array}{c}-0.011 \\
(0.010) \\
\end{array}$ & $\begin{array}{c}-0.030^{* * *} \\
(0.011)\end{array}$ & $\begin{array}{c}0.005 \\
(0.023) \\
\end{array}$ & $\begin{array}{c}0.011 \\
(0.024) \\
\end{array}$ & $\begin{array}{c}-0.016 \\
(0.011) \\
\end{array}$ & $\begin{array}{c}-0.037^{* * *} \\
(0.012)\end{array}$ & $\begin{array}{l}-0.004 \\
(0.015) \\
\end{array}$ & $\begin{array}{l}-0.009 \\
(0.017) \\
\end{array}$ & $\begin{array}{l}-0.023 \\
(0.015) \\
\end{array}$ & $\begin{array}{c}-0.056^{* * *} \\
(0.019)\end{array}$ \\
\hline Observations & $2,915,127$ & $2,915,127$ & 352,749 & 352,749 & $2,562,350$ & $2,562,350$ & $1,437,652$ & $1,437,652$ & $1,477,450$ & $1,477,450$ \\
\hline Adjusted $R^{2}$ & 0.031 & 0.043 & 0.044 & 0.053 & 0.029 & 0.040 & 0.028 & 0.036 & 0.025 & 0.035 \\
\hline Mean Y & 0.084 & 0.124 & 0.061 & 0.088 & 0.088 & 0.129 & 0.065 & 0.094 & 0.104 & 0.154 \\
\hline F statistic & 277.995 & 277.995 & 166.737 & 166.737 & 273.041 & 273.041 & 192.903 & 192.903 & 337.427 & 337.427 \\
\hline
\end{tabular}

Notes: Each cell shows an estimate from a different regression. Panel A shows the OLS estimates from a regression of 30- or 60-day readmission rate on SNF discharges, controlling for an indicator for Day 3, an indicator for Medicare as well as a vector of discharge characteristics such as patients' age, age squared, an indicator for sex, a series of indicators for race, health conditions (Diagnosis Related Group (DRG) fixed effects and indicators for all comorbidities), hospital fixed effects, discharge year and discharge month fixed effects, discharge hour fixed effects, and a dummy for missing discharge hour. Panel B shows the 2SLS estimates where we instrument SNF discharges with an interaction between Day 3 and Medicare. Standard errors are clustered at the HSA level. ${ }^{*}$ Significant at $10 \%,{ }^{* *}$ significant at $5 \%,{ }^{* * *}$ significant at $1 \%$. 
Table 7: First stage by condition: discharge outcomes

\begin{tabular}{|c|c|c|c|c|}
\hline & Home/HHC & $\mathrm{SNF}$ & Other facilities & AMA \\
\hline \multicolumn{5}{|c|}{ Panel A. Knee/hip replacement } \\
\hline Day $3 *$ Medicare & $\begin{array}{c}-0.132^{* * *} \\
(0.012)\end{array}$ & $\begin{array}{c}0.139^{* * *} \\
(0.014)\end{array}$ & $\begin{array}{c}-0.007 \\
(0.011)\end{array}$ & $\begin{array}{l}-0.000 \\
(0.000)\end{array}$ \\
\hline Observations & 400,046 & 400,046 & 400,046 & 400,046 \\
\hline Adjusted $R^{2}$ & 0.342 & 0.279 & 0.277 & 0.003 \\
\hline Mean Y & 0.587 & 0.297 & 0.116 & 0.000 \\
\hline \multicolumn{5}{|c|}{ Panel B. Heart disease } \\
\hline Day $3 *$ Medicare & $\begin{array}{c}-0.019^{* * *} \\
(0.003)\end{array}$ & $\begin{array}{c}0.018^{* * *} \\
(0.001)\end{array}$ & $\begin{array}{c}0.001 \\
(0.003)\end{array}$ & $\begin{array}{c}0.000 \\
(0.001)\end{array}$ \\
\hline Observations & 166,758 & 166,758 & 166,758 & 166,758 \\
\hline Adjusted $R^{2}$ & 0.301 & 0.054 & 0.346 & 0.017 \\
\hline Mean Y & 0.880 & 0.017 & 0.092 & 0.011 \\
\hline \multicolumn{5}{|l|}{ Panel C. Stroke } \\
\hline Day $3 *$ Medicare & $\begin{array}{c}-0.078^{* * *} \\
(0.005)\end{array}$ & $\begin{array}{c}0.071^{* * *} \\
(0.005)\end{array}$ & $\begin{array}{l}0.007^{*} \\
(0.004)\end{array}$ & $\begin{array}{l}-0.001 \\
(0.001)\end{array}$ \\
\hline Observations & 140,224 & 140,224 & 140,224 & 140,224 \\
\hline Adjusted $R^{2}$ & 0.179 & 0.100 & 0.131 & 0.015 \\
\hline Mean Y & 0.848 & 0.057 & 0.087 & 0.008 \\
\hline \multicolumn{5}{|c|}{ Panel D. Other conditions } \\
\hline Day $3 *$ Medicare & $\begin{array}{c}-0.053^{* * *} \\
(0.002)\end{array}$ & $\begin{array}{c}0.051^{* * *} \\
(0.002)\end{array}$ & $\begin{array}{c}0.002^{* * *} \\
(0.001)\end{array}$ & $\begin{array}{c}-0.001^{* *} \\
(0.000)\end{array}$ \\
\hline Observations & $2,208,047$ & $2,208,047$ & $2,208,047$ & $2,208,047$ \\
\hline Adjusted $R^{2}$ & 0.160 & 0.146 & 0.090 & 0.058 \\
\hline Mean Y & 0.911 & 0.044 & 0.036 & 0.009 \\
\hline
\end{tabular}

Notes: Each cell shows an estimate from a different regression. In addition to Day $3 *$ Medicare, each regression includes an indicator for Day 3, an indicator for Medicare as well as a vector of discharge characteristics such as patients' age, age squared, an indicator for sex, a series of indicators for race, health conditions (Diagnosis Related Group (DRG) fixed effects and indicators for all comorbidities), hospital fixed effects, discharge year and discharge month fixed effects, discharge hour fixed effects, and a dummy for missing discharge hour. Standard errors are clustered at the HSA level. ${ }^{*}$ Significant at $10 \%,{ }^{* *}$ significant at $5 \%,{ }^{* * *}$ significant at $1 \%$. 
Table 8: OLS by condition: readmission rates

\begin{tabular}{|c|c|c|c|c|c|c|}
\hline & \multicolumn{2}{|c|}{ Full sample } & \multicolumn{2}{|c|}{ No comorbidity } & \multicolumn{2}{|c|}{ Any comorbidity } \\
\hline & $\begin{array}{l}\text { Knee/hip } \\
\text { replacement }\end{array}$ & $\begin{array}{c}\text { Other } \\
\text { conditions }\end{array}$ & $\begin{array}{l}\text { Knee/hip } \\
\text { replacement }\end{array}$ & $\begin{array}{c}\text { Other } \\
\text { conditions }\end{array}$ & $\begin{array}{l}\text { Knee/hip } \\
\text { replacement }\end{array}$ & $\begin{array}{c}\text { Other } \\
\text { conditions }\end{array}$ \\
\hline \multicolumn{7}{|c|}{ Panel A. 30-day readmission rates } \\
\hline Discharge to SNF & $\begin{array}{c}0.018^{* * *} \\
(0.001)\end{array}$ & $\begin{array}{c}0.026^{* * *} \\
(0.002)\end{array}$ & $\begin{array}{c}0.013^{* * *} \\
(0.002)\end{array}$ & $\begin{array}{c}0.017^{* * *} \\
(0.004)\end{array}$ & $\begin{array}{c}0.018^{* * *} \\
(0.001)\end{array}$ & $\begin{array}{c}0.027^{* * *} \\
(0.002)\end{array}$ \\
\hline Observations & 400,046 & $2,515,070$ & 62,191 & 290,531 & 337,825 & $2,224,509$ \\
\hline Adjusted $R^{2}$ & 0.015 & 0.028 & 0.015 & 0.043 & 0.015 & 0.026 \\
\hline Mean Y & 0.036 & 0.092 & 0.026 & 0.069 & 0.037 & 0.095 \\
\hline \multicolumn{7}{|c|}{ Panel B. 60-day readmission rates } \\
\hline Discharge to SNF & $\begin{array}{c}0.024^{* * *} \\
(0.001)\end{array}$ & $\begin{array}{c}0.042^{* * *} \\
(0.002)\end{array}$ & $\begin{array}{c}0.016^{* * *} \\
(0.003)\end{array}$ & $\begin{array}{c}0.032^{* * *} \\
(0.004)\end{array}$ & $\begin{array}{c}0.025^{* * *} \\
(0.001)\end{array}$ & $\begin{array}{c}0.042^{* * *} \\
(0.002)\end{array}$ \\
\hline Observations & 400,046 & $2,515,070$ & 62,191 & 290,531 & 337,825 & $2,224,509$ \\
\hline Adjusted $R^{2}$ & 0.017 & 0.040 & 0.015 & 0.051 & 0.017 & 0.038 \\
\hline Mean Y & 0.053 & 0.136 & 0.041 & 0.098 & 0.055 & 0.141 \\
\hline
\end{tabular}

Notes: Each cell shows an estimate from a different regression. In addition to the indicator for discharge to SNF, each regression includes an indicator for Day 3, an indicator for Medicare as well as a vector of discharge characteristics such as patients' age, age squared, an indicator for sex, a series of indicators for race, health conditions (Diagnosis Related Group (DRG) fixed effects and indicators for all comorbidities), hospital fixed effects, discharge year and discharge month fixed effects, discharge hour fixed effects, and a dummy for missing discharge hour. Standard errors are clustered at the HSA level. ${ }^{*}$ Significant at $10 \%,{ }^{* *}$ significant at $5 \%,{ }^{* * *}$ significant at $1 \%$. 
Table 9: 2SLS by condition: readmission rates

\begin{tabular}{|c|c|c|c|c|c|c|}
\hline & \multicolumn{2}{|c|}{ Full sample } & \multicolumn{2}{|c|}{ No comorbidity } & \multicolumn{2}{|c|}{ Any comorbidity } \\
\hline & $\begin{array}{l}\text { Knee/hip } \\
\text { replacement }\end{array}$ & $\begin{array}{c}\text { Other } \\
\text { conditions }\end{array}$ & $\begin{array}{l}\text { Knee/hip } \\
\text { replacement }\end{array}$ & $\begin{array}{c}\text { Other } \\
\text { conditions }\end{array}$ & $\begin{array}{l}\text { Knee/hip } \\
\text { replacement }\end{array}$ & $\begin{array}{c}\text { Other } \\
\text { conditions }\end{array}$ \\
\hline \multicolumn{7}{|c|}{ Panel A. 30-day readmission rates } \\
\hline Discharge to SNF & $\begin{array}{l}0.026^{* *} \\
(0.010)\end{array}$ & $\begin{array}{l}-0.010 \\
(0.015)\end{array}$ & $\begin{array}{l}0.043^{* *} \\
(0.020)\end{array}$ & $\begin{array}{c}0.014 \\
(0.048)\end{array}$ & $\begin{array}{c}0.020 \\
(0.013)\end{array}$ & $\begin{array}{l}-0.014 \\
(0.015)\end{array}$ \\
\hline Observations & 400,046 & $2,515,070$ & 62,191 & 290,531 & 337,825 & $2,224,509$ \\
\hline Adjusted $R^{2}$ & 0.015 & 0.028 & 0.010 & 0.043 & 0.015 & 0.025 \\
\hline Mean Y & 0.036 & 0.092 & 0.026 & 0.069 & 0.037 & 0.095 \\
\hline F statistic & 94.942 & 520.255 & 85.830 & 308.921 & 84.136 & 519.957 \\
\hline \multicolumn{7}{|c|}{ Panel B. 60-day readmission rates } \\
\hline Discharge to SNF & $\begin{array}{c}0.039^{* * *} \\
(0.013)\end{array}$ & $\begin{array}{l}-0.020 \\
(0.016)\end{array}$ & $\begin{array}{c}0.044 \\
(0.028)\end{array}$ & $\begin{array}{c}0.049 \\
(0.052)\end{array}$ & $\begin{array}{l}0.036^{* *} \\
(0.016)\end{array}$ & $\begin{array}{l}-0.029^{*} \\
(0.017)\end{array}$ \\
\hline Observations & 400,046 & $2,515,070$ & 62,191 & 290,531 & 337,825 & $2,224,509$ \\
\hline Adjusted $R^{2}$ & 0.016 & 0.039 & 0.012 & 0.051 & 0.016 & 0.036 \\
\hline Mean Y & 0.053 & 0.136 & 0.041 & 0.098 & 0.055 & 0.141 \\
\hline F statistic & 94.942 & 520.255 & 85.830 & 308.921 & 84.136 & 519.957 \\
\hline
\end{tabular}

Notes: Each cell shows an estimate from a different regression. In addition to the indicator for discharge to SNF instrumented with Day $3 *$ Medicare, each regression includes an indicator for Day 3, an indicator for Medicare as well as a vector of discharge characteristics such as patients' age, age squared, an indicator for sex, a series of indicators for race, health conditions (Diagnosis Related Group (DRG) fixed effects and indicators for all comorbidities), hospital fixed effects, discharge year and discharge month fixed effects, discharge hour fixed effects, and a dummy for missing discharge hour. Standard errors are clustered at the HSA level. ${ }^{*}$ Significant at $10 \%,{ }^{* *}$ significant at $5 \%,{ }^{* * *}$ significant at $1 \%$. 
Table 10: 2SLS by condition \& local SNF characteristics, knee and hip replacement

\begin{tabular}{lccccc}
\hline & \multicolumn{2}{c}{ Low occupancy } & & \multicolumn{2}{c}{ High occupancy } \\
\cline { 2 - 3 } \cline { 5 - 6 } 30-day & 60 -day & & 30 -day & 60 -day \\
Panel A. By occupancy & & & \\
\hline Discharge to SNF & $0.031^{* * *}$ & $0.052^{* * *}$ & & 0.008 & -0.001 \\
& $(0.012)$ & $(0.015)$ & & $0.018)$ & $(0.021)$ \\
\hline Observations & 309,140 & 309,140 & & 90,892 & 90,892 \\
Adjusted $R^{2}$ & 0.016 & 0.016 & & 0.011 & 0.012 \\
Mean Y & 0.035 & 0.052 & & 0.036 & 0.054 \\
F statistic & 68.795 & 68.795 & & 135.507 & 135.507 \\
& & & & \\
& Low deficiency & & High deficiency \\
\cline { 2 - 3 } \cline { 5 - 6 } & 30 -day & 60 -day & 30 -day & 60 -day \\
Panel B. By deficiency & & & \\
\hline Discharge to SNF & 0.012 & 0.021 & & $0.033^{* * *}$ & $0.048^{* * *}$ \\
& $(0.019)$ & $(0.025)$ & & $(0.012)$ & $(0.013)$ \\
\hline Observations & 163,734 & 163,734 & & 236,295 & 236,295 \\
Adjusted $R^{2}$ & 0.017 & 0.019 & & 0.013 & 0.014 \\
Mean Y & 0.035 & 0.052 & & 0.036 & 0.053 \\
F statistic & 35.374 & 35.374 & & 139.184 & 139.184 \\
\hline
\end{tabular}

Notes: Each cell shows an estimate from a different regression. We define low vs high deficiency areas based on the average number of deficiency citations across SNFs in a given HSA relative to the median of the corresponding state in the preceding year. Similarly, we define low vs high occupancy areas based on the average occupancy rate across SNFs in a given HSA relative to the median of the corresponding state in the year preceding the admission year. In addition to the indicator for discharge to SNF instrumented with Day $3^{*}$ Medicare, each regression includes an indicator for Day 3, an indicator for Medicare as well as a vector of discharge characteristics such as patients' age, age squared, an indicator for sex, a series of indicators for race, health conditions (Diagnosis Related Group (DRG) fixed effects and indicators for all comorbidities), hospital fixed effects, discharge year and discharge month fixed effects, discharge hour fixed effects, and a dummy for missing discharge hour. Standard errors are clustered at the HSA level. ${ }^{*}$ Significant at $10 \%,{ }^{* *}$ significant at $5 \%,{ }^{* * *}$ significant at $1 \%$. 
Table 11: Back of the envelope calculation (in million)

Panel A. Full sample

Total Medicare population in 2015

55.51

Total Medicare population in our sample states and years

Total Medicare population in our data

77.91

Share of Medicare population showing up in our sample

Share of Medicare population showing up in our day-3 sample

Average SNF care for Medicare

Average SNF stay for Medicare

$.96+1.01=1.97$

$1.97 / 77.91=2.5 \%$

$1.01 / 77.91=1.3 \%$

$\$ 500$ per day

37 days

No comorbidity

Below-median comorbidity index

Average increase in SNF admission due to the three-day rule $6.6 \%$

Share of patients in each category

$11.32 \%$

$48.51 \%$

Potential savings of discharges home rather than to SNF

For our day-3 Medicare sample

Annual savings for the whole Medicare population

$1.01 \times 6.6 \% \times 11.32 \% \times \$ 500 \times 37$ days $=139.60$ $55.51 \times 1.3 \% \times 6.6 \% \times 11.32 \% \times \$ 500 \times 37$ days $=99.74$ $115.09 / 31332=0.32 \%$

$1.01 \times 6.9 \% \times 48.51 \% \times \$ 500 \times 37$ days $=625.42$ $55.51 \times 1.3 \% \times 6.9 \% \times 48.51 \% \times \$ 500 \times 37$ days $=446.86$ $515.60 / 31332=1.43 \%$

Panel B. Knee and hip replacement only

Total joint replacement patients with Medicare in our data Share of Medicare population showing up in the subsample

Share of Medicare population showing up in the day-3 subsample

Average increase in SNF admission due to the three-day rule

Share of total joint replacement patients without complications

60-day readmission effect of SNF discharge

Sources of wastes

(1) Discharge to SNF rather than home

(2) Readmission to hospital

(3) Longer initial hospital stays to qualify for SNF coverage

Estimation of wastes

(1) Discharge to SNF rather than home

(2) Readmission to hospital

Total wastes

Total Medicare expenditure on total joint replacement

Total waste as a share of total Medicare expenditure
$0.04+0.11=0.15$

$0.15 / 77.91=0.19 \%$

$0.11 / 77.91=0.14 \%$

$14 \%$

$97.4 \%$

$4.0 \%$

$\$ 500$ per day for 15 days

$\$ 10,000$ per readmission

For our day-3 Medicare sample with joint replacement

Potential annual savings for the whole Medicare population $0.11 \times 97.4 \% \times 14 \% \times \$ 500 \times 15$ days $=112.50$ $0.11 \times 97.4 \% \times 14 \% \times 4.0 \% \times \$ 10000=6.00$

$55.51 \times 0.14 \% \times 97.4 \% \times 14 \% \times \$ 500 \times 15$ days $=79.48$ $55.51 \times 0.14 \% \times 97.4 \% \times 14 \% \times 4.0 \% \times \$ 10000=4.24$
$112.50+6.00=118.50$

$79.48+4.24=83.73$

$83.73 / 7000=1.20 \%$ 


\section{Appendix A. Appendix Figures}

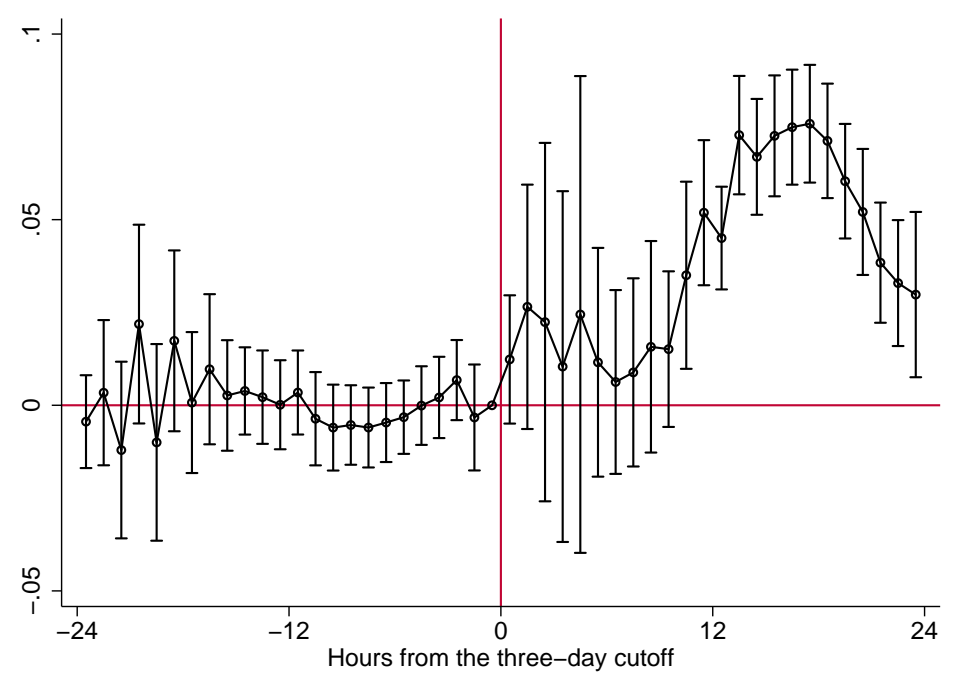

(a) Full sample

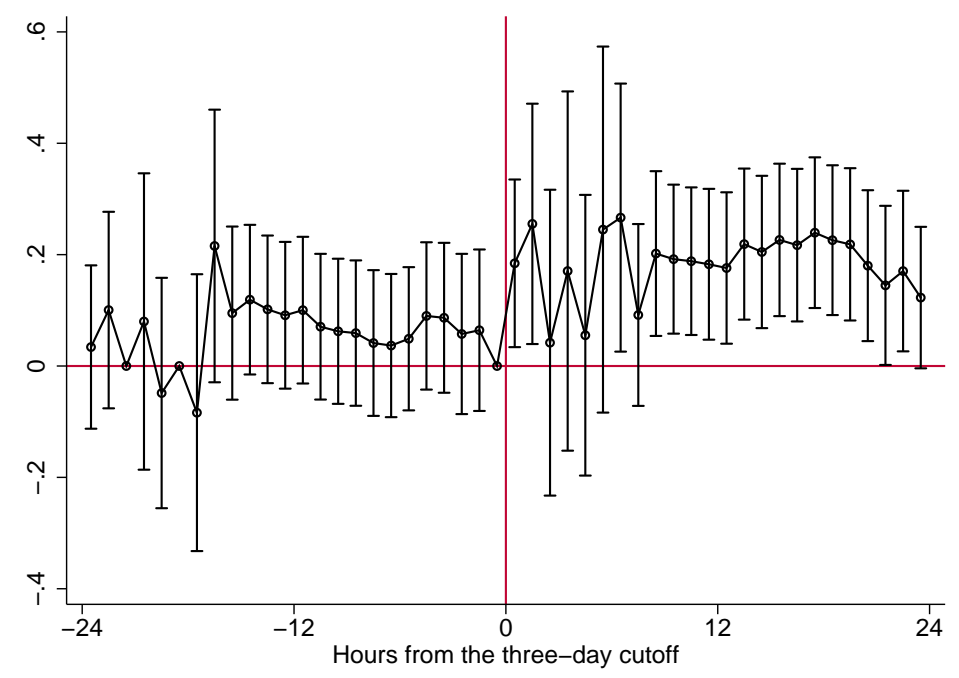

(b) Knee and hip replacement only

Figure A.1: Event study graph, outcome: discharge to SNF

Notes: The corresponding regression is analogous to equation (1), replacing Day3*Medicare with a series of interactions between Medicare and each discharge hour within the 24 hour window before and after the three-day cutoff. 


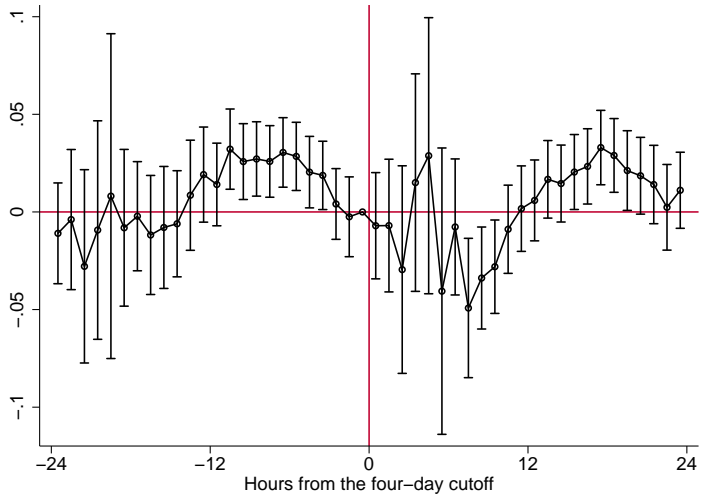

(a) Day 4 cutoff

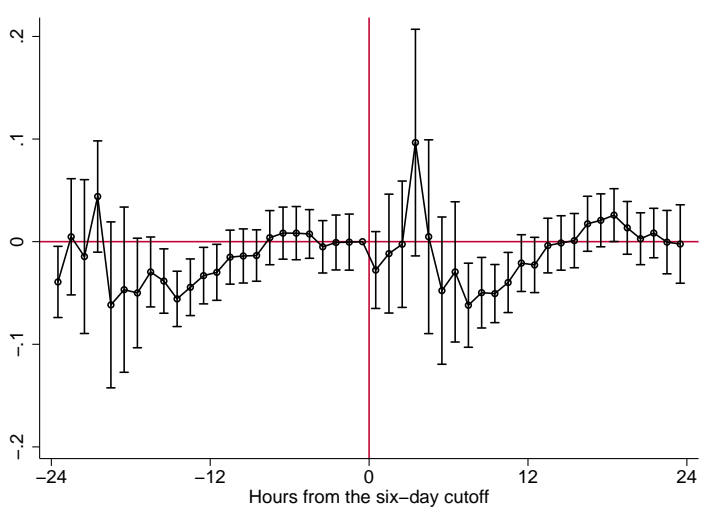

(c) Day 6 cutoff

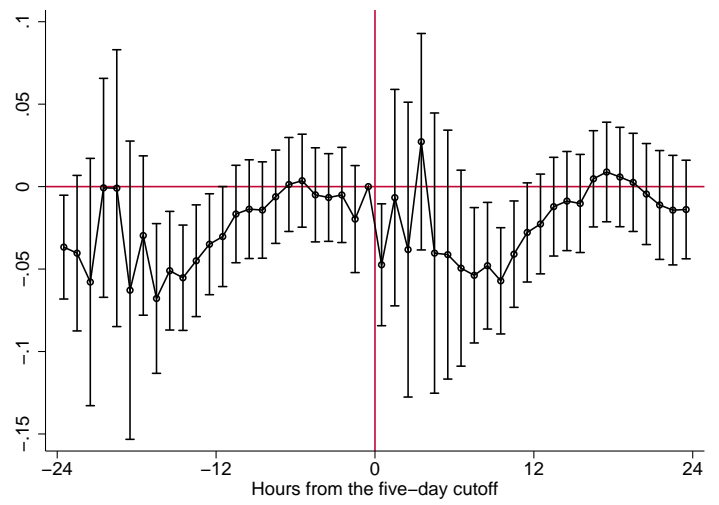

(b) Day 5 cutoff

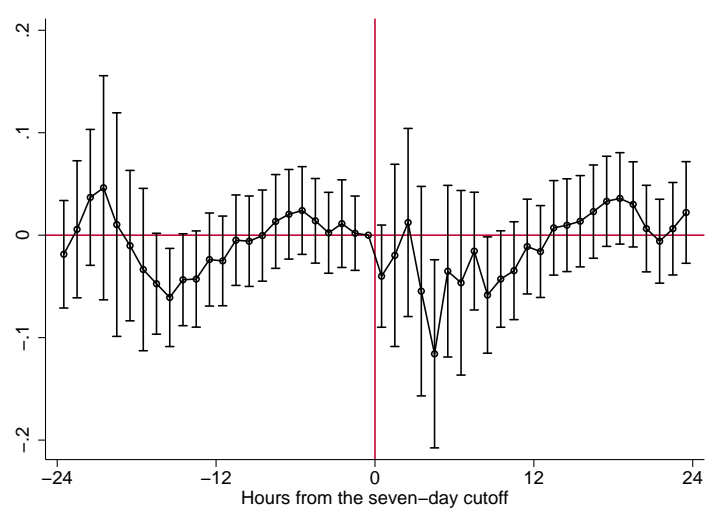

(d) Day 7 cutoff

Figure A.2: Event study graph, outcome: discharge to SNF, placebo cutoffs

Notes: Instead of hours from the three-day cutoff, panels (a), (b), (c), and (d) examine the effects of discharges at hours from the four, five, six, and seven-day cutoffs, respectively. 


\section{Appendix B. Appendix Tables}

Table B.1: First stage discharge outcomes \& 2SLS readmission rates: placebo cutoffs

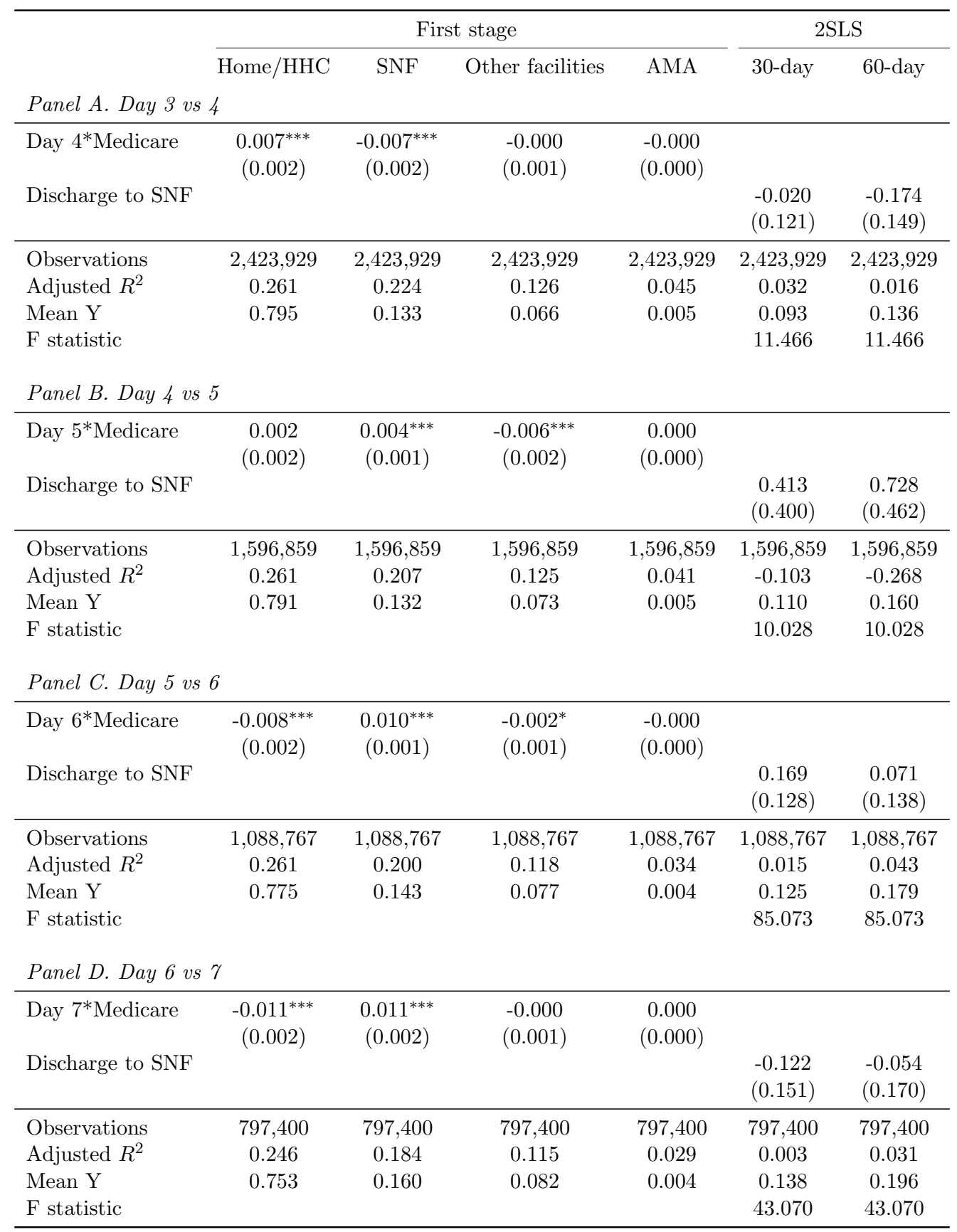

Notes: Each regression includes an indicator for Day 4, 5, 6, or 7, an indicator for Medicare as well as patients' age, age squared, an indicator for sex, a series of indicators for race, health conditions (Diagnosis Related Group (DRG) fixed effects and indicators for all comorbidities), hospital fixed effects, discharge year and discharge month fixed effects, discharge hour fixed effects, and a dummy for missing discharge hour. For 2SLS regressions, we instrument SNF discharges with the interaction between Day 4, 5, 6, or 7 and Medicare. Standard errors are clustered at the HSA level. ${ }^{*}$ Significant at $10 \%,{ }^{* *}$ significant at $5 \%,{ }^{* * *}$ significant at $1 \%$. 
Table B.2: First stage: discharge outcomes, age 60-69

\begin{tabular}{lcccc}
\hline & Home $/ \mathrm{HHC}$ & SNF & Other facilities & AMA \\
\hline Day $3^{*}$ Medicare & $-0.057^{* * *}$ & $0.050^{* * *}$ & $0.007^{* * *}$ & -0.000 \\
& $(0.003)$ & $(0.004)$ & $(0.003)$ & $(0.000)$ \\
\hline Observations & $1,414,079$ & $1,414,079$ & $1,414,079$ & $1,414,079$ \\
Adjusted $R^{2}$ & 0.207 & 0.186 & 0.128 & 0.075 \\
Mean Y & 0.892 & 0.053 & 0.046 & 0.009 \\
\hline
\end{tabular}

Notes: We focus on patients with age between 60 and 69 and repeat the first stage estimations. In addition to Day $3^{*}$ Medicare, each regression includes an indicator for Day 3, an indicator for Medicare as well as a vector of discharge characteristics such as patients' age, age squared, an indicator for sex, a series of indicators for race, health conditions (Diagnosis Related Group (DRG) fixed effects and indicators for all comorbidities), hospital fixed effects, discharge year and discharge month fixed effects, discharge hour fixed effects, and a dummy for missing discharge hour. Standard errors are clustered at the HSA level. ${ }^{*}$ Significant at $10 \%,{ }^{* *}$ significant at $5 \%,{ }^{* * *}$ significant at $1 \%$.

Table B.3: 2SLS: Readmission rates, age 60-69

\begin{tabular}{lcccccccc}
\hline & \multicolumn{2}{c}{ Full sample } & & \multicolumn{2}{c}{ No comorbidity } & & \multicolumn{2}{c}{ Any comorbidity } \\
\cline { 2 - 3 } & 30 -day & 60 -day & & 30 -day & 60 -day & & 30 -day & 60-day \\
\hline Discharge to SNF & -0.012 & $-0.040^{*}$ & & 0.067 & 0.051 & & -0.027 & $-0.056^{* *}$ \\
& $(0.019)$ & $(0.021)$ & & $(0.046)$ & $(0.053)$ & & $(0.020)$ & $(0.023)$ \\
\hline Observations & $1,414,079$ & $1,414,079$ & & 208,702 & 208,702 & & $1,205,345$ & $1,205,345$ \\
Adjusted $R^{2}$ & 0.037 & 0.049 & & 0.054 & 0.063 & & 0.033 & 0.045 \\
Mean Y & 0.077 & 0.113 & & 0.056 & 0.080 & & 0.080 & 0.118 \\
F statistic & 193.982 & 193.982 & & 110.744 & 110.744 & & 186.943 & 186.943 \\
\hline
\end{tabular}

Notes: We focus on patients with age between 60 and 69 and repeat the 2SLS estimations. Each regression includes an indicator for Day 3, an indicator for Medicare as well as a vector of discharge characteristics such as patients' age, age squared, an indicator for sex, a series of indicators for race, health conditions (Diagnosis Related Group (DRG) fixed effects and indicators for all comorbidities), hospital fixed effects, discharge year and discharge month fixed effects, discharge hour fixed effects, and a dummy for missing discharge hour. We instrument SNF discharges with an interaction between Day 3 and Medicare. Standard errors are clustered at the HSA level. ${ }^{*}$ Significant at $10 \%,{ }^{* *}$ significant at $5 \%,{ }^{* * *}$ significant at $1 \%$. 
Table B.4: 2SLS by condition: readmission rates, age 60-69

\begin{tabular}{|c|c|c|c|c|c|c|}
\hline & \multicolumn{2}{|c|}{ Full sample } & \multicolumn{2}{|c|}{ No comorbidity } & \multicolumn{2}{|c|}{ Any comorbidity } \\
\hline & $\begin{array}{l}\text { Knee/hip } \\
\text { replacement }\end{array}$ & $\begin{array}{c}\text { Other } \\
\text { conditions }\end{array}$ & $\begin{array}{l}\text { Knee/hip } \\
\text { replacement }\end{array}$ & $\begin{array}{c}\text { Other } \\
\text { conditions }\end{array}$ & $\begin{array}{l}\text { Knee/hip } \\
\text { replacement }\end{array}$ & $\begin{array}{c}\text { Other } \\
\text { conditions }\end{array}$ \\
\hline \multicolumn{7}{|c|}{ Panel A. 30-day readmission rates } \\
\hline Discharge to SNF & $\begin{array}{l}0.030^{*} \\
(0.016)\end{array}$ & $\begin{array}{l}-0.012 \\
(0.032)\end{array}$ & $\begin{array}{l}0.084^{* *} \\
(0.036)\end{array}$ & $\begin{array}{c}0.134 \\
(0.126)\end{array}$ & $\begin{array}{c}0.018 \\
(0.019)\end{array}$ & $\begin{array}{l}-0.030 \\
(0.033)\end{array}$ \\
\hline Observations & 206,208 & $1,207,859$ & 36,254 & 172,414 & 169,911 & $1,035,414$ \\
\hline Adjusted $R^{2}$ & 0.013 & 0.034 & -0.010 & 0.053 & 0.014 & 0.030 \\
\hline Mean Y & 0.031 & 0.085 & 0.023 & 0.063 & 0.032 & 0.088 \\
\hline F statistic & 87.000 & 423.672 & 69.057 & 196.600 & 77.840 & 405.464 \\
\hline \multicolumn{7}{|c|}{ Panel B. 60-day readmission rates } \\
\hline Discharge to SNF & $\begin{array}{l}0.046^{* *} \\
(0.020)\end{array}$ & $\begin{array}{l}-0.045 \\
(0.036)\end{array}$ & $\begin{array}{c}0.066 \\
(0.047)\end{array}$ & $\begin{array}{c}0.133 \\
(0.144)\end{array}$ & $\begin{array}{l}0.040^{*} \\
(0.023)\end{array}$ & $\begin{array}{l}-0.066^{*} \\
(0.037)\end{array}$ \\
\hline Observations & 206,208 & $1,207,859$ & 36,254 & 172,414 & 169,911 & $1,035,414$ \\
\hline Adjusted $R^{2}$ & 0.014 & 0.046 & 0.005 & 0.062 & 0.015 & 0.042 \\
\hline Mean Y & 0.047 & 0.124 & 0.037 & 0.089 & 0.050 & 0.129 \\
\hline F statistic & 87.000 & 423.672 & 69.057 & 196.600 & 77.840 & 405.464 \\
\hline
\end{tabular}

Notes: We focus on patients with age between 60 and 69 and repeat the 2SLS estimations by health conditions. In addition to the indicator for discharge to SNF instrumented with Day $3 *$ Medicare, each regression includes an indicator for Day 3, an indicator for Medicare as well as a vector of discharge characteristics such as patients' age, age squared, an indicator for sex, a series of indicators for race, health conditions (Diagnosis Related Group (DRG) fixed effects and indicators for all comorbidities), hospital fixed effects, discharge year and discharge month fixed effects, discharge hour fixed effects, and a dummy for missing discharge hour. Standard errors are clustered at the HSA level. ${ }^{*}$ Significant at $10 \%,{ }^{* *}$ significant at $5 \%,{ }^{* * *}$ significant at $1 \%$. 
Table B.5: 2SLS by condition \& local SNF characteristics, knee and hip replacement, age 60-69

\begin{tabular}{lccccc}
\hline & \multicolumn{2}{c}{ Low occupancy } & & \multicolumn{2}{c}{ High occupancy } \\
\cline { 2 - 3 } \cline { 5 - 6 } 30-day & 60 -day & & 30 -day & 60 -day \\
Panel A. By occupancy & & & \\
\cline { 1 - 2 } Discharge to SNF & $0.043^{* *}$ & $0.071^{* * *}$ & & -0.010 & -0.035 \\
& $(0.017)$ & $(0.022)$ & & $(0.036)$ & $(0.045)$ \\
\hline Observations & 158,831 & 158,831 & & 47,368 & 47,368 \\
Adjusted $R^{2}$ & 0.013 & 0.010 & & 0.008 & 0.005 \\
Mean Y & 0.031 & 0.047 & & 0.031 & 0.048 \\
F statistic & 65.106 & 65.106 & & 92.826 & 92.826 \\
& & & & \\
& Low deficiency & & High deficiency \\
\cline { 2 - 3 } \cline { 5 - 6 } & 30 -day & 60 -day & & 30 -day & 60 -day \\
Panel B. By deficiency & & & & \\
\hline Discharge to SNF & 0.021 & 0.017 & & $0.034^{*}$ & $0.059^{* *}$ \\
& $(0.029)$ & $(0.040)$ & & $(0.018)$ & $(0.023)$ \\
\hline Observations & 83,565 & 83,565 & & 122,618 & 122,618 \\
Adjusted $R^{2}$ & 0.016 & 0.017 & & 0.013 & 0.011 \\
Mean Y & 0.030 & 0.046 & 0.031 & 0.048 \\
F statistic & 34.430 & 34.430 & & 116.989 & 116.989 \\
\hline
\end{tabular}

Notes: We focus on patients with age between 60 and 69 and repeat the 2SLS estimations by local SNF characteristics for knee and hip replacement patients. In addition to the indicator for discharge to SNF instrumented with Day $3^{*}$ Medicare, each regression includes an indicator for Day 3, an indicator for Medicare as well as a vector of discharge characteristics such as patients' age, age squared, an indicator for sex, a series of indicators for race, health conditions (Diagnosis Related Group (DRG) fixed effects and indicators for all comorbidities), hospital fixed effects, discharge year and discharge month fixed effects, discharge hour fixed effects, and a dummy for missing discharge hour. Standard errors are clustered at the HSA level. ${ }^{*}$ Significant at $10 \%,{ }^{* *}$ significant at $5 \%,{ }^{* * *}$ significant at $1 \%$.

Table B.6: First stage: discharge outcomes, age 62-67

\begin{tabular}{lcccc}
\hline & Home/HHC & SNF & Other facilities & AMA \\
\hline Day 3*Medicare & $-0.049^{* * *}$ & $0.044^{* * *}$ & $0.006^{* *}$ & -0.001 \\
& $(0.003)$ & $(0.004)$ & $(0.003)$ & $(0.000)$ \\
\hline Observations & 845,080 & 845,080 & 845,080 & 845,080 \\
Adjusted $R^{2}$ & 0.207 & 0.184 & 0.130 & 0.071 \\
Mean Y & 0.893 & 0.052 & 0.046 & 0.009 \\
\hline
\end{tabular}

Notes: We focus on patients with age between 62 and 67 and repeat the first stage estimations. In addition to Day $3 *$ Medicare, each regression includes an indicator for Day 3, an indicator for Medicare as well as a vector of discharge characteristics such as patients' age, age squared, an indicator for sex, a series of indicators for race, health conditions (Diagnosis Related Group (DRG) fixed effects and indicators for all comorbidities), hospital fixed effects, discharge year and discharge month fixed effects, discharge hour fixed effects, and a dummy for missing discharge hour. Standard errors are clustered at the HSA level. ${ }^{*}$ Significant at $10 \%,{ }^{* *}$ significant at $5 \%,{ }^{* * *}$ significant at $1 \%$. 
Table B.7: 2SLS: Readmission rates, age 62-67

\begin{tabular}{lcccccccc}
\hline & \multicolumn{2}{c}{ Full sample } & & \multicolumn{2}{c}{ No comorbidity } & & \multicolumn{2}{c}{ Any comorbidity } \\
\cline { 2 - 3 } & 30-day & 60 -day & & 30-day & 60 -day & & 30 -day & 60-day \\
\hline Discharge to SNF & 0.032 & -0.013 & & $0.141^{* *}$ & 0.113 & & 0.009 & -0.039 \\
& $(0.029)$ & $(0.031)$ & & $(0.071)$ & $(0.082)$ & & $(0.031)$ & $(0.034)$ \\
\hline Observations & 845,080 & 845,080 & & 124,813 & 124,813 & & 720,230 & 720,230 \\
Adjusted $R^{2}$ & 0.037 & 0.050 & & 0.044 & 0.058 & & 0.034 & 0.047 \\
Mean Y & 0.076 & 0.111 & & 0.055 & 0.079 & & 0.079 & 0.117 \\
F statistic & 145.295 & 145.295 & 78.258 & 78.258 & & 140.556 & 140.556 \\
\hline
\end{tabular}

Notes: We focus on patients with age between 62 and 67 and repeat the 2SLS estimations. In addition to the indicator for discharge to SNF instrumented with Day $3^{*}$ Medicare, each regression includes an indicator for Day 3, an indicator for Medicare as well as a vector of discharge characteristics such as patients' age, age squared, an indicator for sex, a series of indicators for race, health conditions (Diagnosis Related Group (DRG) fixed effects and indicators for all comorbidities), hospital fixed effects, discharge year and discharge month fixed effects, discharge hour fixed effects, and a dummy for missing discharge hour. Standard errors are clustered at the HSA level. * Significant at $10 \%,{ }^{* *}$ significant at $5 \%,{ }^{* * *}$ significant at $1 \%$.

Table B.8: 2SLS by condition: readmission rates, age $62-67$

\begin{tabular}{|c|c|c|c|c|c|c|}
\hline & \multicolumn{2}{|c|}{ Full sample } & \multicolumn{2}{|c|}{ No comorbidity } & \multicolumn{2}{|c|}{ Any comorbidity } \\
\hline & $\begin{array}{l}\text { Knee/hip } \\
\text { replacement }\end{array}$ & $\begin{array}{c}\text { Other } \\
\text { conditions }\end{array}$ & $\begin{array}{l}\text { Knee/hip } \\
\text { replacement }\end{array}$ & $\begin{array}{c}\text { Other } \\
\text { conditions }\end{array}$ & $\begin{array}{l}\text { Knee/hip } \\
\text { replacement }\end{array}$ & $\begin{array}{c}\text { Other } \\
\text { conditions }\end{array}$ \\
\hline \multicolumn{7}{|c|}{ Panel A. 30-day readmission rates } \\
\hline Discharge to SNF & $\begin{array}{c}0.067^{* * *} \\
(0.023)\end{array}$ & $\begin{array}{c}0.054 \\
(0.051)\end{array}$ & $\begin{array}{l}0.103^{*} \\
(0.054)\end{array}$ & $\begin{array}{c}0.288 \\
(0.188)\end{array}$ & $\begin{array}{l}0.058^{* *} \\
(0.027)\end{array}$ & $\begin{array}{c}0.022 \\
(0.052)\end{array}$ \\
\hline Observations & 125,320 & 719,738 & 22,010 & 102,754 & 103,259 & 616,947 \\
\hline Adjusted $R^{2}$ & 0.003 & 0.034 & -0.028 & 0.042 & 0.007 & 0.031 \\
\hline Mean Y & 0.030 & 0.084 & 0.022 & 0.062 & 0.032 & 0.087 \\
\hline F statistic & 63.885 & 395.781 & 46.854 & 112.375 & 57.546 & 371.542 \\
\hline \multicolumn{7}{|c|}{ Panel B. 60-day readmission rates } \\
\hline Discharge to SNF & $\begin{array}{l}0.071^{* *} \\
(0.029)\end{array}$ & $\begin{array}{l}-0.006 \\
(0.054)\end{array}$ & $\begin{array}{c}0.056 \\
(0.066)\end{array}$ & $\begin{array}{c}0.257 \\
(0.213)\end{array}$ & $\begin{array}{l}0.068^{* *} \\
(0.033)\end{array}$ & $\begin{array}{l}-0.040 \\
(0.057)\end{array}$ \\
\hline Observations & 125,320 & 719,738 & 22,010 & 102,754 & 103,259 & 616,947 \\
\hline Adjusted $R^{2}$ & 0.009 & 0.047 & 0.007 & 0.056 & 0.010 & 0.043 \\
\hline Mean Y & 0.047 & 0.122 & 0.035 & 0.088 & 0.050 & 0.128 \\
\hline F statistic & 63.885 & 395.781 & 46.854 & 112.375 & 57.546 & 371.542 \\
\hline
\end{tabular}

Notes: We focus on patients with age between 62 and 67 and repeat the 2SLS estimations by health conditions. In addition to the indicator for discharge to SNF instrumented with Day $3 *$ Medicare, each regression includes an indicator for Day 3, an indicator for Medicare as well as a vector of discharge characteristics such as patients' age, age squared, an indicator for sex, a series of indicators for race, health conditions (Diagnosis Related Group (DRG) fixed effects and indicators for all comorbidities), hospital fixed effects, discharge year and discharge month fixed effects, discharge hour fixed effects, and a dummy for missing discharge hour. Standard errors are clustered at the HSA level. ${ }^{*}$ Significant at $10 \%,{ }^{* *}$ significant at $5 \%,{ }^{* * *}$ significant at $1 \%$. 
Table B.9: 2SLS by condition \& local SNF characteristics, knee and hip replacement, age 62-67

\begin{tabular}{|c|c|c|c|c|}
\hline & \multicolumn{2}{|c|}{ Low occupancy } & \multicolumn{2}{|c|}{ High occupancy } \\
\hline & 30-day & 60-day & 30-day & 60-day \\
\hline \multicolumn{5}{|c|}{ Panel A. By occupancy } \\
\hline Discharge to SNF & $\begin{array}{c}0.092^{* * *} \\
(0.029)\end{array}$ & $\begin{array}{c}0.114^{* * *} \\
(0.037)\end{array}$ & $\begin{array}{c}0.000 \\
(0.044)\end{array}$ & $\begin{array}{c}-0.046 \\
(0.053)\end{array}$ \\
\hline Observations & 96,482 & 96,482 & 28,826 & 28,826 \\
\hline Adjusted $R^{2}$ & -0.009 & -0.007 & 0.012 & 0.001 \\
\hline Mean Y & 0.031 & 0.048 & 0.029 & 0.046 \\
\hline \multirow[t]{3}{*}{ F statistic } & 45.157 & 45.157 & 88.075 & 88.075 \\
\hline & \multicolumn{2}{|c|}{ Low deficiency } & \multicolumn{2}{|c|}{ High deficiency } \\
\hline & 30-day & 60-day & 30-day & 60-day \\
\hline \multicolumn{5}{|c|}{ Panel B. By deficiency } \\
\hline Discharge to SNF & $\begin{array}{c}0.053 \\
(0.042)\end{array}$ & $\begin{array}{c}0.050 \\
(0.054)\end{array}$ & $\begin{array}{c}0.073^{* * *} \\
(0.027)\end{array}$ & $\begin{array}{c}0.078^{* *} \\
(0.035)\end{array}$ \\
\hline Observations & 50,948 & 50,948 & 74,351 & 74,351 \\
\hline Adjusted $R^{2}$ & 0.010 & 0.016 & 0.000 & 0.006 \\
\hline Mean Y & 0.030 & 0.047 & 0.030 & 0.048 \\
\hline F statistic & 25.492 & 25.492 & 83.967 & 83.967 \\
\hline
\end{tabular}

Notes: We focus on patients with age between 62 and 67 and repeat the 2SLS estimations by local SNF characteristics for knee and hip replacement patients. In addition to the indicator for discharge to SNF instrumented with Day $3^{*}$ Medicare, each regression includes an indicator for Day 3, an indicator for Medicare as well as a vector of discharge characteristics such as patients' age, age squared, an indicator for sex, a series of indicators for race, health conditions (Diagnosis Related Group (DRG) fixed effects and indicators for all comorbidities), hospital fixed effects, discharge year and discharge month fixed effects, discharge hour fixed effects, and a dummy for missing discharge hour. Standard errors are clustered at the HSA level. ${ }^{*}$ Significant at $10 \%,{ }^{* *}$ significant at $5 \%,{ }^{* * *}$ significant at $1 \%$. 
Table B.10: First stage: discharge outcomes, all inpatient episodes

\begin{tabular}{lcccc}
\hline & Home $/ \mathrm{HHC}$ & SNF & Other facilities & AMA \\
\hline Day 3*Medicare & $-0.068^{* * *}$ & $0.062^{* * *}$ & $0.007^{* * *}$ & -0.000 \\
& $(0.003)$ & $(0.004)$ & $(0.002)$ & $(0.000)$ \\
\hline Observations & $4,256,972$ & $4,256,972$ & $4,256,972$ & $4,256,972$ \\
Adjusted $R^{2}$ & 0.206 & 0.179 & 0.115 & 0.068 \\
Mean Y & 0.846 & 0.087 & 0.057 & 0.009 \\
\hline
\end{tabular}

Notes: We include all inpatient episodes and repeat the first stage estimations. In addition to Day $3 *$ Medicare, each regression includes an indicator for Day 3, an indicator for Medicare as well as a vector of discharge characteristics such as patients' age, age squared, an indicator for sex, a series of indicators for race, health conditions (Diagnosis Related Group (DRG) fixed effects and indicators for all comorbidities), hospital fixed effects, discharge year and discharge month fixed effects, discharge hour fixed effects, and a dummy for missing discharge hour. Standard errors are clustered at the HSA level. ${ }^{*}$ Significant at $10 \%,{ }^{* *}$ significant at $5 \%,{ }^{* * *}$ significant at $1 \%$.

Table B.11: 2SLS: Readmission rates, all inpatient episodes

\begin{tabular}{lcccccccc}
\hline & \multicolumn{2}{c}{ Full sample } & & \multicolumn{2}{c}{ No comorbidity } & & \multicolumn{2}{c}{ Any comorbidity } \\
\cline { 2 - 3 } & 30-day & 60 -day & & 30 -day & 60 -day & & 30-day & 60-day \\
\hline Discharge to SNF & $-0.028^{* *}$ & $-0.040^{* * *}$ & & 0.015 & 0.019 & & $-0.034^{* * *}$ & $-0.048^{* * *}$ \\
& $(0.012)$ & $(0.011)$ & & $(0.026)$ & $(0.025)$ & & $(0.012)$ & $(0.012)$ \\
\hline Observations & $4,256,972$ & $4,256,972$ & & 444,768 & 444,768 & & $3,812,181$ & $3,812,181$ \\
Adjusted $R^{2}$ & 0.058 & 0.078 & & 0.103 & 0.112 & & 0.053 & 0.072 \\
Mean Y & 0.126 & 0.182 & & 0.086 & 0.121 & & 0.130 & 0.189 \\
F statistic & 307.899 & 307.899 & & 152.494 & 152.494 & 309.103 & 309.103 \\
\hline
\end{tabular}

Notes: We include all inpatient episodes and repeat the 2SLS estimations. In addition to the indicator for discharge to SNF instrumented with Day $3^{*}$ Medicare, each regression includes an indicator for Day 3, an indicator for Medicare as well as a vector of discharge characteristics such as patients' age, age squared, an indicator for sex, a series of indicators for race, health conditions (Diagnosis Related Group (DRG) fixed effects and indicators for all comorbidities), hospital fixed effects, discharge year and discharge month fixed effects, discharge hour fixed effects, and a dummy for missing discharge hour. Standard errors are clustered at the HSA level. ${ }^{*}$ Significant at $10 \%,{ }^{* *}$ significant at $5 \%$, ${ }^{* * *}$ significant at $1 \%$. 
Table B.12: 2SLS by condition: readmission rates, all inpatient episodes

\begin{tabular}{|c|c|c|c|c|c|c|}
\hline & \multicolumn{2}{|c|}{ Full sample } & \multicolumn{2}{|c|}{ No comorbidity } & \multicolumn{2}{|c|}{ Any comorbidity } \\
\hline & $\begin{array}{l}\text { Knee/hip } \\
\text { replacement }\end{array}$ & $\begin{array}{c}\text { Other } \\
\text { conditions }\end{array}$ & $\begin{array}{l}\text { Knee/hip } \\
\text { replacement }\end{array}$ & $\begin{array}{c}\text { Other } \\
\text { conditions }\end{array}$ & $\begin{array}{l}\text { Knee/hip } \\
\text { replacement }\end{array}$ & $\begin{array}{c}\text { Other } \\
\text { conditions }\end{array}$ \\
\hline \multicolumn{7}{|c|}{ Panel A. 30-day readmission rates } \\
\hline Discharge to SNF & $\begin{array}{l}0.024^{* *} \\
(0.010)\end{array}$ & $\begin{array}{l}-0.029^{*} \\
(0.017)\end{array}$ & $\begin{array}{l}0.044^{* *} \\
(0.020)\end{array}$ & $\begin{array}{c}0.046 \\
(0.053)\end{array}$ & $\begin{array}{c}0.017 \\
(0.012)\end{array}$ & $\begin{array}{c}-0.037^{* *} \\
(0.016)\end{array}$ \\
\hline Observations & 450,738 & $3,806,223$ & 68,378 & 376,369 & 382,336 & $3,429,830$ \\
\hline Adjusted $R^{2}$ & 0.016 & 0.052 & 0.009 & 0.101 & 0.016 & 0.047 \\
\hline Mean Y & 0.037 & 0.136 & 0.027 & 0.097 & 0.039 & 0.140 \\
\hline F statistic & 97.255 & 532.289 & 88.590 & 230.071 & 85.622 & 543.258 \\
\hline \multicolumn{7}{|c|}{ Panel B. 60-day readmission rates } \\
\hline Discharge to SNF & $\begin{array}{c}0.043^{* * *} \\
(0.012)\end{array}$ & $\begin{array}{c}-0.031^{* *} \\
(0.015)\end{array}$ & $\begin{array}{l}0.049^{* *} \\
(0.024)\end{array}$ & $\begin{array}{c}0.082 \\
(0.052)\end{array}$ & $\begin{array}{c}0.038^{* * *} \\
(0.015)\end{array}$ & $\begin{array}{c}-0.041^{* *} \\
(0.016)\end{array}$ \\
\hline Observations & 450,738 & $3,806,223$ & 68,378 & 376,369 & 382,336 & $3,429,830$ \\
\hline Adjusted $R^{2}$ & 0.018 & 0.070 & 0.011 & 0.109 & 0.018 & 0.064 \\
\hline Mean Y & 0.055 & 0.197 & 0.042 & 0.135 & 0.058 & 0.204 \\
\hline F statistic & 97.255 & 532.289 & 88.590 & 230.071 & 85.622 & 543.258 \\
\hline
\end{tabular}

Notes: We include all inpatient episodes and repeat the 2SLS estimations by health conditions. In addition to the indicator for discharge to SNF instrumented with Day $3^{*}$ Medicare, each regression includes an indicator for Day 3 , an indicator for Medicare as well as a vector of discharge characteristics such as patients' age, age squared, an indicator for sex, a series of indicators for race, health conditions (Diagnosis Related Group (DRG) fixed effects and indicators for all comorbidities), hospital fixed effects, discharge year and discharge month fixed effects, discharge hour fixed effects, and a dummy for missing discharge hour. Standard errors are clustered at the HSA level. * Significant at $10 \%,{ }^{* *}$ significant at $5 \%,{ }^{* * *}$ significant at $1 \%$. 
Table B.13: 2SLS by local SNF characteristics, knee and hip replacement, all inpatient episodes

\begin{tabular}{|c|c|c|c|c|}
\hline & \multicolumn{2}{|c|}{ Low occupancy } & \multicolumn{2}{|c|}{ High occupancy } \\
\hline & 30-day & 60-day & 30-day & 60-day \\
\hline \multicolumn{5}{|c|}{ Panel A. By occupancy } \\
\hline Discharge to SNF & $\begin{array}{l}0.028^{* *} \\
(0.012)\end{array}$ & $\begin{array}{c}0.049^{* * *} \\
(0.015)\end{array}$ & $\begin{array}{c}0.010 \\
(0.016)\end{array}$ & $\begin{array}{c}0.023 \\
(0.019)\end{array}$ \\
\hline Observations & 348,211 & 348,211 & 102,510 & 102,510 \\
\hline Adjusted $R^{2}$ & 0.016 & 0.018 & 0.013 & 0.016 \\
\hline Mean Y & 0.037 & 0.055 & 0.038 & 0.057 \\
\hline \multirow[t]{3}{*}{ F statistic } & 70.602 & 70.602 & 135.605 & 135.605 \\
\hline & \multicolumn{2}{|c|}{ Low deficiency } & \multicolumn{2}{|c|}{ High deficiency } \\
\hline & 30-day & 60-day & 30-day & 60-day \\
\hline \multicolumn{5}{|c|}{ Panel B. By deficiency } \\
\hline Discharge to SNF & $\begin{array}{c}0.018 \\
(0.018) \\
\end{array}$ & $\begin{array}{c}0.037 \\
(0.025) \\
\end{array}$ & $\begin{array}{l}0.026^{* *} \\
(0.011) \\
\end{array}$ & $\begin{array}{c}0.044^{* * *} \\
(0.013) \\
\end{array}$ \\
\hline Observations & 185,616 & 185,616 & 265,108 & 265,108 \\
\hline Adjusted $R^{2}$ & 0.017 & 0.020 & 0.015 & 0.017 \\
\hline Mean Y & 0.036 & 0.054 & 0.038 & 0.056 \\
\hline F statistic & 36.587 & 36.587 & 140.875 & 140.875 \\
\hline
\end{tabular}

Notes: We include all inpatient episodes and repeat the 2SLS estimations by local SNF characteristics for knee and hip replacement patients. In addition to the indicator for discharge to SNF instrumented with Day $3^{*}$ Medicare, each regression includes an indicator for Day 3, an indicator for Medicare as well as a vector of discharge characteristics such as patients' age, age squared, an indicator for sex, a series of indicators for race, health conditions (Diagnosis Related Group (DRG) fixed effects and indicators for all comorbidities), hospital fixed effects, discharge year and discharge month fixed effects, discharge hour fixed effects, and a dummy for missing discharge hour. Standard errors are clustered at the HSA level. ${ }^{*}$ Significant at $10 \%,{ }^{* *}$ significant at $5 \%,{ }^{* * *}$ significant at $1 \%$.

Table B.14: First stage: discharge outcomes, dropping MA

\begin{tabular}{lcccc}
\hline & Home/HHC & SNF & Other facilities & AMA \\
\hline Day $3^{*}$ Medicare & $-0.083^{* * *}$ & $0.073^{* * *}$ & $0.011^{* * *}$ & -0.000 \\
& $(0.004)$ & $(0.005)$ & $(0.004)$ & $(0.000)$ \\
\hline Observations & $2,447,892$ & $2,447,892$ & $2,447,892$ & $2,447,892$ \\
Adjusted $R^{2}$ & 0.228 & 0.198 & 0.126 & 0.058 \\
Mean Y & 0.862 & 0.075 & 0.055 & 0.008 \\
\hline
\end{tabular}

Notes: We drop patients from NY and FL whom we could identify as enrolled in Medicare Advantage (MA) and repeat the first stage estimations. In addition to Day $3^{*}$ Medicare, each regression includes an indicator for Day 3 , an indicator for Medicare as well as a vector of discharge characteristics such as patients' age, age squared, an indicator for sex, a series of indicators for race, health conditions (Diagnosis Related Group (DRG) fixed effects and indicators for all comorbidities), hospital fixed effects, discharge year and discharge month fixed effects, discharge hour fixed effects, and a dummy for missing discharge hour. Standard errors are clustered at the HSA level. * Significant at $10 \%,{ }^{* *}$ significant at $5 \%,{ }^{* * *}$ significant at $1 \%$. 
Table B.15: 2SLS: Readmission rates, dropping MA

\begin{tabular}{|c|c|c|c|c|c|c|}
\hline & \multicolumn{2}{|c|}{ Full sample } & \multicolumn{2}{|c|}{ No comorbidity } & \multicolumn{2}{|c|}{ Any comorbidity } \\
\hline & 30-day & 60-day & 30-day & 60-day & 30-day & 60-day \\
\hline Discharge to SNF & $\begin{array}{l}-0.008 \\
(0.010)\end{array}$ & $\begin{array}{c}-0.024^{* *} \\
(0.011)\end{array}$ & $\begin{array}{c}0.022 \\
(0.024)\end{array}$ & $\begin{array}{c}0.021 \\
(0.026)\end{array}$ & $\begin{array}{l}-0.013 \\
(0.011)\end{array}$ & $\begin{array}{c}-0.032^{* *} \\
(0.012)\end{array}$ \\
\hline Observations & $2,447,892$ & $2,447,892$ & 309,438 & 309,438 & $2,138,427$ & $2,138,427$ \\
\hline Adjusted $R^{2}$ & 0.032 & 0.045 & 0.046 & 0.054 & 0.030 & 0.042 \\
\hline Mean Y & 0.084 & 0.123 & 0.061 & 0.086 & 0.087 & 0.128 \\
\hline F statistic & 204.637 & 204.637 & 115.857 & 115.857 & 202.329 & 202.329 \\
\hline
\end{tabular}

Notes: We drop patients from NY and FL whom we could identify as enrolled in Medicare Advantage (MA) and repeat the 2SLS estimations. In addition to the indicator for discharge to SNF instrumented with Day $3^{*}$ Medicare, each regression includes an indicator for Day 3, an indicator for Medicare as well as a vector of discharge characteristics such as patients' age, age squared, an indicator for sex, a series of indicators for race, health conditions (Diagnosis Related Group (DRG) fixed effects and indicators for all comorbidities), hospital fixed effects, discharge year and discharge month fixed effects, discharge hour fixed effects, and a dummy for missing discharge hour. Standard errors are clustered at the HSA level. ${ }^{*}$ Significant at $10 \%,{ }^{* *}$ significant at $5 \%,{ }^{* * *}$ significant at $1 \%$.

Table B.16: 2SLS by condition: readmission rates, dropping MA

\begin{tabular}{|c|c|c|c|c|c|c|}
\hline & \multicolumn{2}{|c|}{ Full sample } & \multicolumn{2}{|c|}{ No comorbidity } & \multicolumn{2}{|c|}{ Any comorbidity } \\
\hline & $\begin{array}{l}\text { Knee/hip } \\
\text { replacement }\end{array}$ & $\begin{array}{c}\text { Other } \\
\text { conditions }\end{array}$ & $\begin{array}{l}\text { Knee/hip } \\
\text { replacement }\end{array}$ & $\begin{array}{c}\text { Other } \\
\text { conditions }\end{array}$ & $\begin{array}{c}\text { Knee/hip } \\
\text { replacement }\end{array}$ & $\begin{array}{c}\text { Other } \\
\text { conditions }\end{array}$ \\
\hline \multicolumn{7}{|c|}{ Panel A. 30-day readmission rates } \\
\hline Discharge to SNF & $\begin{array}{c}0.028^{* * *} \\
(0.010)\end{array}$ & $\begin{array}{l}-0.001 \\
(0.013)\end{array}$ & $\begin{array}{l}0.048^{* *} \\
(0.021)\end{array}$ & $\begin{array}{c}0.043 \\
(0.042)\end{array}$ & $\begin{array}{l}0.023^{*} \\
(0.012)\end{array}$ & $\begin{array}{l}-0.007 \\
(0.014)\end{array}$ \\
\hline Observations & 344,350 & $2,103,530$ & 55,750 & 253,655 & 288,563 & $1,849,846$ \\
\hline Adjusted $R^{2}$ & 0.014 & 0.029 & 0.007 & 0.044 & 0.014 & 0.026 \\
\hline Mean Y & 0.034 & 0.092 & 0.026 & 0.068 & 0.036 & 0.095 \\
\hline F statistic & 74.181 & 688.815 & 62.593 & 325.946 & 68.491 & 709.509 \\
\hline \multicolumn{7}{|c|}{ Panel B. 60-day readmission rates } \\
\hline Discharge to SNF & $\begin{array}{c}0.039^{* * *} \\
(0.013)\end{array}$ & $\begin{array}{l}-0.008 \\
(0.014)\end{array}$ & $\begin{array}{l}0.053^{*} \\
(0.029)\end{array}$ & $\begin{array}{c}0.058 \\
(0.047)\end{array}$ & $\begin{array}{l}0.036^{* *} \\
(0.015)\end{array}$ & $\begin{array}{l}-0.016 \\
(0.015)\end{array}$ \\
\hline Observations & 344,350 & $2,103,530$ & 55,750 & 253,655 & 288,563 & $1,849,846$ \\
\hline Adjusted $R^{2}$ & 0.016 & 0.040 & 0.010 & 0.052 & 0.016 & 0.038 \\
\hline Mean Y & 0.051 & 0.135 & 0.040 & 0.097 & 0.053 & 0.140 \\
\hline F statistic & 74.181 & 688.815 & 62.593 & 325.946 & 68.491 & 709.509 \\
\hline
\end{tabular}

Notes: We drop patients from NY and FL whom we could identify as enrolled in Medicare Advantage (MA) and repeat the 2 SLS estimations by health conditions. In addition to the indicator for discharge to SNF instrumented with Day $3 *$ Medicare, each regression includes an indicator for Day 3, an indicator for Medicare as well as a vector of discharge characteristics such as patients' age, age squared, an indicator for sex, a series of indicators for race, health conditions (Diagnosis Related Group (DRG) fixed effects and indicators for all comorbidities), hospital fixed effects, discharge year and discharge month fixed effects, discharge hour fixed effects, and a dummy for missing discharge hour. Standard errors are clustered at the HSA level. ${ }^{*}$ Significant at $10 \%,{ }^{* *}$ significant at $5 \%,{ }^{* * *}$ significant at $1 \%$. 
Table B.17: 2SLS by condition \& local SNF characteristics, knee and hip replacement, dropping MA

\begin{tabular}{lccccc}
\hline & \multicolumn{2}{c}{ Low occupancy } & & \multicolumn{2}{c}{ High occupancy } \\
\cline { 2 - 3 } \cline { 5 - 6 } 30-day & 60 -day & & 30-day & 60 -day \\
Panel A. By occupancy & & & \\
\hline Discharge to SNF & $0.035^{* * *}$ & $0.055^{* * *}$ & & 0.006 & -0.008 \\
& $(0.011)$ & $(0.015)$ & & $0.018)$ & $(0.022)$ \\
\hline Observations & 265,032 & 265,032 & & 79,305 & 79,305 \\
Adjusted $R^{2}$ & 0.014 & 0.015 & & 0.011 & 0.011 \\
Mean Y & 0.034 & 0.051 & & 0.035 & 0.052 \\
F statistic & 54.488 & 54.488 & & 108.253 & 108.253 \\
& & & & \\
& Low deficiency & & High deficiency \\
\cline { 2 - 3 } \cline { 5 - 6 } & 30 -day & $60-$ day & & 30 -day & $60-$ day \\
Panel B. By deficiency & & & \\
\hline Discharge to SNF & 0.018 & 0.025 & & $0.033^{* * *}$ & $0.047^{* * *}$ \\
& $(0.017)$ & $(0.023)$ & & $(0.012)$ & $(0.014)$ \\
\hline Observations & 140,156 & 140,156 & & 204,175 & 204,175 \\
Adjusted $R^{2}$ & 0.016 & 0.018 & & 0.013 & 0.014 \\
Mean Y & 0.033 & 0.050 & & 0.035 & 0.052 \\
F statistic & 28.371 & 28.371 & 104.874 & 104.874 \\
\hline
\end{tabular}

Notes: We drop patients from NY and FL whom we could identify as enrolled in Medicare Advantage (MA) and repeat the 2SLS estimations by local SNF characteristics for knee and hip replacement patients. In addition to the indicator for discharge to SNF instrumented with Day $3^{*}$ Medicare, each regression includes an indicator for Day 3 , an indicator for Medicare as well as a vector of discharge characteristics such as patients' age, age squared, an indicator for sex, a series of indicators for race, health conditions (Diagnosis Related Group (DRG) fixed effects and indicators for all comorbidities), hospital fixed effects, discharge year and discharge month fixed effects, discharge hour fixed effects, and a dummy for missing discharge hour. Standard errors are clustered at the HSA level. * Significant at $10 \%,{ }^{* *}$ significant at $5 \%,{ }^{* * *}$ significant at $1 \%$.

Table B.18: First stage: discharge outcomes, 12-hour window

\begin{tabular}{lcccc}
\hline & Home $/ \mathrm{HHC}$ & SNF & Other facilities & AMA \\
\hline Day $3^{*}$ Medicare & $-0.070^{* * *}$ & $0.054^{* * *}$ & $0.017^{* *}$ & -0.000 \\
& $(0.007)$ & $(0.006)$ & $(0.008)$ & $(0.000)$ \\
\hline Observations & $1,111,287$ & $1,111,287$ & $1,111,287$ & $1,111,287$ \\
Adjusted $R^{2}$ & 0.213 & 0.183 & 0.140 & 0.062 \\
Mean Y & 0.893 & 0.050 & 0.048 & 0.008 \\
\hline
\end{tabular}

Notes: We focus on 12 hours before and after the three-day cutoff and repeat the first stage estimations. In addition to Day $3 *$ Medicare, each regression includes an indicator for Day 3, an indicator for Medicare as well as a vector of discharge characteristics such as patients' age, age squared, an indicator for sex, a series of indicators for race, health conditions (Diagnosis Related Group (DRG) fixed effects and indicators for all comorbidities), hospital fixed effects, discharge year and discharge month fixed effects, discharge hour fixed effects, and a dummy for missing discharge hour. Standard errors are clustered at the HSA level. ${ }^{*}$ Significant at $10 \%,{ }^{* *}$ significant at $5 \%,{ }^{* * *}$ significant at $1 \%$. 
Table B.19: 2SLS: Readmission rates, 12-hour window

\begin{tabular}{lcccccccc}
\hline & \multicolumn{2}{c}{ Full sample } & & \multicolumn{2}{c}{ No comorbidity } & & \multicolumn{2}{c}{ Any comorbidity } \\
\cline { 2 - 3 } & 30-day & 60 -day & & 30-day & 60 -day & & 30-day & 60-day \\
\hline Discharge to SNF & $-0.090^{* * *}$ & $-0.121^{* * *}$ & & -0.064 & $-0.092^{*}$ & & $-0.092^{* * *}$ & $-0.123^{* * *}$ \\
& $(0.031)$ & $(0.035)$ & & $(0.046)$ & $(0.053)$ & & $(0.034)$ & $(0.038)$ \\
\hline Observations & $1,111,287$ & $1,111,287$ & & 134,973 & 134,973 & & 976,271 & 976,271 \\
Adjusted $R^{2}$ & 0.026 & 0.038 & & 0.046 & 0.052 & & 0.024 & 0.035 \\
Mean Y & 0.080 & 0.118 & & 0.058 & 0.083 & & 0.083 & 0.123 \\
F statistic & 79.766 & 79.766 & & 56.096 & 56.096 & & 80.340 & 80.340 \\
\hline
\end{tabular}

Notes: We focus on 12 hours before and after the three-day cutoff and repeat the 2SLS estimations. In addition to the indicator for discharge to SNF instrumented with Day $3 *$ Medicare, each regression includes an indicator for Day 3, an indicator for Medicare as well as a vector of discharge characteristics such as patients' age, age squared, an indicator for sex, a series of indicators for race, health conditions (Diagnosis Related Group (DRG) fixed effects and indicators for all comorbidities), hospital fixed effects, discharge year and discharge month fixed effects, discharge hour fixed effects, and a dummy for missing discharge hour. Standard errors are clustered at the HSA level. * Significant at $10 \%,{ }^{* *}$ significant at $5 \%,{ }^{* * *}$ significant at $1 \%$.

Table B.20: 2SLS by condition: readmission rates, 12-hour window

\begin{tabular}{|c|c|c|c|c|c|c|}
\hline & \multicolumn{2}{|c|}{ Full sample } & \multicolumn{2}{|c|}{ No comorbidity } & \multicolumn{2}{|c|}{ Any comorbidity } \\
\hline & $\begin{array}{l}\text { Knee/hip } \\
\text { replacement }\end{array}$ & $\begin{array}{c}\text { Other } \\
\text { conditions }\end{array}$ & $\begin{array}{l}\text { Knee/hip } \\
\text { replacement }\end{array}$ & $\begin{array}{c}\text { Other } \\
\text { conditions }\end{array}$ & $\begin{array}{l}\text { Knee/hip } \\
\text { replacement }\end{array}$ & $\begin{array}{c}\text { Other } \\
\text { conditions }\end{array}$ \\
\hline \multicolumn{7}{|c|}{ Panel A. 30-day readmission rates } \\
\hline Discharge to SNF & $\begin{array}{c}0.022 \\
(0.013)\end{array}$ & $\begin{array}{c}-0.168^{* * *} \\
(0.054)\end{array}$ & $\begin{array}{c}0.028 \\
(0.036)\end{array}$ & $\begin{array}{l}-0.176 \\
(0.136)\end{array}$ & $\begin{array}{c}0.019 \\
(0.017)\end{array}$ & $\begin{array}{c}-0.160^{* * *} \\
(0.059)\end{array}$ \\
\hline Observations & 141,812 & 969,449 & 23,918 & 111,006 & 117,845 & 858,400 \\
\hline Adjusted $R^{2}$ & 0.015 & 0.018 & 0.017 & 0.039 & 0.015 & 0.017 \\
\hline Mean Y & 0.029 & 0.088 & 0.022 & 0.066 & 0.030 & 0.090 \\
\hline F statistic & 56.955 & 218.277 & 38.311 & 76.606 & 55.013 & 219.843 \\
\hline \multicolumn{7}{|c|}{ Panel B. 60-day readmission rates } \\
\hline Discharge to SNF & $\begin{array}{l}0.042^{* *} \\
(0.017)\end{array}$ & $\begin{array}{c}-0.174^{* * *} \\
(0.058)\end{array}$ & $\begin{array}{c}0.052 \\
(0.044)\end{array}$ & $\begin{array}{l}-0.213 \\
(0.146)\end{array}$ & $\begin{array}{l}0.039^{*} \\
(0.020)\end{array}$ & $\begin{array}{c}-0.160^{* *} \\
(0.062)\end{array}$ \\
\hline Observations & 141,812 & 969,449 & 23,918 & 111,006 & 117,845 & 858,400 \\
\hline Adjusted $R^{2}$ & 0.014 & 0.031 & 0.012 & 0.046 & 0.014 & 0.030 \\
\hline Mean Y & 0.043 & 0.129 & 0.034 & 0.093 & 0.045 & 0.134 \\
\hline F statistic & 56.955 & 218.277 & 38.311 & 76.606 & 55.013 & 219.843 \\
\hline
\end{tabular}

Notes: We focus on 12 hours before and after the three-day cutoff and repeat the 2SLS estimations by health conditions. In addition to the indicator for discharge to SNF instrumented with Day $3 *$ Medicare, each regression includes an indicator for Day 3, an indicator for Medicare as well as a vector of discharge characteristics such as patients' age, age squared, an indicator for sex, a series of indicators for race, health conditions (Diagnosis Related Group (DRG) fixed effects and indicators for all comorbidities), hospital fixed effects, discharge year and discharge month fixed effects, discharge hour fixed effects, and a dummy for missing discharge hour. Standard errors are clustered at the HSA level. ${ }^{*}$ Significant at $10 \%,{ }^{* *}$ significant at $5 \%,{ }^{* * *}$ significant at $1 \%$. 
Table B.21: 2SLS by condition \& local SNF characteristics, knee and hip replacement, 12-hour window

\begin{tabular}{|c|c|c|c|c|}
\hline & \multicolumn{2}{|c|}{ Low occupancy } & \multicolumn{2}{|c|}{ High occupancy } \\
\hline & 30-day & 60-day & 30-day & 60-day \\
\hline \multicolumn{5}{|c|}{ Panel A. By occupancy } \\
\hline Discharge to SNF & $\begin{array}{c}0.027^{*} \\
(0.014)\end{array}$ & $\begin{array}{c}0.056^{* * *} \\
(0.020)\end{array}$ & $\begin{array}{c}0.003 \\
(0.028)\end{array}$ & $\begin{array}{l}-0.003 \\
(0.033)\end{array}$ \\
\hline Observations & 106,029 & 106,029 & 35,771 & 35,771 \\
\hline Adjusted $R^{2}$ & 0.017 & 0.014 & 0.008 & 0.008 \\
\hline Mean Y & 0.028 & 0.043 & 0.030 & 0.044 \\
\hline \multirow[t]{3}{*}{ F statistic } & 44.526 & 44.526 & 41.137 & 41.137 \\
\hline & \multicolumn{2}{|c|}{ Low deficiency } & \multicolumn{2}{|c|}{ High deficiency } \\
\hline & 30-day & 60-day & 30-day & 60-day \\
\hline \multicolumn{5}{|c|}{ Panel B. By deficiency } \\
\hline Discharge to SNF & $\begin{array}{l}-0.008 \\
(0.025)\end{array}$ & $\begin{array}{c}0.015 \\
(0.030)\end{array}$ & $\begin{array}{c}0.037^{* *} \\
(0.015)\end{array}$ & $\begin{array}{c}0.054^{* * *} \\
(0.018)\end{array}$ \\
\hline Observations & 53,674 & 53,674 & 88,119 & 88,119 \\
\hline Adjusted $R^{2}$ & 0.014 & 0.016 & 0.014 & 0.013 \\
\hline Mean Y & 0.027 & 0.040 & 0.030 & 0.045 \\
\hline F statistic & 27.875 & 27.875 & 69.240 & 69.240 \\
\hline
\end{tabular}

Notes: We focus on 12 hours before and after the three-day cutoff and repeat the 2SLS estimations by local SNF characteristics for knee and hip replacement patients. In addition to the indicator for discharge to SNF instrumented with Day $3^{*}$ Medicare, each regression includes an indicator for Day 3, an indicator for Medicare as well as a vector of discharge characteristics such as patients' age, age squared, an indicator for sex, a series of indicators for race, health conditions (Diagnosis Related Group (DRG) fixed effects and indicators for all comorbidities), hospital fixed effects, discharge year and discharge month fixed effects, discharge hour fixed effects, and a dummy for missing discharge hour. Standard errors are clustered at the HSA level. ${ }^{*}$ Significant at $10 \%,{ }^{* *}$ significant at $5 \%,{ }^{* * *}$ significant at $1 \%$. 
Table B.22: First stage: discharge outcomes, 5-hour window, regression discontinuity (RD)

\begin{tabular}{lcccc}
\hline & Home/HHC & SNF & Other facilities & AMA \\
\hline Above & $-0.044^{* *}$ & $0.041^{* * *}$ & -0.002 & 0.004 \\
& $(0.020)$ & $(0.010)$ & $(0.019)$ & $(0.007)$ \\
\hline Observations & 60,854 & 60,854 & 60,854 & 60,854 \\
Adjusted $R^{2}$ & 0.216 & 0.117 & 0.198 & 0.039 \\
Mean Y & 0.868 & 0.039 & 0.078 & 0.016 \\
\hline
\end{tabular}

Notes: We restrict the sample to Medicare patients discharged between 5 hours before and after the three-day cutoff and run a standard RD model, controlling for a linear spline of the running variable, which is the hours from the three-day cutoff. We also control for age, age squared, an indicator for sex, a series of indicators for race, health conditions (Diagnosis Related Group (DRG) fixed effects and indicators for all comorbidities), hospital fixed effects, discharge year fixed effects, and discharge month fixed effects. Standard errors are clustered at the HSA level. * Significant at $10 \%,{ }^{* *}$ significant at $5 \%,{ }^{* * *}$ significant at $1 \%$.

Table B.23: First stage: discharge outcomes, dropping a subsample with significant comorbidity difference

\begin{tabular}{lcccc}
\hline & Home/HHC & SNF & Other facilities & AMA \\
\hline Day $3^{*}$ Medicare & $-0.073^{* * *}$ & $0.063^{* * *}$ & $0.010^{* * *}$ & -0.000 \\
& $(0.004)$ & $(0.004)$ & $(0.003)$ & $(0.000)$ \\
\hline Observations & $1,286,994$ & $1,286,994$ & $1,286,994$ & $1,286,994$ \\
Adjusted $R^{2}$ & 0.227 & 0.207 & 0.132 & 0.061 \\
Mean Y & 0.888 & 0.060 & 0.045 & 0.007 \\
\hline
\end{tabular}

Notes: We drop patients with comorbidities that have a significant difference between Medicare patients who are discharged after versus before the three-day cutoff relative to non-Medicare patients and repeat the first stage estimations. In addition to Day $3 *$ Medicare, each regression includes an indicator for Day 3, an indicator for Medicare as well as a vector of discharge characteristics such as patients' age, age squared, an indicator for sex, a series of indicators for race, health conditions (Diagnosis Related Group (DRG) fixed effects and indicators for all comorbidities), hospital fixed effects, discharge year and discharge month fixed effects, discharge hour fixed effects, and a dummy for missing discharge hour. Standard errors are clustered at the HSA level. ${ }^{*}$ Significant at $10 \%,{ }^{* *}$ significant at $5 \%$, *** significant at $1 \%$. 
Table B.24: 2SLS: Readmission rates, dropping a subsample with significant comorbidity difference

\begin{tabular}{lcccccccc}
\hline & \multicolumn{2}{c}{ Full sample } & & \multicolumn{2}{c}{ No comorbidity } & & \multicolumn{2}{c}{ Any comorbidity } \\
\cline { 2 - 3 } & 30-day & 60 -day & & 30-day & 60 -day & & 30-day & 60-day \\
\hline Discharge to SNF & -0.012 & $-0.029^{*}$ & & 0.005 & 0.011 & & -0.022 & $-0.048^{* *}$ \\
& $(0.016)$ & $(0.017)$ & & $(0.023)$ & $(0.024)$ & & $(0.019)$ & $(0.021)$ \\
\hline Observations & $1,286,994$ & $1,286,994$ & & 352,749 & 352,749 & & 934,214 & 934,214 \\
Adjusted $R^{2}$ & 0.031 & 0.041 & & 0.044 & 0.053 & & 0.026 & 0.036 \\
Mean Y & 0.071 & 0.104 & & 0.061 & 0.088 & & 0.075 & 0.110 \\
F statistic & 202.614 & 202.614 & & 166.737 & 166.737 & & 200.242 & 200.242 \\
\hline
\end{tabular}

Notes: We drop patients with comorbidities that have a significant difference between Medicare patients who are discharged after versus before the three-day cutoff relative to non-Medicare patients and repeat the 2SLS estimations. In addition to the indicator for discharge to SNF instrumented with Day $3^{*}$ Medicare, each regression includes an indicator for Day 3, an indicator for Medicare as well as a vector of discharge characteristics such as patients' age, age squared, an indicator for sex, a series of indicators for race, health conditions (Diagnosis Related Group (DRG) fixed effects and indicators for all comorbidities), hospital fixed effects, discharge year and discharge month fixed effects, discharge hour fixed effects, and a dummy for missing discharge hour. Standard errors are clustered at the HSA level. ${ }^{*}$ Significant at $10 \%,{ }^{* *}$ significant at $5 \%,{ }^{* * *}$ significant at $1 \%$.

Table B.25: 2SLS by condition: readmission rates, dropping a subsample with significant comorbidity difference

\begin{tabular}{|c|c|c|c|c|c|c|}
\hline & \multicolumn{2}{|c|}{ Full sample } & \multicolumn{2}{|c|}{ No comorbidity } & \multicolumn{2}{|c|}{ Any comorbidity } \\
\hline & $\begin{array}{l}\text { Knee/hip } \\
\text { replacement }\end{array}$ & $\begin{array}{c}\text { Other } \\
\text { conditions }\end{array}$ & $\begin{array}{l}\text { Knee/hip } \\
\text { replacement }\end{array}$ & $\begin{array}{c}\text { Other } \\
\text { conditions }\end{array}$ & $\begin{array}{l}\text { Knee/hip } \\
\text { replacement }\end{array}$ & $\begin{array}{c}\text { Other } \\
\text { conditions }\end{array}$ \\
\hline \multicolumn{7}{|c|}{ Panel A. 30-day readmission rates } \\
\hline Discharge to SNF & $\begin{array}{l}0.025^{*} \\
(0.014)\end{array}$ & $\begin{array}{l}-0.012 \\
(0.029)\end{array}$ & $\begin{array}{l}0.043^{* *} \\
(0.020)\end{array}$ & $\begin{array}{c}0.014 \\
(0.048)\end{array}$ & $\begin{array}{c}0.012 \\
(0.021)\end{array}$ & $\begin{array}{l}-0.025 \\
(0.032)\end{array}$ \\
\hline Observations & 195,314 & $1,091,664$ & 62,191 & 290,531 & 133,095 & 801,100 \\
\hline Adjusted $R^{2}$ & 0.013 & 0.029 & 0.010 & 0.043 & 0.013 & 0.024 \\
\hline Mean Y & 0.032 & 0.078 & 0.026 & 0.069 & 0.034 & 0.081 \\
\hline F statistic & 98.388 & 329.527 & 85.830 & 308.921 & 86.025 & 307.054 \\
\hline \multicolumn{7}{|c|}{ Panel B. 60-day readmission rates } \\
\hline Discharge to SNF & $\begin{array}{l}0.027^{*} \\
(0.017)\end{array}$ & $\begin{array}{l}-0.017 \\
(0.032)\end{array}$ & $\begin{array}{c}0.044 \\
(0.028)\end{array}$ & $\begin{array}{c}0.049 \\
(0.052)\end{array}$ & $\begin{array}{c}0.013 \\
(0.023)\end{array}$ & $\begin{array}{l}-0.043 \\
(0.037)\end{array}$ \\
\hline Observations & 195,314 & $1,091,664$ & 62,191 & 290,531 & 133,095 & 801,100 \\
\hline Adjusted $R^{2}$ & 0.014 & 0.039 & 0.012 & 0.051 & 0.014 & 0.034 \\
\hline Mean Y & 0.047 & 0.114 & 0.041 & 0.098 & 0.050 & 0.119 \\
\hline F statistic & 98.388 & 329.527 & 85.830 & 308.921 & 86.025 & 307.054 \\
\hline
\end{tabular}

Notes: We drop patients with comorbidities that have a significant difference between Medicare patients who are discharged after versus before the three-day cutoff relative to non-Medicare patients and repeat the 2SLS estimations by health conditions. In addition to the indicator for discharge to SNF instrumented with Day $3^{*}$ Medicare, each regression includes an indicator for Day 3, an indicator for Medicare as well as a vector of discharge characteristics such as patients' age, age squared, an indicator for sex, a series of indicators for race, health conditions (Diagnosis Related Group (DRG) fixed effects and indicators for all comorbidities), hospital fixed effects, discharge year and discharge month fixed effects, discharge hour fixed effects, and a dummy for missing discharge hour. Standard errors are clustered at the HSA level. ${ }^{*}$ Significant at $10 \%,{ }^{* *}$ significant at $5 \%,{ }^{* * *}$ significant at $1 \%$. 
Table B.26: 2SLS by local SNF characteristics, knee and hip replacement, dropping a subsample with significant comorbidity difference

\begin{tabular}{lccccc}
\hline & \multicolumn{2}{c}{ Low occupancy } & \multicolumn{2}{c}{ High occupancy } \\
\cline { 2 - 3 } \cline { 5 - 6 } 30-day & 60 -day & & 30 -day & 60 -day \\
Panel A. By occupancy & & & \\
\hline Discharge to SNF & $0.041^{* * *}$ & $0.051^{* *}$ & & -0.028 & -0.046 \\
& $(0.015)$ & $(0.020)$ & & $(0.027)$ & $(0.031)$ \\
\hline Observations & 150,353 & 150,353 & & 44,951 & 44,951 \\
Adjusted $R^{2}$ & 0.013 & 0.013 & & 0.002 & 0.000 \\
Mean Y & 0.032 & 0.047 & & 0.031 & 0.047 \\
F statistic & 73.379 & 73.379 & & 89.493 & 89.493 \\
& & & & \\
& Low deficiency & & High deficiency \\
\cline { 2 - 3 } \cline { 5 - 6 } & 30 -day & $60-$ day & & 30 -day & 60 -day \\
Panel B. By deficiency & & & \\
\hline Discharge to SNF & 0.027 & 0.038 & & 0.025 & 0.022 \\
& $(0.028)$ & $(0.034)$ & & $(0.016)$ & $(0.021)$ \\
\hline Observations & 79,074 & 79,074 & & 116,223 & 116,223 \\
Adjusted $R^{2}$ & 0.015 & 0.015 & & 0.013 & 0.014 \\
Mean Y & 0.031 & 0.047 & 0.032 & 0.048 \\
F statistic & 37.180 & 37.180 & & 138.196 & 138.196 \\
\hline
\end{tabular}

Notes: We drop patients with comorbidities that have a significant difference between Medicare patients who are discharged after versus before the three-day cutoff relative to non-Medicare patients and repeat the 2SLS estimations by local SNF characteristics for knee and hip replacement patients. In addition to the indicator for discharge to SNF instrumented with Day $3^{*}$ Medicare, each regression includes an indicator for Day 3, an indicator for Medicare as well as a vector of discharge characteristics such as patients' age, age squared, an indicator for sex, a series of indicators for race, health conditions (Diagnosis Related Group (DRG) fixed effects and indicators for all comorbidities), hospital fixed effects, discharge year and discharge month fixed effects, discharge hour fixed effects, and a dummy for missing discharge hour. Standard errors are clustered at the HSA level. ${ }^{*}$ Significant at $10 \%,{ }^{* *}$ significant at $5 \%,{ }^{* * *}$ significant at $1 \%$. 
Table B.27: First stage: discharge outcomes, additional controls of admission hour, total hours in the hospital, and ER admission

\begin{tabular}{lcccc}
\hline & Home $/ \mathrm{HHC}$ & SNF & Other facilities & AMA \\
\hline Day $3^{*}$ Medicare & $-0.077^{* * *}$ & $0.069^{* * *}$ & $0.009^{* * *}$ & -0.000 \\
& $(0.003)$ & $(0.004)$ & $(0.003)$ & $(0.000)$ \\
\hline Observations & $2,915,127$ & $2,915,127$ & $2,915,127$ & $2,915,127$ \\
Adjusted $R^{2}$ & 0.238 & 0.215 & 0.124 & 0.053 \\
Mean Y & 0.862 & 0.078 & 0.052 & 0.008 \\
\hline
\end{tabular}

Notes: In addition to Day $3 *$ Medicare, each regression includes an indicator for Day 3, an indicator for Medicare as well as a vector of discharge characteristics such as patients' age, age squared, an indicator for sex, a series of indicators for race, health conditions (Diagnosis Related Group (DRG) fixed effects and indicators for all comorbidities), hospital fixed effects, discharge year and discharge month fixed effects, discharge hour fixed effects, admission hour, total hours in the hospital, an indicator for ER admission, and a series of indicators for missing values. Standard errors are clustered at the HSA level. ${ }^{*}$ Significant at $10 \%,{ }^{* *}$ significant at $5 \%,{ }^{* * *}$ significant at $1 \%$.

Table B.28: 2SLS: Readmission rates, additional controls of admission hour, total hours in the hospital, and ER admission

\begin{tabular}{lcccccccc}
\hline & \multicolumn{2}{c}{ Full sample } & & \multicolumn{2}{c}{ No comorbidity } & & \multicolumn{2}{c}{ Any comorbidity } \\
\cline { 2 - 3 } & 30-day & 60-day & & 30-day & 60-day & & 30-day & 60-day \\
\hline Discharge to SNF & -0.012 & $-0.030^{* * *}$ & & 0.005 & 0.010 & & -0.016 & $-0.038^{* * *}$ \\
& $(0.010)$ & $(0.011)$ & & $(0.023)$ & $(0.024)$ & & $(0.011)$ & $(0.012)$ \\
\hline Observations & $2,914,288$ & $2,914,288$ & & 352,608 & 352,608 & & $2,561,652$ & $2,561,652$ \\
Adjusted $R^{2}$ & 0.031 & 0.043 & & 0.044 & 0.053 & & 0.029 & 0.040 \\
Mean Y & 0.084 & 0.124 & & 0.061 & 0.088 & & 0.088 & 0.129 \\
F statistic & 270.348 & 270.348 & & 158.923 & 158.923 & & 266.238 & 266.238 \\
\hline
\end{tabular}

Notes: In addition to the indicator for discharge to SNF instrumented with Day $3 *$ Medicare, each regression includes an indicator for Day 3, an indicator for Medicare as well as a vector of discharge characteristics such as patients' age, age squared, an indicator for sex, a series of indicators for race, health conditions (Diagnosis Related Group (DRG) fixed effects and indicators for all comorbidities), hospital fixed effects, discharge year and discharge month fixed effects, discharge hour fixed effects, admission hour, total hours in the hospital, an indicator for ER admission, and a series of indicators for missing values. Standard errors are clustered at the HSA level. ${ }^{*}$ Significant at $10 \%,{ }^{* *}$ significant at $5 \%,{ }^{* * *}$ significant at $1 \%$. 
Table B.29: 2SLS by condition: readmission rates, additional controls of admission hour, total hours in the hospital, and ER admission

\begin{tabular}{|c|c|c|c|c|c|c|}
\hline & \multicolumn{2}{|c|}{ Full sample } & \multicolumn{2}{|c|}{ No comorbidity } & \multicolumn{2}{|c|}{ Any comorbidity } \\
\hline & $\begin{array}{l}\text { Knee/hip } \\
\text { replacement }\end{array}$ & $\begin{array}{c}\text { Other } \\
\text { conditions }\end{array}$ & $\begin{array}{c}\text { Knee/hip } \\
\text { replacement }\end{array}$ & $\begin{array}{c}\text { Other } \\
\text { conditions }\end{array}$ & $\begin{array}{l}\text { Knee/hip } \\
\text { replacement }\end{array}$ & $\begin{array}{c}\text { Other } \\
\text { conditions }\end{array}$ \\
\hline \multicolumn{7}{|c|}{ Panel A. 30-day readmission rates } \\
\hline Discharge to SNF & $\begin{array}{c}0.026^{* * *} \\
(0.010)\end{array}$ & $\begin{array}{l}-0.010 \\
(0.015)\end{array}$ & $\begin{array}{c}0.041^{* *} \\
(0.020)\end{array}$ & $\begin{array}{c}0.015 \\
(0.049)\end{array}$ & $\begin{array}{c}0.021 \\
(0.013)\end{array}$ & $\begin{array}{l}-0.015 \\
(0.015)\end{array}$ \\
\hline Observations & 400,000 & $2,514,277$ & 62,185 & 290,396 & 337,785 & $2,223,851$ \\
\hline Adjusted $R^{2}$ & 0.015 & 0.028 & 0.011 & 0.043 & 0.015 & 0.025 \\
\hline Mean Y & 0.036 & 0.092 & 0.026 & 0.069 & 0.037 & 0.095 \\
\hline F statistic & 94.978 & 495.974 & 84.261 & 293.335 & 84.566 & 495.546 \\
\hline \multicolumn{7}{|c|}{ Panel B. 60-day readmission rates } \\
\hline Discharge to SNF & $\begin{array}{c}0.039^{* * *} \\
(0.012)\end{array}$ & $\begin{array}{c}-0.021 \\
(0.016)\end{array}$ & $\begin{array}{c}0.044 \\
(0.028)\end{array}$ & $\begin{array}{c}0.049 \\
(0.052)\end{array}$ & $\begin{array}{l}0.036^{* *} \\
(0.015)\end{array}$ & $\begin{array}{l}-0.030^{*} \\
(0.017)\end{array}$ \\
\hline Observations & 400,000 & $2,514,277$ & 62,185 & 290,396 & 337,785 & $2,223,851$ \\
\hline Adjusted $R^{2}$ & 0.016 & 0.039 & 0.012 & 0.051 & 0.016 & 0.036 \\
\hline Mean Y & 0.053 & 0.136 & 0.041 & 0.098 & 0.055 & 0.141 \\
\hline F statistic & 94.978 & 495.974 & 84.261 & 293.335 & 84.566 & 495.546 \\
\hline
\end{tabular}

Notes: In addition to the indicator for discharge to SNF instrumented with Day $3 *$ Medicare, each regression includes an indicator for Day 3, an indicator for Medicare as well as a vector of discharge characteristics such as patients' age, age squared, an indicator for sex, a series of indicators for race, health conditions (Diagnosis Related Group (DRG) fixed effects and indicators for all comorbidities), hospital fixed effects, discharge year and discharge month fixed effects, discharge hour fixed effects, admission hour, total hours in the hospital, an indicator for ER admission, and a series of indicators for missing values. Standard errors are clustered at the HSA level. ${ }^{*}$ Significant at $10 \%,{ }^{* *}$ significant at $5 \%,{ }^{* * *}$ significant at $1 \%$. 
Table B.30: 2SLS by condition \& local SNF characteristics, knee and hip replacement, additional controls of admission hour, total hours in the hospital, and ER admission

\begin{tabular}{|c|c|c|c|c|}
\hline & \multicolumn{2}{|c|}{ Low occupancy } & \multicolumn{2}{|c|}{ High occupancy } \\
\hline & 30-day & 60-day & 30-day & 60-day \\
\hline \multicolumn{5}{|c|}{ Panel A. By occupancy } \\
\hline Discharge to SNF & $\begin{array}{c}0.031^{* * *} \\
(0.011)\end{array}$ & $\begin{array}{c}0.052^{* * *} \\
(0.015)\end{array}$ & $\begin{array}{c}0.010 \\
(0.018)\end{array}$ & $\begin{array}{c}0.001 \\
(0.021)\end{array}$ \\
\hline Observations & 309,105 & 309,105 & 90,881 & 90,881 \\
\hline Adjusted $R^{2}$ & 0.016 & 0.016 & 0.012 & 0.013 \\
\hline Mean Y & 0.035 & 0.052 & 0.036 & 0.054 \\
\hline \multirow[t]{3}{*}{ F statistic } & 69.028 & 69.028 & 128.890 & 128.890 \\
\hline & \multicolumn{2}{|c|}{ Low deficiency } & \multicolumn{2}{|c|}{ High deficiency } \\
\hline & 30-day & 60-day & 30-day & 60-day \\
\hline \multicolumn{5}{|c|}{ Panel B. By deficiency } \\
\hline Discharge to SNF & $\begin{array}{c}0.013 \\
(0.019) \\
\end{array}$ & $\begin{array}{c}0.022 \\
(0.024) \\
\end{array}$ & $\begin{array}{c}0.033^{* * *} \\
(0.011)\end{array}$ & $\begin{array}{c}0.048^{* * *} \\
(0.013)\end{array}$ \\
\hline Observations & 163,722 & 163,722 & 236,261 & 236,261 \\
\hline Adjusted $R^{2}$ & 0.017 & 0.019 & 0.013 & 0.014 \\
\hline Mean Y & 0.035 & 0.052 & 0.036 & 0.053 \\
\hline F statistic & 36.018 & 36.018 & 137.429 & 137.429 \\
\hline
\end{tabular}

Notes: In addition to the indicator for discharge to SNF instrumented with Day $3 *$ Medicare, each regression includes an indicator for Day 3, an indicator for Medicare as well as a vector of discharge characteristics such as patients' age, age squared, an indicator for sex, a series of indicators for race, health conditions (Diagnosis Related Group (DRG) fixed effects and indicators for all comorbidities), hospital fixed effects, discharge year and discharge month fixed effects, discharge hour fixed effects, admission hour, total hours in the hospital, an indicator for ER admission, and a series of indicators for missing values. Standard errors are clustered at the HSA level. ${ }^{*}$ Significant at $10 \%,{ }^{* *}$ significant at $5 \%,{ }^{* * *}$ significant at $1 \%$.

Table B.31: First stage: discharge outcomes, ER admission only

\begin{tabular}{lcccc}
\hline & Home/HHC & SNF & Other facilities & AMA \\
\hline Day $3^{*}$ Medicare & $-0.049^{* * *}$ & $0.048^{* * *}$ & 0.001 & -0.001 \\
& $(0.002)$ & $(0.002)$ & $(0.001)$ & $(0.000)$ \\
\hline Observations & $1,708,710$ & $1,708,710$ & $1,708,710$ & $1,708,710$ \\
Adjusted $R^{2}$ & 0.181 & 0.159 & 0.129 & 0.047 \\
Mean Y & 0.890 & 0.048 & 0.050 & 0.012 \\
\hline
\end{tabular}

Notes: We restrict the sample to those admitted through emergency room only. In addition to Day $3 *$ Medicare, each regression includes an indicator for Day 3, an indicator for Medicare as well as a vector of discharge characteristics such as patients' age, age squared, an indicator for sex, a series of indicators for race, health conditions (Diagnosis Related Group (DRG) fixed effects and indicators for all comorbidities), hospital fixed effects, discharge year and discharge month fixed effects, discharge hour fixed effects, and a dummy for missing discharge hour. Standard errors are clustered at the HSA level. ${ }^{*}$ Significant at $10 \%,{ }^{* *}$ significant at $5 \%,{ }^{* * *}$ significant at $1 \%$. 
Table B.32: 2SLS: Readmission rates, ER admission only

\begin{tabular}{lcccccccc}
\hline & \multicolumn{2}{c}{ Full sample } & & \multicolumn{2}{c}{ No comorbidity } & & \multicolumn{2}{c}{ Any comorbidity } \\
\cline { 2 - 3 } & 30-day & 60 -day & & 30 -day & 60 -day & & 30 -day & 60-day \\
\hline Discharge to SNF & -0.015 & -0.028 & & 0.018 & 0.116 & & -0.021 & $-0.041^{*}$ \\
& $(0.020)$ & $(0.021)$ & & $(0.076)$ & $(0.077)$ & & $(0.020)$ & $(0.022)$ \\
\hline Observations & $1,708,710$ & $1,708,710$ & & 158,620 & 158,620 & & $1,550,031$ & $1,550,031$ \\
Adjusted $R^{2}$ & 0.022 & 0.032 & & 0.028 & 0.036 & & 0.021 & 0.031 \\
Mean Y & 0.096 & 0.141 & & 0.073 & 0.105 & & 0.098 & 0.145 \\
F statistic & 421.586 & 421.586 & & 284.574 & 284.574 & & 418.607 & 418.607 \\
\hline
\end{tabular}

Notes: We restrict the sample to those admitted through emergency room only. In addition to the indicator for discharge to SNF and Day $3^{*}$ Medicare, each regression includes an indicator for Day 3, an indicator for Medicare as well as a vector of discharge characteristics such as patients' age, age squared, an indicator for sex, a series of indicators for race, health conditions (Diagnosis Related Group (DRG) fixed effects and indicators for all comorbidities), hospital fixed effects, discharge year and discharge month fixed effects, discharge hour fixed effects, and a dummy for missing discharge hour. We instrument SNF discharges with an interaction between Day 3 and Medicare. Standard errors are clustered at the HSA level. ${ }^{*}$ Significant at $10 \%,{ }^{* *}$ significant at $5 \%,{ }^{* * *}$ significant at $1 \%$.

Table B.33: OLS: Readmission rates controlling for Day $3^{*}$ Medicare

\begin{tabular}{lcccccccc}
\hline & \multicolumn{2}{c}{ Full sample } & & \multicolumn{2}{c}{ No comorbidity } & & \multicolumn{2}{c}{ Any comorbidity } \\
\cline { 2 - 3 } & 30-day & 60 -day & & 30 -day & 60 -day & & 30 -day & 60-day \\
\hline SNF & $0.021^{* * *}$ & $0.031^{* * *}$ & & $0.013^{* * *}$ & $0.018^{* * *}$ & & $0.022^{* * *}$ & $0.033^{* * *}$ \\
& $(0.002)$ & $(0.002)$ & & $(0.003)$ & $(0.003)$ & & $(0.002)$ & $(0.002)$ \\
Day 3*Medicare & $-0.002^{* * *}$ & $-0.004^{* * *}$ & & -0.000 & -0.000 & & $-0.003^{* * *}$ & $-0.005^{* * *}$ \\
& $(0.001)$ & $(0.001)$ & & $(0.001)$ & $(0.002)$ & & $(0.001)$ & $(0.001)$ \\
\hline Observations & $2,915,127$ & $2,915,127$ & & 352,749 & 352,749 & & $2,562,350$ & $2,562,350$ \\
Adjusted $R^{2}$ & 0.031 & 0.045 & & 0.044 & 0.053 & & 0.030 & 0.043 \\
Mean Y & 0.084 & 0.124 & 0.061 & 0.088 & & 0.088 & 0.129 \\
\hline
\end{tabular}

Notes: In addition to the indicator for discharge to SNF and Day $3^{*}$ Medicare, each regression includes an indicator for Day 3, an indicator for Medicare as well as a vector of discharge characteristics such as patients' age, age squared, an indicator for sex, a series of indicators for race, health conditions (Diagnosis Related Group (DRG) fixed effects and indicators for all comorbidities), hospital fixed effects, discharge year and discharge month fixed effects, discharge hour fixed effects, and a dummy for missing discharge hour. Standard errors are clustered at the HSA level. * Significant at $10 \%,{ }^{* *}$ significant at $5 \%,{ }^{* * *}$ significant at $1 \%$. 
Table B.34: First stage by hospital bed availability: discharge outcomes

\begin{tabular}{lcccc}
\hline & Home/HHC & SNF & Other facilities & AMA \\
Panel. Above-median inpatient days & & & & \\
\hline Day $3^{*}$ Medicare & $-0.068^{* * *}$ & $0.052^{* * *}$ & $0.017^{* * *}$ & -0.000 \\
& $(0.004)$ & $(0.006)$ & $(0.005)$ & $(0.000)$ \\
\hline Observations & 806,372 & 806,372 & 806,372 & 806,372 \\
Adjusted $R^{2}$ & 0.247 & 0.209 & 0.143 & 0.076 \\
Mean Y & 0.857 & 0.077 & 0.059 & 0.007 \\
& & & & \\
Panel B. Below-median inpatient days & & & & -0.000 \\
\hline Day $3^{*}$ Medicare & $-0.067^{* * *}$ & $0.052^{* * *}$ & $0.016^{* * *}$ & $(0.006)$ \\
\hline Observations & $(0.004)$ & $(0.005)$ & $(0.006)$ & $(0.000)$ \\
Adjusted $R^{2}$ & 750,707 & 750,707 & 750,707 & 750,707 \\
Mean Y & 0.249 & 0.214 & 0.138 & 0.081 \\
\hline
\end{tabular}

Notes: We define hospital bed availability as months in which total inpatient days are below the median in a given hospital-year. In addition to Day $3^{*}$ Medicare, each regression includes an indicator for Day 3, an indicator for Medicare as well as a vector of discharge characteristics such as patients' age, age squared, an indicator for sex, a series of indicators for race, health conditions (Diagnosis Related Group (DRG) fixed effects and indicators for all comorbidities), hospital fixed effects, discharge year and discharge month fixed effects, discharge hour fixed effects, and a dummy for missing discharge hour. Standard errors are clustered at the HSA level. ${ }^{*}$ Significant at $10 \%,{ }^{* *}$ significant at $5 \%,{ }^{* * *}$ significant at $1 \%$. 